\title{
INJECTING FREEDOM?
}

EXAMINING DEPO-PROVERA'S DISCOURSE OF 'FREEING' WOMEN FROM

MENSTRUATION AND WOMEN'S PERCEPTIONS OF IT

\section{By}

\author{
Emily Snyder, B.A. (Hons.)
}

A thesis submitted to the Faculty of Graduate Studies and Research in partial fulfillment of the requirements for the degree of

Master of Arts

Department of Sociology and Anthropology

Carleton University, Ottawa, Ontario

August 21, 2006

(C) 2006, Emily Snyder 


$\begin{array}{ll}\begin{array}{l}\text { Library and } \\ \text { Archives Canada }\end{array} & \begin{array}{l}\text { Bibliothèque et } \\ \text { Archives Canada }\end{array} \\ \begin{array}{l}\text { Published Heritage } \\ \text { Branch }\end{array} & \begin{array}{l}\text { Direction du } \\ \text { Patrimoine de l'édition }\end{array} \\ \begin{array}{l}\text { 395 Wellington Street } \\ \text { Ottawa ON K1A ON4 }\end{array} & \begin{array}{l}\text { 395, rue Wellington } \\ \text { Ottawa ON K1A ON4 } \\ \text { Canada }\end{array}\end{array}$

Your file Votre référence ISBN: 978-0-494-18299-4 Our file Notre référence ISBN: 978-0-494-18299-4

NOTICE:

The author has granted a nonexclusive license allowing Library and Archives Canada to reproduce, publish, archive, preserve, conserve, communicate to the public by telecommunication or on the Internet, loan, distribute and sell theses worldwide, for commercial or noncommercial purposes, in microform, paper, electronic and/or any other formats.

The author retains copyright ownership and moral rights in this thesis. Neither the thesis nor substantial extracts from it may be printed or otherwise reproduced without the author's permission.
AVIS:

L'auteur a accordé une licence non exclusive permettant à la Bibliothèque et Archives Canada de reproduire, publier, archiver, sauvegarder, conserver, transmettre au public par télécommunication ou par l'Internet, prêter, distribuer et vendre des thèses partout dans le monde, à des fins commerciales ou autres, sur support microforme, papier, électronique et/ou autres formats.

L'auteur conserve la propriété du droit d'auteur et des droits moraux qui protège cette thèse. $\mathrm{Ni}$ la thèse ni des extraits substantiels de celle-ci ne doivent être imprimés ou autrement reproduits sans son autorisation.
In compliance with the Canadian

Privacy Act some supporting forms may have been removed from this thesis.

While these forms may be included in the document page count, their removal does not represent any loss of content from the thesis.
Conformément à la loi canadienne sur la protection de la vie privée, quelques formulaires secondaires ont été enlevés de cette thèse.

Bien que ces formulaires aient inclus dans la pagination, il n'y aura aucun contenu manquant.

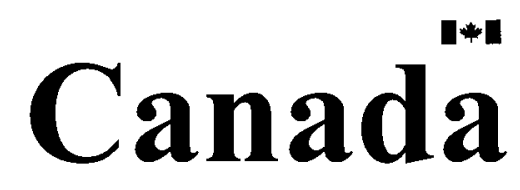




\begin{abstract}
This thesis examines Depo-Provera's promotion that suppressing menstruation with their product will provide women with a sense of freedom. I argue, by drawing on the work of Michel Foucault, Zygmunt Bauman, and Nikolas Rose that while some women might feel free from stopping menstruation, this practice must also be understood as something that is regulatory. I examine how freedom is implicated with power and illustrate how we are often governed through freedom. I show that menstrual suppression is done, whether intentionally or not, in accordance with negative social and cultural norms which depict women's bleeding bodies as problematic and in need of management and control. By analyzing Depo-Provera's marketing, as well as the responses from the women that I interviewed, I explore the concepts of freedom and regulation. This necessitates discussing resistance as well. Furthermore, questions are raised about a potential social, cultural, and medical shift concerning how we come to define and construct what 'normal' menstruation is. Overall, the women in my sample understood menstruation itself, as well as their truths and perceptions of it, as quite malleable. The majority of them questioned Depo-Provera's claim of freedom. Many felt that it is sending out a negative message about women. Others felt that suppressing menstruation could simultaneously involve both freedom and regulation, thus, freedom could come at a cost. The social implications of these findings are discussed.
\end{abstract}




\section{ACKNOWLEDGEMENTS}

I would like to thank several people who supported and encouraged me throughout this project. Thank you to my family, DJ, John, and Tara for listening to my ideas over the past year.

I would especially like to thank Dr. Alan Hunt and Dr. Jennifer Pylypa for their guidance. Thank you for challenging me and for your willingness to listen to my many questions.

Lastly, to all of the women who participated in this study - thank you for sharing your ideas, stories, and concerns. 


\section{TABLE OF CONTENTS}

CHAPTER ONE: 'New' Means for Menstrual Management: An Introduction ........................3

I. Menstrual Suppression ............................................................................................

II. Why Regulate Menstruation?.................................................................................13

III. Depo-Provera - an Extension of Regulation or a Path to Freedom? ...........................16

IV. Thesis Outline ............................................................................................................21

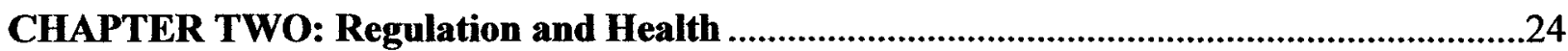

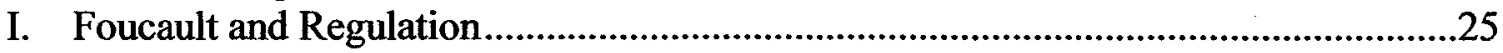

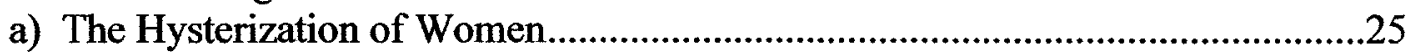

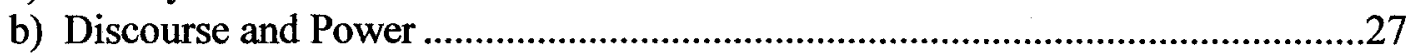

c) Resistance and Power .............................................................................................30

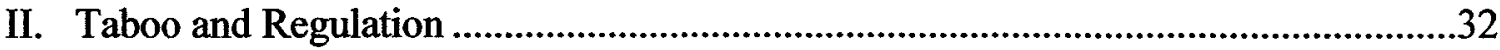

III. Medicine and Regulation .........................................................................................34

CHAPTER THREE: Marketing Freedom .........................................................................41

I. Pharmaceutical Drug Advertising ...........................................................................42

II. Depo-Provera Website Analysis .................................................................................45

a) Depo-Provera's Modern Woman...........................................................................46

b) Eliminating Hassles ...........................................................................................48

c) Depo-Provera and 'Expert Knowledge' ...............................................................50

d) Consuming Freedom ......................................................................................52

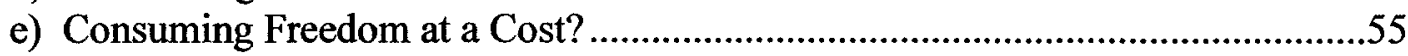

III. Theorizing Freedom.................................................................................................59

CHAPTER FOUR: Ethnographic Research and Women: Theoretical Frameworks and

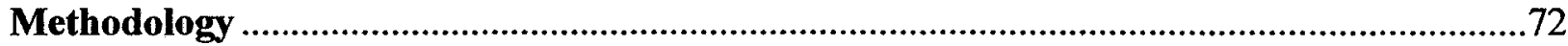

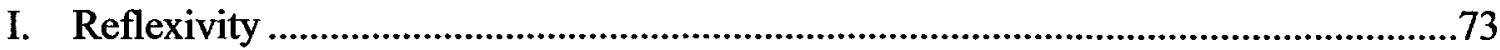

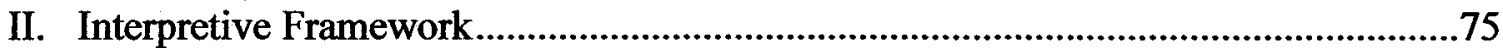

III. 'Experience' and 'False Consciousness' - Some Research Dilemmas? .....................78

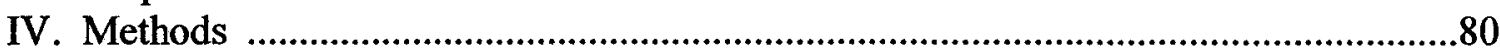

CHAPTER FIVE: Women's Perceptions of Stopping Menstruation: Some Findings ..........84

I. General Attitudes toward Menstruation .....................................................................84

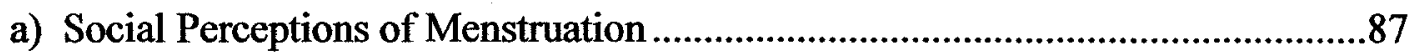

II. Attitudes toward Stopping Menstruation ..................................................................91

III. Conceptual Implications .....................................................................................97

a) The Malleability of Menstruation ..........................................................................97

b) Depo-Provera's Misleading Proposition of Freedom..........................................103

CHAPTER SIX: Playing 'Truth Games': A Discussion ....................................................113

I. Adjusting ‘Truths' .................................................................................................114

a) Exercising Resistance ....................................................................................119

II. Depo-Provera's Fallacy ............................................................................124

a) The Falsities of Freedom of Choice.......................................................................124 
b) Consuming Norms: Regulated Empowerment ..........................................129

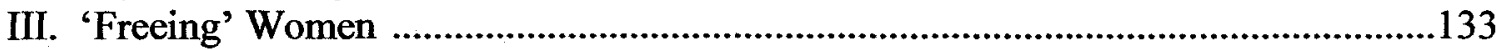

a) Why Stop Menstruation Now? ...........................................................133

b) Striving for a Society without Menstruation ................................................136

c) Who Benefits from 'Freeing' Women? ........................................................141

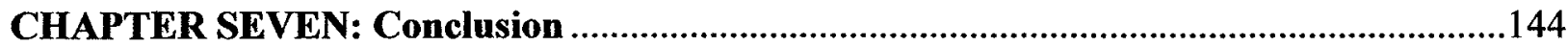

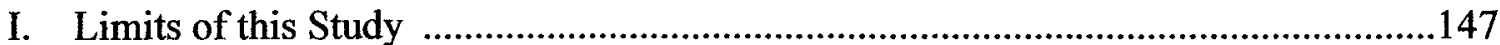

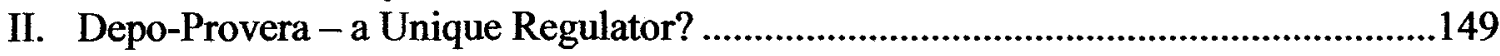

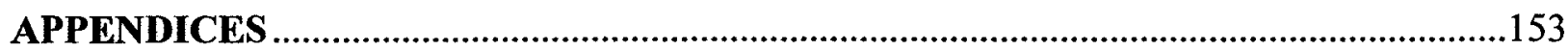

Appendix One: Depo-Provera Website Excerpts ....................................................153

Appendix Two: Depo-Provera Website Analysis ...........................................................157

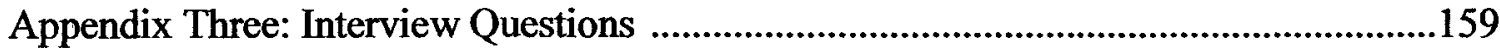

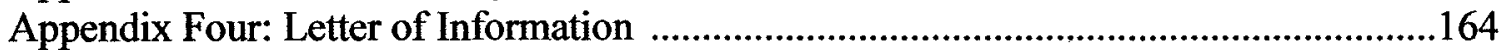

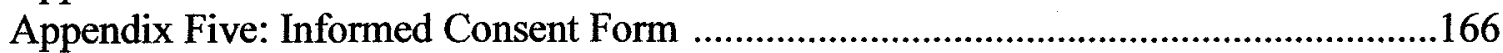

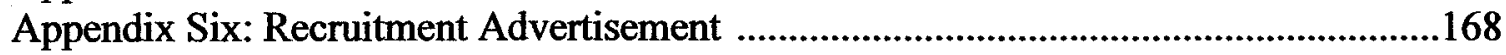

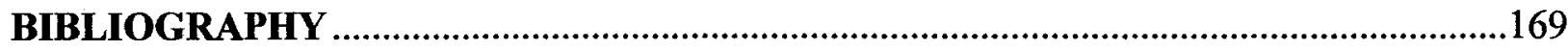




\section{CHAPTER ONE: \\ 'NEW' MEANS FOR MENSTRUAL MANAGEMENT: AN INTRODUCTION}

I don't know. I - I was glad that it could come back, you know what I mean? Like, but then I was like - should I be able to - well I guess it's good, but should you be able to have that much control over something that is supposed to be a natural experience? You know what I mean? Like, should I be able to just decide - 'I want to have my period this day' or 'I don't want to have it this day.' You know - I don't know if (...) so it kind of gives you some internal conflict on whether I should actually be able to do that and how safe it is for me and what the long-term effects of that will be. So there's kind of some apprehension that's there. (Tamara, participant from my study) ${ }^{1}$

In her work, Emily Martin describes that women's bleeding bodies are socially and medically depicted as symbolic of disorder - their bodies are uncontrollable because of menstruation (1987:47). Are women's bleeding bodies still understood this way today? A variety of 'feminine hygiene' products exist with which women can (according to the companies' advertising anyways) gain a sense of control over their bodies. L. Block Coutts and D.H. Berg explain that with the 'feminine hygiene' industry,

the complex menstrual management systems proffered in the advertisements suggest that with the right products, the problematic aspects of one's period can be effectively negated. The potential for menstrual discovery can be reduced to the point of little or no concern. One's tainted state of femininity, the effect of the menses, need not be known to anyone if it is properly managed with the right products. (1994:13)

With the increasing popularity and promotion of hormonal contraceptive drugs that can lessen or stop menstruation - are women's 'menstrual management systems' enhanced? Do women now have 'better' options? Is it possible that these hormonal drugs have the potential to eliminate the symbolism that menstruating women are the embodiment of chaos? The quote above, from Tamara - a woman in my study, illustrates how difficult it

\footnotetext{
${ }^{1}$ All of the participants were given pseudonyms.
} 
can be to grasp the meaning and impact of stopping menstruation. She is conflicted by how much control she could have over it.

Of particular interest to me here, is the following question - is the control that comes from these drugs highly regulatory or does this control over bleeding have the potential to provide women with a sense of freedom? I am concerned that DepoProvera's promotion of menstrual suppression is encouraging women to self-regulate their bodies in culturally normative ways. Although some individual women might feel a sense of freedom from stopping menstruation, suppressing it validates negative norms which depict women's bleeding bodies as problematic. I question what the personal and social implications are for encouraging women to seek freedom in this way. Regardless of individual women's, or even the drug manufacturer's intentions, the practice of menstrual suppression sends out and reinforces the message that there is something deeply wrong with menstruation, which requires extreme regulation and management. I explore these assertions by first applying theoretical ideas about freedom and regulation to an analysis of Depo-Provera's marketing. I then shift over to applying these ideas to the women's responses about menstrual suppression, from the interviews that I conducted.

\section{MENSTRUAL SUPPRESSION}

'Menstrual suppression' - being able to menstruate less or with some drugs, stop it completely, is not a new concept or a new medical practice. When the contraceptive pill (hereinafter the pill) was developed, it was possible at that time to release the product as both a contraceptive and something that could stop menstruation. However, the producers of the drug were concerned that not only was this contraceptive something new that 
women had to grasp, but to add to this that menstruation would stop - this was thought to be too shocking for women. Lianne George explains that menstruation was intact (with the 'sugar pill' or 'placebo' week) so that the drug would not seem too extreme and could then potentially gain acceptance by the Catholic Church $(2005: 42)$. Furthermore, the drug was manufactured to allow for bleeding, as this was believed to provide women with necessary reassurance that they are not pregnant (Coutinho 1999:7). It is opportune here to quote Judy Wajcman who vindicates that "birth control has always been a matter of social and political acceptability rather than of medicine and technology" (1994:168). Tied in with this, one must also remember that contraception is not only about medicine there are significant financial profits to be had. George describes menstrual suppression as "an objective the pharmaceutical industry has been chasing for years" (41). What is 'new' about menstrual suppression is that it is increasingly being framed in terms of 'lifestyle,' rather than medical problems (Andrist et al. 2004b).

Sarah Thomas and Charlotte Ellertson, who are in favour of menstrual suppression, describe it as “one of medicine's best-kept secrets" (2000:922). I am not convinced that it is presently a secret, although several decades ago when the pill first came out, this option was kept from women. Much of the debate about menstrual suppression centers on whether this practice is harmful or beneficial to women's health, as well as raising questions about what 'natural' or 'normal' menstruation is (Andrist et al. 2004a; Hitchcock \& Prior 2004a). This debate recently appeared on the cover of Maclean's magazine. The cover declared "THE END OF THE PERIOD/ Menstruation will soon be optional, and a new war over women's bodies has begun. Parents, doctors, and feminists take side" (Dec.12-19 2005). This is not an option that will soon be coming 
out - it is a very viable option for women in Canada, as well as numerous countries throughout the world. Although I did not conduct a media analysis on this debate - even a cursory look on the internet, through news/media archives, as well as through academic literature indicates a compelling amount of talk about this subject, which has been going on for years. Particular instances cause the debate to inflate at times. For instance - the release of Elsimar Coutinho's (1999) book - Is Menstruation Obsolete? - sparked much debate. Furthermore, the development of new medical techniques and hormonal drugs conjure up increased discussion.

Currently, one could stop menstruating via a surgical procedure in which the lining in the uterus is destroyed by burning the cells in it. ${ }^{2}$ Medicinally, there are several options (none of these, surgery or drugs, are proven to be entirely safe) - eliminating the 'sugar pill' or 'placebo' week with the pill or taking the contraceptive patch (hereinafter the patch) continuously without any breaks for bleeding. Seasonale is an oral contraceptive which is specifically designed to allow for bleeding four times a year (Andrist et al. 2004a) (their slogan on their website is "Fewer periods. More possibilities"). Also, Anya, an oral contraceptive, can stop menstruation entirely - it is to be taken every day of the year, as to not allow for withdrawal bleeding (George 2005). Depo-Provera, the drug of focus in this thesis, is an injection taken four times a year which is supposed to lessen or completely stop menstruation. Lastly, menstruation can be stopped with depo-subQ provera 104, a drug which was recently released to do the same as Depo-Provera, but with a lower dosage of hormones.

\footnotetext{
${ }^{2}$ This surgical procedure is called endometrial ablations. CBC news reports that this "nine-minute procedure involves circulating a very hot saline solution inside the uterus until the cells are killed. Women who feel discomfort are treated with over-the-counter pain relief' (CBC website 2002).
} 
I am focusing on Depo-Provera because it has been around for several decades now and there is a steadily growing base of literature on it. As well, because it has been around for a while, many women recognize what it is and what it can do regarding menstruation. It is currently a very popular birth control method, particularly with younger women (Public Health Agency of Canada website). Furthermore, what fascinates me about this drug is its marketing campaign which explicitly promotes the idea of 'freedom' to women via the usage of their product. Their slogan is "Depo-Provera. Freedom from the everyday." Medical research on the drug has been conducted and must continue to grow. Here, I aim to develop a sociological examination of the drug and the implications of the promotion of freedom from menstruation. The subject of stopping menstruation with Depo-Provera reifies a tangled mess of social norms, medical consumerism, regulation, freedom, power, resistance, and malleable 'truths' - personal, political, social, and medical. Although the focus here is on Depo-Provera, it is vital to note that the conceptual findings from the ensuing discussions can, and should, be applied to other methods that allow for menstrual suppression.

Again, my focus is primarily sociological, however there are some medical aspects of the drug that are prudent to discuss. Despite all of the dialogue about menstrual suppression, there still remains a deficit of consistent research on the safety of this practice (Hitchcock \& Prior 2004b; Johnston-Robledo et al. 2003; Andrist et al. 2004a; 2004b). Coutinho, a proponent of suppressing menstruation, argues that monthly bleeding is a risk to women's health as well as that it can have negative repercussions on society. For instance he contends that PMS (premenstrual syndrome) could affect women's 
performance in the workplace and more generally, their social functioning (1999:73). ${ }^{3} \mathrm{~A}$.

M. Kaunitz echoes this belief:

The burden of menstruation ranges from a monthly nuisance to a major health concern of women. In the United States, menstrual disorders are the most common gynecologic complaint, affecting nearly 2.5 million women aged 18 to 50. (2000:277)

Thomas and Ellertson also depict menstruation as a hazard:

There can be no other disease or condition that affects so many people on such a regular basis with consequences, at both the individual and societal level, which is not prioritised in some way by health professionals or policy makers. (2000:922 emphasis added)

This 'disease,' they claim, costs the "US industry about $8 \%$ of its total bill wage" (922).

In terms of personal risks, Coutinho argues that with menstruation women commonly experience dysmenorrhea or cramps (81). F. E. Khoiny shares these concerns (1996:197). Coutinho also mentions the following risks: migraines, endometriosis, asthma, insomnia, arthritis, epilepsy, menstrual thrombocytopenia, porphyria, pneumothrax, myomas, and anemia (81-92). He advocates menstrual suppression via the continuous use of hormonal drugs as a solution, and maintains that the possible side effects of these drugs are not as significant as the risks of monthly menstruation (117). Initially, he extends his offer of stopping menstruation only to women with problematic cycles but then, in the end, concludes that it might be valuable for some women to use it before any of these problems have a chance to arise. He claims that "the longer a woman is not menstruating, the greater the benefit" (159).

Susan Rako, as well as Christine Hitchcock and Jerilynn Prior, recognize that menstrual suppression might be beneficial for women with serious medical problems

\footnotetext{
${ }^{3}$ When Coutinho and Segal make this remark, they cite a doctor from 1953 to back up this claim. It is very strange that they would not have used current research on PMS to reflect on this idea.
} 
(2003; 2004a). Yet, as Hitchcock and Prior argue, very few women actually have serious medical problems with their menstrual cycles and they believe that it is unacceptable to promote this medical option to women with 'normal' cycles (202). Rako disagrees with Coutinho's perspective. She laments that a positive depiction of menstrual suppression is "making its way through our society like a disease" (2003:19). She understands menstruation as something that is part of a woman's overall health. Rako abhors Coutinho's narrow focus on bleeding and instead argues that hormones that are naturally in our body impact our brain, bones, lungs, blood vessels, and cardiovascular system menstruation goes beyond our reproductive system and organs (202).

There is also a lack of consistent literature on the safety of Depo-Provera. The drug is a progestin-only (synthetic progesterone) injectable long-acting contraceptive. It is administered four times a year (every three months) and is highly effective. ${ }^{4}$ In addition to preventing ovulation and making the cervical mucous thicker, the endometrium (lining of blood in the uterus) is thinned. Thus menstruation can lessen or stop while using this drug (Hyde et al. 2001:192). When the drug was owned by Upjohn (it is now owned by Pfizer), appeals for approval of its use were made in the US in 1978 and 1984 but were turned down by the US FDA (Food and Drug Administration) because of safety concerns (Corea 1991:161). It was eventually approved in the US in 1992 and in Canada in 1997, yet concerns about its safety still remain (Corea 1991:161; Women's Health Clinic). There are numerous potential side effects, some of which have gained

\footnotetext{
${ }^{4}$ It is has a typical-user failure rate of less than 1\% (Hyde et al. 2001:192).
} 
more attention than others. ${ }^{5}$ If one experiences adverse side effects while using this drug, it is possible that these could persist for several months. Although the injections are given every three months - this time period is the minimum which the drug could last. Thus injections are given every three months to ensure that women do not get pregnant but it is possible that the drug from one shot could remain in a woman's body for eight to ten months (Rakusen 1981: 84-85).

The number one reason for discontinuing usage of this drug is irregular bleeding. The second most common reason is weight gain (Khoiny 1996:198-199). There is also considerable concern and uncertainty in the literature about cancer (Rako 2003:100-101), how long it takes for fertility to return (Rakusen 1981:89-90; Khoiny 1996:198), loss of libido for women (Kaunitz 2001:79), and the effect on adolescent health, especially regarding bone mineral density loss (which was only recently discovered) (Khoiny 1996). There are discrepancies throughout the literature about the side effects of this drug (Bunkle 1993:296-298; Rako 2003:100). Furthermore, there is a lack of long-term studies (Hitchcock \& Prior 2004b:197), particularly on adolescents (Khoiny 1996:196).

\footnotetext{
${ }^{5}$ The side effects which the drug manufacturer prioritizes are: bone mineral density loss (which means one is at risk for osteoporosis), headaches, and there are concerns about blood clots or strokes. Concerning cancer - for breast cancer, they claim that there is a 'slight to no' increased risk. There are also other potential risks that receive less emphasis from the drug manufacturer, since they claim that a small percentage of women might experience them. These are: nervousness, abdominal cramps, dizziness, weakness or fatigue, decrease in sexual desire, nausea, vaginal discharge, vaginal irritation, breast tenderness or swelling, bloating, swelling of the hands and/or feet, backache, depression, insomnia, acne, rashes, pelvic pain, joint pain, hot flushes, and changes in hair growth (either an increase or decrease). It is important to recognize that several of the side effects of Depo-Provera have, and could lead to death. Some of the most serious reactions to Depo-Provera, which were reported by very few women includes: fainting, convulsions, jaundice, urinary tract infections, allergic reactions, paralysis, osteoporosis, infertility, deep vein thrombosis, pulmonary embolus, breast cancer, and cervical cancer. One should also be aware, that if they have any of the following conditions - they could be at even more risk if they were to use DepoProvera - this includes: epilepsy, asthma, kidney disease, diabetes, depression, migraine headaches, breast cancer, history of blood clots, stroke, heart or liver disease (Pfizer Patient Drug Information on DepoProvera, this can be accessed through the Depo-Provera website www.depoprovera.com).
} 
Els Bransen describes medicine as "a melting-pot of contradictory theories and practices, controversies and inexplicable phenomena, about which doctors and laypeople are in constant debate" (1992:99). Both Phillida Bunkle and Jill Rakusen however, attest that the role of 'laypeople' is quite limited $(1993 ; 1981)$. They argue that the information that is available to us about Depo-Provera is biased. The pharmaceutical company owns its major studies on the drug and others do not have access to closely examine these (1993:290-294; 1981:94). Bunkle describes this as "authoritative knowledge" because Depo-Provera has power and control over the technological and scientific knowledge about the product (298). It is relevant to note that Coutinho, an advocate of menstrual suppression, helped to develop Depo-Provera (his translator Segal helped to develop Norplant) (Hitchcock \& Prior 2004b:195). ${ }^{6}$

Although the drug was only recently approved for widespread use in North America, it has been used around the world and in 'limited' ways in North America for several decades now. Despite uncertainties about the safety of the drug, in the late 1970s and early 80 s, it was pushed into 'Third World' markets. It was promoted as a contraceptive that was easy to administer and one that would be ideal for family planning. There were significant profits to be had in these markets and Upjohn ensured that it had its place in them through aggressive promotion, as well as bribery of government officials and hospital employees (Rakusen 1981:78; Bunkle 1993:

\footnotetext{
${ }^{6}$ Coutinho was involved in a study in which Depo-Provera was being tested to try and stop spontaneous abortions and premature delivery. In this study, he realized that the women stopped ovulating and menstruating while on Depo-Provera. Thus while he was trying to help these women find a way to have children, he ended up making them temporarily infertile and discovering this drug (Coutinho \& Segal 1999: 8-9).
} 
288-289). ${ }^{7}$ Many women were vulnerable to abuse with this product. Minority groups, as well as women with mental illnesses were (and still are) in danger of being administered this drug without their consent, or if asked, they could potentially be misinformed about the possible risks of the drug. There are problems with language barriers, illiteracy, patients being treated as inferior and incapable of understanding, as well as biases that doctors might have about the drug (Corea 1991; Rakusen 1981).

Depo-Provera was either banned or severely regulated in most 'First World' countries during this time, yet it was still often used on women who fit the stereotypes of a 'Third World' woman (Bunkle 1993:289; Wajcman 1994:158). ${ }^{8}$ For instance, in Britain, the drug was administered to a large population of black and Asian women, even though it was considered unsafe for the rest of the (white) women in society (Rakusen:81). Depo-Provera's history highlights how very saturated 'medicine' is with social, cultural, political, and economic 'values.' Minority women are depicted as less responsible and competent, as well as less valuable overall; given that they were being administered a drug that's safety was unknown. It is important to note that Depo-Provera is, regrettably, not the only hormonal contraceptive that has been used in highly racialized and discriminatory ways to exploit women for profit and politics (Rakusen $1981)^{9}$

\footnotetext{
${ }^{7}$ Rakusen explains - "In a deposition to the US Securities and Exchange Commission unearthed by Minkin (1979), the manufacturers of DP admitted paying $\$ 2,710,000$ in bribes to 'employees of foreign governments and to their intermediaries for the purpose of obtaining sales to government agencies'. Bribes to hospital employees raised this total to $\$ 4,098,000$, and a further $\$ 147,579$ was paid out 'in connection with other foreign governmental actions related to the company's business'. Upjohn's deposition specifically notes that the above figures exclude 'small amounts which were paid to minor government employees to expedite governmental services"' (1981:78).

${ }^{8}$ It was approved for widespread use in New Zealand (Bunkle 1993:289).

${ }^{9}$ For instance, the pill, the IUD (Rakusen 1981: 101), and more recently Norplant (Hitchcock \& Prior 2004b: 199).
} 


\section{WHY REGULATE MENSTRUATION?}

Menstrual suppression is presumably not 'the norm' in our society. Presently more women menstruate than do not. Current social norms about menstruation are compatible with the idea of menstrual suppression and can be exploited to promote the practice. Karen Houpper argues that despite feminists' efforts to encourage more positive discourses about menstruation, little has changed in our society (1999:7-8). Normative ideas exist that menstruation is unclean and thus a threat to femininity (so this plays off of another social norm that women ought to be fresh, clean, and attractive) (Kane 1990:82; Merskin 1999:946). Menstrual blood is also a threat in terms of 'leaks.' Women are told consistently by the 'feminine hygiene' industry that their bodies must be managed 'properly.' Failed bodily management signifies a lack of control and is deemed to necessarily lead to embarrassment for women (Rosengarten 2000:92; Laws 1990:36). The bodily management of menstruation, as well as the general topic, is supposed to be discrete. Houpper describes that we live in a "culture of concealment" (14). The utilization of euphemisms can often be profuse when menstruation is addressed (for instance 'period,' 'that time of the month,' the usage of blue liquid in commercials to represent blood). These encourage discretion and could evoke feelings of shame (Walker 1997:2-3; Bramwell 2001:88; Merksin:947).

Menstruation certainly has multiple meanings amongst people. Anne Walker contends that,

The sensation of menstruation (its look, feel and smell) and its emotional interpretation vary from woman to woman and period to period. The dominant menstrual discourse is one of pain, mess and unpredictability and it is this which is most often remarked upon and talked about. (1997:6) 
These normative ideas do exist and can influence knowledge construction in countless spaces in our society (medicine, religion, work, etc.) (Lander 1988; Martin 1987; Walker 1997). Both males and females contribute to and sustain these social norms.

What concerns me, as well as others, is that the norms about menstruation are possibly too pervasive to be presenting women with a potentially unsafe product - Depo-Provera. Women might be potentially vulnerable to being exploited because of how ubiquitous negative social norms that would favour the 'disappearance' of menstruation are. DepoProvera offers to eliminate something that many deem to be socially taboo (Hitchcock \& Prior 2004a). It offers to control something that has, for centuries, been dubbed one of women's weaknesses. There is always the possibility for resisting and manipulating norms though. Laura Fingerson describes menstruation as "a sociological phenomenon" that is "a site of power, control, agency and resistance" (2005:94).

'Normal' menstruation is difficult to define. Women might put up with varying circumstances with menstruation yet each might conclude that their experiences are 'normal.' It is predominantly believed in our society, that menstruation which occurs on a monthly basis is 'normal.' Yet this is becoming increasingly challenged by the promotion of hormonal contraceptives that aim to lessen or stop menstruation. For instance, Thomas and Ellertson adhere to the idea that monthly menstruation is abnormal. They state that "women and health professionals are conditioned to think of monthly menstruation as the holy grail of womanhood" (2000:923). They argue that we only value it because we are being duped by cultural beliefs about its necessity. They want women to be aware that the choice is available to not menstruate. 
Coutinho also purports a competing truth about menstruation. Citing the impact of frequent pregnancies and lactation on the natural suppression of menstruation, he claims that

Contrary to common belief, regular monthly menstruation became part of a woman's life relatively recently in the historical presence of humans on earth. It is a consequence of societal and cultural changes that cause distant evolutionary adaptations to conflict with the best interests for the health of the modern woman. It is reasonable to assume that at the dawn of the human epoch women menstruated rarely or not at all - it would have been extraordinary for a woman to menstruate regularly. (1999:1-2)

He wants to challenge the following normative ideas: that monthly menstruation is natural, that menstruation is representative of femininity, that it is representative of youthfulness, and that it cleans out the body (13). While he describes the changes in menstrual patterns as happening for cultural reasons, he simultaneously makes claims about what is 'natural' for women - here, possibly an illogical deduction that just because women are capable of bearing children, that this is their natural role to continuously do so. Sophie Laws also shares this concern and describes that

such sexist 'explanations' are banal and circular: they blend the social together with the biological into a smooth mixture of commonsensical ideas which ultimately explain nothing. I will not argue with them - rather I ask who benefits from these ideas?" (1990:3:emphasis added)

Coutinho describes not suppressing menstruation as a "conformist attitude" and as upholding the status quo (137). In the forward to his work, Kate Miller puts forth the disclaimer that Coutinho does not want to advocate menstrual suppression because it is culturally and socially awkward, rather he wants women to live healthy (thus menstruation-free) lives (1999). The problem is - that while this may have been his intention, we cannot sever medicine from cultural influences in this manner. Hitchcock and Prior argue that Coutinho and his translator Segal's work 
says in a new way what our culture believes: women's menstruation is smelly, painful, disruptive, and in short, negative. Western culture has viewed women's reproductive system as abnormal and deficient primarily because it differs from men's. This negative view is a self-fulfilling prophecy. If we ask why menstruation is sometimes distasteful, symptomatic, and abnormal, as Coutinho and Segal assert, the primary answer is the lower status of women in society. (2004b:199)

Hitchcock and Prior contend that monthly menstruation is natural and that "menstruation with ovulation is an important physiological part of women's lives. It is neither detrimental nor obsolete" (201).

While I personally struggle with the justifications, particularly the evolutionary ones, that monthly menstruation is unnatural - I do think that it is vital to examine and reflect on what we understand to be predominantly 'normal.' Shifts in medical truths about menstruation could occur and could define monthly menstruation as unnecessary. Hitchcock and Prior argue that suppressing menstruation is often promoted based on ideas "of convenience and choice, particularly for women who are already taking OC [oral contraceptives] for contraception" (2004a:201). I think that the ideas of lifestyle and convenience will help to push for a redefinition of what is normal.

\section{DEPO-PROVERA - AN EXTENSION OF REGULATION OR A PATH TO FREEDOM?}

Kaunitz argues that most women are in favour of stopping menstruation. In his work he cites several studies about how women stopped menstruating in trials and enjoyed this so much that they did not want to go back to monthly bleeding (2000:278-279). One must question though - since participation in these trials is voluntary, are these women already predisposed to disliking menstruation? Would the results be any different if the sample was more random? Also, in several of the studies that he draws on, the participants had problems with menstruation (278-279). L. C. Andrist et al. found a correlation between 
experiencing menstrual pain and wanting to stop menstruation (2004a:35). ${ }^{10}$ This seems logical, yet it is important to note that Ingrid Johnston-Robledo et al. discovered otherwise in their research (2003). They assert that,

it is surprising that women who reported more physical and psychological symptoms were not more likely than other women to support suppression or express an interest in more information about menstrual suppression. They were, however, more likely to express a desire to live without menstrual periods. (71)

Many of their participants were unfamiliar with menstrual suppression. They concluded that the women were interested in the idea of stopping menstruation but were hesitant about actually doing this in practice. They wondered if their findings occurred this way because the concept was new to so many of them.

In an initial survey done by Andrist et al., they found that women differed greatly in their attitudes toward stopping menstruation. They deduced that the results likely materialized in this way because of the women's different bodies, experiences, and beliefs. They also questioned the impact of cultural norms about menstruation on the women's attitudes (2004a:35-36). They did find that for some of the women, concerns about normality and abnormality arose. These women expressed that they would be anxious if not menstruating on a monthly basis as this would make them feel abnormal. Part of this anxiety stemmed from not knowing whether or not one was pregnant. Andrist et al. also conducted a second, more detailed study to further explore the subject of menstrual suppression. They found that many women did not want to stop menstruating because of concerns about side effects, long-term health, and whether or not they would be fertile again (2004b:362). Johnston-Robledo et al. also identified concerns about safety and a return to fertility, as well as concerns about money (2003:71).

\footnotetext{
${ }^{10}$ Their research was not done on stopping menstruation with Depo-Provera but was about stopping it with long-acting oral contraception.
} 
There is a lack of research on how health-care providers deal with menstrual suppression. Andrist et al. explored this. They comment,

We are aware of only one survey on providers' practices regarding menstrual suppression. The Association of Reproductive Health Professionals and the National Association of Nurse Practitioners in Women's Health polled their annual meeting registrants in the fall of 2002. One hundred seventeen providers responded; of these, $77 \%$ said they prescribed extended use of contraceptives for the following reasons: endometriosis (83\%), patient request (79\%), lifestyle (78\%) menorrhagia (73\%) and dysmenorrhea (73\%). (2004b:p.360)

It is interesting to note that drugs were prescribed for both medical and lifestyles reasons. The category 'patient request' is quite ambiguous. Andrist et al. found that many of the patients in their second study liked having the option of being able to stop menstruation $(362-363)$.

The research on women's attitudes toward stopping menstruation through the use of hormonal drugs is limited. It is clear that more research needs to be done. What we can take from it though is that women's attitudes toward menstrual suppression are complex. This becomes quite evident in my own research; women have mixed feelings about menstruation itself, as well as about stopping menstruation. Their concerns and beliefs are often negotiated and reworked in different circumstances.

Not only is sorting out women's ideas about stopping menstruation complex but the topic is further complicated by raising questions about whether or not this practice is something that is regulatory, or if it has the potential to provide women with freedom. By stopping menstruation with Depo-Provera, to what degree do women feel that they are admitting that there is something wrong with their bodies - that there is something wrong with menstruating and that it needs to be managed and controlled with a drug? Do they see this drug as an extension of social, consumer, and medical norms that tell women that their bleeding bodies are problematic and in need of regulation? Or, to what degree do 
they understand this drug as something positive for women - that it could provide them with a sense of freedom? By having the opportunity to easily and relatively affordably stop menstruation, to what extent are women finally free from having their bodies problematized by menstruation? Is it possible that using Depo-Provera could involve both regulation and freedom simultaneously? These questions are not simple to answer. I continue to raise difficult questions throughout my work with the anticipation that they will encourage others to critically assess this topic. I concur with Nikolas Rose who attests that one's work should not be a final truth, but rather be a work in progress that others can learn and draw from (1999:13-14).

The majority of the women in my study have mixed feelings about stopping menstruation. Many of them experienced significant amounts of inner conflict when discussing this subject. They were hesitant to embrace stopping menstruation because they generally depicted doing this as unnatural (and thus unhealthy). One of the women actually experiences 'natural' menstruation. The other fourteen women experience something symbolic of menstruation (because of the usage of different hormonal contraceptives). Many of the women know that they are regulating menstruation with hormonal drugs, yet still utilized a 'natural discourse' to describe their bleeding (perhaps they are unaware that their bleeding is not occurring naturally). Others know that they are controlling their menstrual cycles and make note of their contradiction of manipulating it, yet maintained that they value it as something natural. There were a couple of women who explicitly drew attention to the symbolism of their bleeding and said that they take comfort in this symbolism of something natural. For many of the women, this symbolism of natural monthly bleeding alleviates this conflict between their thoughts (menstruation 
is natural) and their actions (problematizing their bodies to a certain degree by regulating menstruation through drugs). The majority of them were content with regulating menstruation with the pill and the patch because it gives them a sense of control but also allows them to hold onto the symbolism of natural bleeding - which shows them that they have not taken things 'too far' with their bodily management. While the majority of them liked the idea of completely controlling and stopping menstruation, in practice they were concerned about their physical and mental health with this intense regulation. There were however, certain circumstances in which the women expressed that they would be willing to let go of or compromise their current understandings about menstruation. Again, it is important to reiterate that for most of the women, I observed significant amounts of inner conflict not only with their thoughts, but between contradictory thoughts and actions. Not only is actual menstruation understood as something that is malleable, but their truths and perceptions about it are malleable as well.

Despite valuing control, most of the women in my study were not completely open to the idea of stopping menstruation and were generally not responsive to the idea that stopping menstruation with Depo-Provera leads to freedom. Only one woman clearly felt that it offered freedom (Carla - one of the Depo-Provera users). The rest of the women fell into two main groups. The first group expressed a lot of resentment toward the company for depicting women's bodies as something that women need to be freed from. Many of them expressed a clash between Depo-Provera's 'truths' about women's freedom and bodies and their own personal experiences and 'truths.' The women in this group questioned the message that Depo-Provera is sending out about women's bodies they felt that freedom was an inappropriate word to use. The women in the second group 
had mixed feelings about the offer of 'freedom' because they felt that it was a limited offer or freedom at a cost. Some of the women felt that although menstruation might stop - one is still engaging in bodily regulation when suppressing menstruation. Also they expressed that freedom could be limited because of the potential cost of putting one's health at risk in an effort to attain freedom. Many of the women felt that 'freedom' was too substantial of a word to use to describe what Depo-Provera can (and cannot) do. Furthermore, several of the women rejected the idea of freedom of choice as something positive - thus rejecting another truth that Depo-Provera promotes. I argue that while it is possible for some women to feel a sense of freedom while using this drug, it must also be understood as something that is regulatory and one must be aware that the self-regulation involved with suppressing menstruation builds off of and validates negative cultural norms about women's bleeding bodies as flawed and in need of control.

\section{THESIS OUTLINE}

'Regulation' and 'freedom' are quite abstract. It is vital to address these concepts in some detail before exploring my assertions about my findings. In Chapter Two, I tackle the concept of regulation. I draw primarily on Michel Foucault's earlier work on sexuality to examine the ideas of power and resistance. I address how power is implicated in the production of knowledge. It is vital to be aware of this when analyzing how medicine and consumerism depict menstruation. In this chapter, I examine medicine and 'taboo' as means of regulation. In Chapter Three, I shift over to consumerism and explore DepoProvera's claims of freedom by analyzing their website. I begin to theorize freedom with the work of Zygmunt Bauman. His ideas are useful for understanding the potential connection between freedom and consumption. In addition, I draw on the work of 
Nikolas Rose and Foucault's later work to comprehend how we are encouraged to selfregulate through the idea of freedom. With Foucault's later work, the connection of ethics to freedom and the self also emerges. The ideas from these theorists help to illustrate how Depo-Provera's promise of freedom is actually a promotion of self-regulating in accordance with cultural norms.

In Chapter Four, I briefly discuss some methodological issues before explaining my findings. In an effort to embrace reflexivity, I explain how critical theory is a part of my interpretive framework, which influences how I approach research. Specifically, I show how this approach is connected to discourse analysis, which I used to analyze my data. As well, critical theory influences how I interpret the dilemmas that researchers often face of how to deal with 'experience' and the idea of false consciousness. I then continue to briefly address methodological concerns regarding my sample. In Chapter Five, I reveal how the women felt, in detail, about stopping menstruation and how they interpreted Depo-Provera's promises of freedom.

In Chapter Six, I attend to further discussing some of the major findings from my study. I address the idea of the malleability of the women's truths and highlight that this is not something unique that is only done within the context of menstrual suppression and freedom. Also, I focus on resistance in more detail - examining how the women exercised this, as well as other possibilities for resistance within medical consumerism. In addition, I concentrate on trying to understand freedom even further in this chapter. I raise questions about the consumerist logic, particularly the idea that freedom of choice does not necessarily lead to freedom. Furthermore, I illustrate how one might simultaneously seek freedom and be regulated or self-regulating - freedom can be limited 
in this sense. At the end of this chapter I introduce questions about why these drugs that can lessen or stop menstruation are becoming so popular now. What is it about our current social condition that has allowed for their emergence, which was, in the past, disallowed? I present a scenario in which we live in a predominantly non-menstruating society in the future. With this, I ask - if the majority or women stop menstruating, does this mean that our bodies will no longer be depicted as cyclical and problematic? Will an increase in control over menstruation mean that the topic will become more accepted? Or, will negative cultural norms simply be reinforced even more so in this society, and the topic, pushed into non-existence? I use the women's responses to discuss this scenario. Lastly, questions are raised about who might benefit in this non-menstruating society who benefits from women being 'freed' from menstruation? In Chapter Seven, I continue to reflect on the implications of stopping menstruation for women, and society more generally. In particular, I argue that the regulatory project that Depo-Provera is promoting is not unique. Depo-Provera is merely an extension of medicine and the 'feminine hygiene' industry, and thus it as well, is imbued with culturally normative sentiments which encourage women to self-regulate their problematic bodies in the name of empowerment. 


\section{CHAPTER TWO: \\ REGULATION AND HEALTH}

It is important to examine how ideas about regulation are connected to health.

Understanding some of the theoretical work on regulation, power and knowledge, taboo, and medicalization helps to work through my questions about how Depo-Provera regulates women. My aim in this chapter is to provide a critical approach to knowledge construction and to show how it is implicated with power. This is vital to grasp, as it helps to reveal why women's bodies and menstruation might be perceived and depicted in particular ways. Furthermore, I illustrate the importance of understanding that power and regulation are pervasive in the 'everyday' - they do not exist only in a visible, top-tobottom regulatory fashion, rather they can also saturate our cultural and social norms which we might in turn (knowingly or not) take up and use to self-regulate. Despite the pervasiveness of regulation, I also explicate that regulation, power, taboo, and medicalization all have fissures in them in which they could be challenged and resisted.

The theoretical perspectives predominantly used in this chapter are drawn from the work of Foucault. I begin by exploring his ideas about power, knowledge, regulation, and self-regulation and how these are applied to women - their bodies, minds, and health. Next I engage a discussion about taboo - it is quite standard to encounter menstruation described this way throughout the literature (Rosengarten 2000; Merskin 1994; Houpper 1999). I illustrate how taboo is a regulatory concept. Lastly, I focus on connecting ideas about regulation with medicine by exploring medicalization. 


\section{FOUCAULT AND REGULATION}

\section{a) The Hysterization of Women}

Foucault's work on sexuality is most relevant to my analyses. In The History of Sexuality (Volume One), he begins by exposing the Victorian era as not one of silence concerning sex and sexuality, but rather he describes it as a somewhat noisy time. Foucault does not mean to deny that sex was regulated; instead he argues that sex was spoken about in particular ways. For example, schools and also the confession in psychiatric and religious contexts were means of bringing sex into discourse (1978:12-19). Foucault maintains that "What is peculiar to modern societies, in fact, is not that they consigned sex to a shadow of existence, but that they dedicated themselves to speaking about it ad infinitum, while exploiting it as the secret" (35). He raises questions about how and why sexuality was moralized in this manner.

Although Foucault does not specifically mention the topic of menstruation, his work on sexuality is still valuable for reflecting on it. He contends that with sexuality "one had to speak of it as of a thing to be not simply condemned or tolerated but managed, inserted into systems of utility, regulated for the greater good of all, made to function according to an optimum" (24). As was illustrated in Chapter One, menstruation is also expected to be managed and spoken about in particular ways. Undoubtedly, it is to be managed in a way that benefits everyone, not just individual women. If women can manage menstruation how they 'ought' to, then everyone could take comfort in this 'normalcy.' Menstruation is not a concept that pre-exists and is then regulated. Rather, those with power can significantly influence the production of knowledge. By having power over the production of knowledge, subjects can be regulated (105-106). Furthermore, regulation occurs, in part, through encouraging self-regulation. Foucault 
explains that at the end of the eighteenth century, self-surveillance was promoted as a way to extend regulation to the entire social body. Medicine is an exemplar of this (116).

The female body is implicated by the power and knowledge of medicine in which it is, according to Foucault, "analyzed - qualified and disqualified - as being thoroughly saturated with sexuality" (104). Women's bodies were pathologized because of the negative meaning attributed to them. Concerning regulation, Foucault argues that there were,

four great strategies that were deployed in the nineteenth century: the sexualization of children, the hysterization of women, the specification of the perverted, and the regulation of populations - all strategies that went by way of a family which must be viewed, not as a powerful agency of prohibition, but as a major factor of sexualization. (114) ${ }^{11}$

In the setting of the bourgeois family, medicine regulated the family (or at least attempted to). The women in these families were thought of as idle. Because of this idleness, the women were sexualized in a way that constructed their femininity as pathology:

one of the first to be 'sexualized,' was the 'idle' woman. She inhabited the outer edge of the 'world,' in which she always had to appear as a value, and of the family, where she was assigned a new destiny charged with conjugal and parental obligations. Thus there emerged the 'nervous' woman, the woman afflicted with 'vapors'; in this figure, the hysterization of women found its anchorage point. (121)

Foucault uses 'hysterization' to describe how women were depicted as anxious and potentially temperamental, and how this was then used as a justification for encouraging more control over women and their bodies. Foucault maintains that the hysterization of women initially occurred in the bourgeois family because the bourgeoisie desired a

\footnotetext{
${ }^{11}$ Turner disagrees with Foucault's contention that the hysterization of women was something that developed in the nineteenth century. Instead he argues that it goes as far back as ancient Egypt. Turner asserts that although there were cultural changes throughout the centuries, the idea of hysteria was continuously applied to women (1995:92).
} 
distinct sexuality and body from the working class. ${ }^{12}$ The bourgeoisie wanted to be regulated by health to gain status and ensure that their children were well-managed (124126). Foucault elucidates - "social differentiation would be affirmed, not by the 'sexual" quality of the body, but by the intensity of its repression" (129). Bryan Turner understands the hysterization of women as an example of patriarchal medicine - he explains how constructing women in this way reinforced social relations - specifically gendered and sexual relations (1995:90-91). Foucault depicts the stigma as regulation, but also as something that many people believed would benefit them if they managed themselves accordingly - thus self-regulation reinforced the regulation promoted by medicine.

\section{b) Discourse and Power}

Gena Corea shows how cultural values influence how the knowledge about Depo-Provera is constructed and disseminated - "When we talk about the scientific evidence on this contraceptive, we cannot ignore the politics of knowledge, the fact that a relationship exists between knowledge and the way power is structured in any society" (1991:162). Foucault encourages others to question how particular truths are attempted through discourse, how we communicate either through words, text, or images. His analysis of power and discourse is useful. He describes discourses as plural and saturated with power - “discourses are tactical elements or blocks operating in a field of force relations, there can exist different and even contradictory discourses within the same strategy, they can, on the contrary, circulate without changing their form from one strategy to another opposing strategy" (1978:101-102). The most dominant and persuasive discourses or

\footnotetext{
${ }^{12}$ Eventually these ideas about regulating health worked their way into the working class family (Foucault 1978:121).
} 
'truths' could be those purported by or backed by experts - those with an often assumed mastery over knowledge (Foucault 1978:12; Rako 2003:96; Abercrombie 1994:46). For example, the scientific and medical experts that produce Depo-Provera, and the marketing experts who promote it - construct and present knowledge in a manner that speaks a truth about freedom. It is necessary to ask what this 'truth' says about women and their bodies. Quite often, people do not trust expertise and will resist or try to negotiate power and meaning (Lowe 2005; Bransen 1992). It is crucial to propose alternative truths and to seek out underlying messages in discourses. For instance, to explore the discourse of freedom that Depo-Provera uses, I have drawn on an alternate discourse about regulation.

Power is not an unproblematic, straightforward concept. Foucault understands power as plural - it exists in all parts of society - "Power is everywhere; not because it embraces everything, but because it comes from everywhere" (1978:93). This does not mean that institutions do not have substantial power in society. Foucault is not overlooking institutional power, rather he is trying to push people to think beyond traditional conceptions of power - to examine all potential spaces for power (11). He explains:

The analysis, made in terms of power, must not assume that the sovereignty of the state, the form of the law, or the over-all unity of a domination are given at the outset; rather, these are only the terminal forms power takes. It seems to me that power must be understood in the first instance as the multiplicity of force relations immanent in the sphere in which they operate and which constitute their own organization; as the process which, through ceaseless struggles and confrontations, transforms, strengthens, or reverses them; as the support which these force relations find in one another, thus forming a chain or a system, or on the contrary, the disjunctions and contradictions which isolate them from one another; and lastly, as the strategies in which they take effect, whose general design or institution crystallization is embodied in the state apparatus, in the formulation of the law, in the various social hegemonies. (92-93) 
Not only is power plural, but it also shifts - it is negotiable.

For Foucault, power is not "acquired, seized, or shared, something that one holds on to or allows to slip away" (1978:94). He does not intend for his conception of power to mean that everyone has equal access to it (McLaren 1997:115). When analyzing Foucault's work, Susan Bordo argues that "modern power (as opposed to sovereign power) is non-authoritarian, non-conspiratorial, and indeed non-orchestrated; yet it none the less produces and normalises bodies to serve prevailing relations of dominance and subordination" (1993:190). I, and others, contend that social and cultural norms must be examined when trying to understand power, knowledge construction or maintenance, and regulation and self-regulation (Bordo 1993; Corea 1991). Bordo argues that with Foucault's ideas about power, there is an acknowledgement that some people will try to maintain and conform to certain social norms to gain status which could conversely have a negative impact on others $(1978: 192)$. Although I do not think that Foucault rejects the idea of norms or the influence of them, he instead seems to speak largely in terms of examining discourse. When reflecting on the plurality of discourse, he says,

we must not imagine a world of discourse divided between accepted discourse and excluded discourse, or between the dominant discourse and the dominated one; but as a multiplicity of discursive elements that can come into play in various strategies. (100)

While I understand the value of examining the plethora of discourses in our society, I do not think it is harmful to distinguish between the dominant and the dominated discourses, and I believe that he himself makes these distinctions (albeit sometimes indirectly) throughout his own work. Janet Lee and Janet Sasser-Coen also emphasize the importance of understanding dominant discourses, as we often internalize them and manage ourselves accordingly (unless we resist them) (1996). Consistent with Foucault, 
they caution that dominant discourses are incomplete sources of knowledge - they usually include a partial perspective.

\section{c) Resistance and Power}

Foucault considers power and resistance to be relational concepts. Resistance is also everywhere. He further explains that,

there is a plurality of resistances, each of them a special case: resistances are possible, necessary, improbable; others that are spontaneous, savage, solitary, concerted, rampant, or violent; still others that are quick to compromise, interested, or sacrificial; by definition, they can only exist in the strategic field of power relations. (1978:96)

Margaret McLaren points out that Foucault distinguishes between domination - which is for the most part stable and difficult to resist, and power - which is changeable and open to opposition from resistance (1997:116). If power does exist everywhere in our society, as Foucault claims it does, then in relation to women and their bodies - their bodies cannot escape the presence of power relations, but, this power can be negotiated through resistance (Fingerson 2005:92). Martin also argues that power and resistance are relational. When discussing the power of medical knowledge and the impact on women, she attests that,

women - whose bodily experience is denigrated and demolished by models implying failed production, waste, decay, and breakdown - have it literally within them to confront the story science tells with another story, based in their own experience. (1987:197)

Throughout this thesis I return to instances of resistance, developing my own, as well as conveying others' understanding of it.

One common criticism of Foucault, particularly from feminist theorists, is that his ideas about power and resistance are too abstract and problematic for actual social action. There is concern that his conception of power as everywhere causes people to get trapped 
- it is so pervasive that there is no way to escape the dominance of power (McLaren 1997:115; Bordo 1993:191; Lupton 1997:101). Nettleton argues though that Foucault's ideas are not "invariably gloomy" - we are not paralyzed by power because there is the potential for resistance (1997:210). Yet the premise that power and resistance are relational, for many, offers little solace from this perceived dilemma. McLaren attests that Foucault's understanding of resistance is "underdeveloped" (1997:123). Several theorists argue that examples of how resistance could be achieved are not explained thoroughly enough (Turner 1995:14; McLaren 1997:123; Still 1994:152). None of these theorists, in the end, reject using Foucault. I as well, do not believe that these criticisms are substantial enough to completely discard Foucault.

Another feminist criticism of Foucault is that although he challenges and deconstructs overarching truths and discourses as part of his work - there are nevertheless normative ways of thinking that pervade his own work. For instance, Judith Still argues that his focus is largely androcentric (1994:152-154). McLaren also expresses that many feminists are concerned that Foucault did not devote enough analysis to gender (1997:114). These criticisms also do not justify abandoning Foucault's work. Many feminists appreciate his ideas and instead employ a critical approach and try to work gender more thoroughly into the analysis when they feel it is lacking (Still 1994; McLaren 1997). Throughout my own work I draw on his ideas, and as with any theory, add to them when I feel it is necessary. Instead of seeking one 'perfect' theory (if such a thing exists), I would rather be flexible and combine several theories that can complement each other in interesting ways. 


\section{TABOO AND REGULATION}

Why is menstruation so often depicted as taboo? What is the purpose of this? Foucault's work is a helpful starting point for understanding 'taboo.' He explains that concerning sexuality, the Victorians proposed it be subjected to "taboo, nonexistence, and silence" (1978:4-5). Moreover, he conveys that "Not only did it not exist, it had no right to exist and would be made to disappear upon its least manifestation - whether in acts or in words" (4:emphasis added). Feminine hygiene advertising tries to push menstruation into a state of non-existence through the endorsement of concealment and discretion (Houpper 1999; Coutts \& Berg 1993). As was mentioned in Chapter One, Depo-Provera also has the potential to eradicate menstruation, to a certain degree. But just as sexuality was actually spoken of, menstruation is as well, but both in a limited way.

The meaning and construction of the 'menstrual taboo' is contested. For instance, Rosengarten argues that it is representative of a failed reproductive cycle. She contends that it is the waste and failure of not reproducing that is the basis for taboo (2000:96). I question if this is the origin of the taboo. It is unlikely that one source or theory resolves why menstruation is repeatedly depicted as taboo. Another perspective comes from Mary Douglas (1966). Through her research on how societies handle 'pollution' and dirt, she shows how taboos are used to maintain order. Menstruation is often regarded as pollution or dirt. She reasons that people are not necessarily afraid of that which is dirt, rather they are concerned with a lack of control over dirt - "I believe that some pollutions are used as analogies for expressing a general view of social order" (3). She further defends that,

As we know it, dirt is essentially disorder. There is no such thing as absolute dirt: it exists in the eye of the beholder. If we shun dirt, it is not because of craven fear, still less dread of holy terror. Nor do our ideas about disease account for the range of our behaviour in cleaning or avoiding dirt. Dirt offends against order. 
Eliminating it is not a negative movement, but a positive effort to organise the environment. (2)

Foucault argues that power operates through taboo (1978:84). It encourages personal management and on a larger scale sets out social expectations (Merskin 1999; Foucault 1978; Douglas 1966). I agree with Douglas' argument that controlling dirt helps to maintain social order, yet I find her denial of the role of fear problematic. I find it unconvincing that entire societies would attempt to strongly regulate something which they initially had no fear of. I question if taboos about menstruation originated from not knowing exactly what menstrual blood was, which then could have contributed to a stigmatization of women's bodies, and eventually as we became more knowledgeable about menstruation, the taboo shifted to being about order, reflecting and sustaining social norms regarding the behaviour and value of women.

Laws completely rejects the concept of taboo for describing how, specifically British culture, treats menstruation. She believes that something is defined as taboo because of a fear of the supernatural. By labeling menstruation as taboo, and thus relating it to the supernatural, she is concerned that the meaning of menstruation and the management of it will be seen as unchangeable. She attests that "Social rules are within the power of human beings to change - but if they are understood as resulting from deep unknowable psychic horrors rather than plain politics, they are made to seem inevitable, beyond change" (1990:68). Laws is also apprehensive that relating menstruation to the supernatural overlooks the role of males in maintaining menstrual rules $(6 ; 67-68)$. She instead uses the term 'menstrual etiquette' to describe the social rules and practices surrounding menstruation. I do not however think that such a departure from taboo needs to be made based on the idea of the supernatural. The definition of taboo does not have to 
include this. For instance, incest is recognized as taboo in all cultures - the supernatural is not a necessary part of it for it to be considered taboo.

Taboo is unequivocally connected to social and cultural norms and is aimed at encouraging people to act in conformity with them. The menstrual taboo specifically, I believe is fuelled by both males and females, albeit with different contributions, outcomes, and implications. I agree with David Akin who argues that taboos need to be understood in context (particularly historical context), they are not always clear, they can be rejected, manipulated, fluctuate in strength and imposition, and they can change and shift in meaning over time (2003). I do not think that menstruation must be defined as taboo in our society. If the concept of menstruation as taboo were to disappear, it is likely that the regulation of menstruation would still persist. There are several ways to describe the regulation of menstruation - taboo, etiquette, discourse. Another way of understanding how menstruation is regulated is by examining medicalization. It is relevant to note that although I am addressing taboo and medicine separately, the two are not disconnected.

\section{MEDICINE AND REGULATION}

The term medicalization is often used to describe how medicine infiltrates numerous aspects of our lives. The penetration of medicine is also often described, particularly by Foucault and those who use his work, as the 'medical gaze' or 'clinical gaze' (Armstrong 1997:20-21; Kholer Riessman 2003:46-47). To describe our society as medicalized, means that not only are individuals defined in medical terms (as having either good health or bad health), but the society as a whole is subjected to being managed by medicine (Kholer Riessman 2003). Elina Oinas explains that, "sociologists have 
generally used this concept to characterise a negative development in western societies, i.e. the increasing social control of everyday life by medical experts" (1998:52). In her work on power and medicine in society, Deborah Lupton favours a Foucauldian approach for critiquing medicalization (1997). ${ }^{13}$ She shows that his work enables her to see doctors and patients as connected to a web of power rather than having an isolated, top-to-bottom power relationship. Catherine Kholer Riessman points out that medicalization often removes the political and social context by turning something into a 'medical problem' (2003:56). Using Foucault's work allows Lupton to analyze the power/knowledge relationship in the context of social and cultural influences (1997). By focusing on Foucault, she is trying to concentrate on the process of medicalization. Moreover, she is explicating the argument that power and medicalization are not solely in the hands of medicine - the aim is not to 'get rid of' medical professionals' power - this would not displace power, as it is too dispersed (Lupton 1997:99-100; see also Kholer Riessman 2003:59). There is no one group in particular that we can completely 'put the blame on' with medicalization. For example, although male ideals and values do play a significant part in the medicalization of menstruation, there are countless women who embrace these ideas and self-regulate (knowingly or not) accordingly. Kholer Riessman suggests that many women feel a sense of agency in the overall medicalization process:

Women collaborate in the medicalization process because of their own needs and motives, which in turn grow out of the class-specific nature of their subordination. In addition, other groups bring economic interests to which both physicians and women are responsive. (2003:59)

\footnotetext{
${ }^{13}$ She chooses this over what she describes as a traditional approach. The traditional critiques of medicalization focus on institutionalized power, fighting for patient's rights (for example to see medical files), challenging overmedicalization, criticizing medicine as targeting vulnerable, disadvantaged groups, and challenging the idea that doctors should be solely in control of medical knowledge and defining what good health is (Lupton 1997b:95-96). She criticizes this traditional approach as too "black-and-white," not focused enough on patients' agency concerning their potential for resistance, and overlooking the positive contributions that medical knowledge can make (97-98).
} 
Oinas also maintains that women actively participate in medicalization in varying ways (1998).

Lee and Sasser-Coen, who describe the body (particularly the menstruating body) as a "cultural entity," argue that "Cultural discourses of the body and its menstrual secretions and cycles represent the point where power relations are manifest in their most concrete form" (1996:7). The medicalization of menstruation reinforces and constructs norms about women and their bodies. Turner argues that "medical disorders are associated with low social status and the absence of power where medical doctrines, because they reflect dominant values, tend to express and reinforce existing hierarchies of social control" (1995:109). Louise Lander also constructs medicine as political. She dubs medicine - "masculinist medicine reflecting a masculinist society" (1988:6). The medical model focuses on informing women about the biological process of menstruation, rather than the actual experience of it (which is most often what women really want to know) (Martin 1987; Oinas 1998). Lowe also contends that women's experiences, particularly not validating women's expressions of experiencing negative side effects from contraceptive drugs, are often overlooked and medical knowledge is favoured instead (2005:364). This could be the result of a combination of the medical model favouring objectivity (Bunkle 1993:298) and cultural assumptions about women as not being trustworthy and also having unstable bodies, thus somewhat unknowable bodies. Furthermore, when prescribing contraceptive drugs, stereotypes about race and class come into play. For example, doctors might use stereotypes to assess whether a mother is competent enough for particular types of birth control (Lowe 2005:363). 
Why does medicalization occur? Kholer Riessman explains that the answer to this is not agreed upon (2003). The existence of medicalization could be prompted by power, authority, and organization. Reissman points out that many theorists also focus on the motivation of money. Thus far I have mainly explored the idea of medicalizing women's bodies in terms of power and social order. It is important for my analysis of medicine and menstruation to not overlook money as a motivator. When thinking specifically about women, Kholer Riessman says, "it is important to emphasize that corporations, in their effort to maximize profits, work through both physicians and women" (57). DepoProvera, is of course, no exception.

When trying to enforce medicalization or promote a particular health regime health associations, doctors, or companies appeal to the idea of 'good health.' Foucault describes that there was a shift in the eighteenth century from trying to control people through death, to trying to control them via the idea of life and health (1978:142-145). Women were, and still are, regulated in this way. Foucault suggests that the "hysterization of women, which involved a thorough medicalization of their bodies and their sex, was carried out in the name of the responsibility they owed to the health of their children, the solidity of the family institution, and the safeguarding of society" (146-147). 'Good health' is not necessarily a purely positive endeavour though. Ideas about what good health is might actually not be good for all people, but it is pushed in a universal way. Social norms are often internalized. Oinas contends that although women recognize that their bodies vary from one another - they often still seek out a norm - one that fits with predominant ideas of femininity (1998). Depo-Provera, if working as the company claims it should, facilitates a way for women to conform to and manage their bodies 
according to social norms - they can be hygienic, discrete about menstruation, active in society, and feminine. From the interviews done for this study though, we see that women self-regulate in a variety of different, possibly even contradictory ways. People might self-regulate in resistance, conformity, or both (Nettleton 1997).

Sarah Nettleton argues that in our society, there is an increasing 'responsibilization' of people. Health care is not exempt from this (1997:209). Arthur Frank explains that this derives from the influence of neo-liberal ideals - the most relevant here - the beliefs that we have the right to choices and that we can make whatever choices we please, and encouraging people to be responsible for themselves as well as social change and improvement (2002:19-20). The idea exists that those who do not take responsibility for their health, lack control and competence (Harding 1997:143144; Turner 1995:208). Jennifer Harding asserts that this is a dangerous way to think because there are many people who do not have the time or resources to meet the standards of 'good health.' For women, this norm is based on the white, middle-class woman - not always something that can be achieved (1997:143-144). Or, for that matter, not something that is always desirable. Moreover, as Saras Henderson and Alan Petersen point out - not everyone wants to be overly responsible for their own health (2002). People care about their health in varying degrees.

The idea of conforming to ideals of 'good health' raises interesting questions about menstrual suppression. If the idea were to eventually become widely accepted, does this mean that women who fail to suppress menstruation will become pathologized and perceived as lacking control over their bodies? The irresponsible menstrual manager is currently thought of as the woman who fails to conceal the evidence of menstruation 
(leaks, smells, wrappers). Could the irresponsible menstrual manager shift to being a woman who fails to control her menstrual cycle via hormonal injections?

Persuading people to manage their health can be done through the idea of risk. In a 'risk society,' everyone is at risk of bad health, always potentially sick. In this type of society, it is argued that risk is normal and we are continually faced with decisions in which we are expected to try to reduce anxiety and risk (Petersen 1997; Gastaldo 1997; Turner 1995). We are, perhaps incorrectly, assumed to be rational and calculating about our self-management (Petersen 1997). Turner explains that it is debatable whether our society is currently more or less 'risky' than in the past, nevertheless it is an interesting concept to examine. The connection between disease, risk, and regulating people through 'good health' is not a new idea, although I am also uncertain if it has intensified or not. The risk society is also linked to medicine and consumerism. Turner explains that "Within the risk society there is an insatiable appetite for medical products and services which has produced a global market for the medical profession whose social power has been correspondingly enhanced" (1995:223). Medical consumerism is discussed in detail in the next chapter.

What is wrong with promoting 'good health'? The concerns that I have illustrated are about how good health is defined and conveyed, and how power, knowledge and regulation are intertwined in this process. Good health can be a very positive thing for many people, but we still need to consider how and why we are being asked to be responsible for our health. Denise Gastaldo, who focuses on health education, cautions that the idea of good health needs to be approached critically because it often reinforces norms and encourages regulation under the guise of empowering people (1997). She does 
not however, think that people do not actually benefit from practicing good health. Also, I and others, do not mean to depict medicine as entirely bad (see Lupton 1997). Clearly, medicine has made and will continue to make amazing contributions to the well-being of our society. Concerning menstrual suppression, many women will appreciate the medical knowledge about stopping menstruation as something that benefits them, yet as has been illustrated in this chapter, one must recognize that their bleeding body will simultaneously be constructed and valued as problematic. The issues of medicalization, responsibilization, and good health are complex - in a multitude of ways we can concurrently conform and resist, be regulated or self-regulate, and yet still feel a sense of empowerment. It is now necessary to turn our attention to how consumerism and freedom fit in with all of this. 


\section{CHAPTER THREE: \\ MARKETING FREEDOM}

The contraception industry is continually expanding. While many people think of the 1960 s as a boom period for this industry, Andrea Tone illuminates the Depression in the US as the first instance of significant, steady growth. She argues that contraception aimed toward females in the 1930s built up the consumer base which helped create further demand for newer and better types of contraception (1996:485-486). There was much more profit to be made by expanding on female contraception - "Within this highly profitable and unfettered trade, women became the market's most reliable and, by extension, most exploited customers" (Tone 1996:486). Very early on, Tone explains, contraceptive advertising depicted women as having free choice and their consumption of the 'right' products was to lead to empowerment (496). This trend continues today. In this chapter, I focus on Depo-Provera's usage of the idea of freedom in its marketing. Not only is freedom from getting pregnant or having to worry about one's birth control offered to potential consumers, but freedom from one's menstrual cycle is promoted.

I explore Depo-Provera's website as a means of understanding how the company addresses prospective consumers. It is imperative to analyze what they are trying to tell people about menstruation, contraception, women's bodies, and freedom, before turning our attention to how women actually feel about these things. Analyzing Depo-Provera's promises of freedom provides an opportunity to begin discussing some theoretical aspects concerning this concept, and in particular, how consumerism is paired with, and often equated with, freedom. I argue that while Depo-Provera presents itself as empowering women, self-regulation and bodily management in accordance with social and cultural norms are the means through which women are encouraged to try to attain this freedom. 
I begin with a discussion on pharmaceutical drug advertising. I then shift to examining Depo-Provera's website. I first tackle analyses of how they depict gender, menstruation and contraception, and how medical knowledge and expertise are used on the site. How they portray 'freedom' is then examined. This includes analyzing how Depo-Provera offers women limited freedom - one that involves self-regulation. Then, I shift the discussion to theorizing the concept freedom. Bauman's work concerning the idea of attaining freedom through consumption is first examined. Next, the work of Nikolas Rose is utilized to examine the practice of attempting to govern and sway people through the idea of freedom. Foucault's later work on ethics and freedom is also explored and questioned to help further understand how self-regulation and freedom could be connected.

\section{PHARMACEUTICAL DRUG ADVERTISING}

Estelle B. Freedman examines the multiple ways in which women's bodies are commodified - through products targeting beauty, to reproduction, to disease and health, weight, plastic surgery, and so forth (2002). She remarks that "Along with medicalization, commercialization has exerted an increasingly powerful influence on the cultural meanings of the female body" (209). Simon Williams comments that both men and women are further targeted by commodification of pleasure with our bodies as well, there is commodification of the idea of bodily control (1998:443). Arguably though, this does not happen in a similar fashion or intensity between men and women. Commodification builds on and often reflects social relations and thus can reflect social inequalities (Riordan 2001). 
Dominant ideologies are very often part of advertising. Robert Goldman describes how we are bombarded with so many advertisements on a daily basis that we often do not bother to consider the deeper social meanings and underlying ideologies that they frequently build on (1992:1-2). Ideology can have the biggest impact when it does not come across as such (Coupland \& Williams 2002:422). Mica Nava illustrates how women, children, and people with lower education were (and still are?) believed to be the most easily manipulated by advertising and mass consumption (1999:51). The effects of the media though, are quite varied. Different people, on different occasions, and in different contexts might be passive receivers or active interpreters. Some people might be duped, might want to comply, or might resist messages in advertisements.

When specifically looking at pharmaceutical drug advertising, Barbara Mintzes explains that direct-to consumer advertising (DTCA) of prescription drugs is only legal in two countries in the world - the US ${ }^{14}$ and New Zealand (2002:908). This of course does not mean that people in other countries are not exposed to these advertisements. With cross-border channels, satellite, international marketing of magazines and other print media, as well as the internet, DTCA can reach far beyond the confines of its country of origin. For instance in Canada, we continually encounter these advertisements.

Lisa Basara explains that,

the primary functions of DTCA are to enlighten consumers regarding a particular product available for the management of a certain disease or condition and to persuade the consumer to discuss the product/disease with his or her physician. Pharmaceutical marketers anticipate that the consumer's consultation with a physician will ultimately lead to the request and provision of a prescription for a specific pharmaceutical drug product. (1992:319)

\footnotetext{
${ }^{14}$ DTCA took off in the US in the late 1970s, but was actually banned from 1983-1985 (Sorofman 1992:381).
} 
She points out that DTCA actually does increase sales (327). It is interesting to note that the consumption of prescription drugs increases even though patients/consumers pursuing certain choices must go through a health-care provider to obtain their prescription. It is likely though that consumption does not increase solely because of patient consumers being exposed to DTCA. There are other ways for 'lay' people to learn about prescription drugs (books, journals) (Sorofman 1992:382). Health-care providers are subjected to advertising of the products as well (Caudill \& Lurie 1992; Fuqua 2002).

The impact of DTCA is debated. The intentions of the pharmaceutical companies are not entirely clear (for profit or promoting health? for regulation and social control, or empowerment?), as well as the impact on the medical field and society (Bonaccorso \& Sturchio 2002; Mintzes 2002). While the knowledge received from these advertisements could be empowering for potential patients/consumers (Bonaccorso \& Sturchio 2002: Fuqua 2002), some concerns exist that the advertisements are just an extension of medicalization - that they "trivialize prescription drugs" (Basara 1992:323) and that they decontextualize and twist knowledge in a way that medicalizes normal aspects of life and promotes a way of thinking in which people see themselves as always potentially at risk of bad health (Mintzes 2002:908).

The use of the internet for health purposes is rising. With this, comes an increasing concern from health-care professionals about the accuracy of internet health information. Michael Hardey carried out a study of people who used the internet to both find and produce health information. He found that while some people were uncritical of what they read, there were also those who were critical of both 'lay' sites and expert sites - for instance pharmaceutical company websites (2001:392-397). Many of the people 
who used the internet for health information did so because they felt that their doctors were not giving them detailed enough information, in many cases, because doctors had little time to spend with them. Many people also use the internet because of the anonymity it affords. Hardey argues that the internet has an impact on medicine by reinforcing the ideas of patients as active consumers. This consumer status is furthered by the opportunity for many people to purchase prescription drugs via the internet - "a rapidly growing part of e-commerce" (Hardey 2001:399). He wonders what affect all of this could have on health-care systems - if it will cause them to become more patientcentered, or eventually obsolete.

\section{DEPO-PROVERA WEBSITE ANALYSIS ${ }^{15}$}

The Depo-Provera website is an example of DTCA. ${ }^{16}$ Although typically thought of as either commercials or print advertisements, DTCA is also on the internet - in both the form of advertising links and official company websites (see Appendix One). I argue that DTCA with a website can be incredibly thorough compared to commercial or print form. There is considerable space for text and images and audiences can be more interactive. The Depo-Provera website provides visitors with the possibility to explore "The DepoProvera advantage," how the product works, whether or not the product is right for them, and what side effects there might be. They can read a doctor's account of the product, can

\footnotetext{
${ }^{15}$ I initially intended on finding print advertisements from Depo-Provera as well - for instance, ones that could be found in waiting rooms at health clinics. When I called the company to inquire about any print advertisements, I was told that no promotional material existed at the time (I called several times in Fall '05) because Pfizer had recently taken over the drug. From going back onto old archived Depo-Provera websites (via the 'WayBackMachine' on www.archive.org), it is evident that Pfizer took over in 2003 (before them it was the Pharmacia Company, and even before this the manufacturers were the Pharmacia and Upjohn Company).

${ }^{16}$ It is interesting to note that on their website, in small print, it is stated that the website is only intended for US citizens (www.depoprovera.com). While I understand that this is done for regulatory reasons of controlling DTCA, regulations such as these are ineffective in the global information era.
} 
watch a testimonial video, and can access Pfizer's medical information on the drug. If already a user - they can utilize the injection reminder. Perhaps most importantly (from Depo-Provera's promotional point of view anyways), they can explore how they could experience freedom with Depo-Provera. It is stated on the bottom of the website, in small print, that the website exists for educational purposes and that doctors need to be contacted for further information. The content of the website is fairly detailed, although it is quite repetitive - particularly when telling visitors that with Depo-Provera they could become more confident and free.

\section{a) Depo-Provera's 'Modern Woman'}

Many scholars argue that while a lot of advertising is presented in ways that target the individual (for example, by offering them personal freedom), quite often the behaviour that is being endorsed is highly normative behaviour. Norms are exploited for advertising and normative responses are desired (Merskin 1999; Fuqua 2002). Depo-Provera utilizes normative ideas about 'the modern woman' on its website. It makes assumptions about what women want and need in their lives. Women are presented as strong, thoughtful, intelligent, and deserving of a product that claims to empower them further. The socially desirable 'modern woman' prototype is presented as a busy 'go-getter' who cannot be concerned with having to remember to use other types of birth control, particularly the pill. While her intelligence is apparent it is simultaneously undermined by depicting women as continuously anxious about their birth control - whether or not they will remember it and if it is working. Depo-Provera assuages these anxieties by claiming that when one uses the product - "that's confidence. That's freedom." A prominent idea on the website is that women need to feel in control. None of the pictures on the website 
portray women as having a passive demeanour. The women are very well-dressed, are very attractive, and several are engaging activities such as writing, or working on a computer. These success-oriented, well-put together women are reassured that "Your time is your time. Because you're too busy to let your birth control control your schedule." It is important to note that only women who are, or are on their way, to being affluent professionals are depicted on this website. Is it assumed that these women have more choices and are more active consumers because of their financial status? Or is it assumed that they deserve more choices and freedoms? Professional women are certainly not Depo-Provera's only target audience. We can recall here, from Chapter One, that Depo-Provera has an extensive history of targeting lower class women. It would be somewhat illogical though to try to sell this product with images of women who are not well-off. It is most conceivable that these images of affluent, stylish women are used because they are appealing to a variety of women. Moreover, they encourage women who are not like the images to want to use the product - to aspire to be 'sophisticated modern women.'

Goldman explains that many advertisers targeting women will use ideas of feminism in their marketing. But this is most often an exploited, misconstrued form of feminism - one that encourages women to feel empowered at the cost (although it might not be a cost for some) of conforming to social expectations about femininity (1992:108). Depo-Provera's 'modern woman' does have a demanding life, but we are shown from the pictures on the website that these women are still beautiful and smiling amidst all of this. The photos are situated in a feminine colour-scheme of white, pinks, purples, and a soft blue. As well, the women are wearing clothes in these colours. Goldman comments that, 
Commodity feminism declares that control and ownership over one's body/face/self, accomplished through the right acquisitions, can maximize one's value at both work and home. As far as corporate marketers are now concerned, this new 'freedom' has become essential to the accumulation of capital - to reproducing the commodity form. (1992:153)

I think that this is useful to consider, yet Goldman's point of this being a new approach that "corporate marketers are now concerned" (emphasis added) with seems quite inaccurate. As is discussed shortly, the method of appealing to right acquisitions, here the right to freedom, to encourage a desired behavioural outcome is nothing new. That aside, a major concern that Goldman has with appropriating feminism for advertising, is that in some cases, "when framed by ideologies of individualism and free choice, feminism put into commodity form forgets its origins in a critique of unequal social, economic and political relations" (132). Depo-Provera has presented images and narratives of women who are strong and who will make competent, empowering choices for themselves - yet they still possess many traditional feminine elements. Despite the heavy focus on freedom, social gender boundaries have not been challenged on this website. This includes how the topics of contraception and menstruation are dealt with.

\section{b) Eliminating Hassles?}

Choosing what is supposed to be a discrete, reversible birth control method and suppressing a socially awkward topic - menstruation, are, in our society, socially acceptable choices. Assumptions are made on the Depo-Provera website that woman are, for the most part, inconvenienced and embarrassed by birth control. They postulate that women want birth control to be a private topic - "Your birth control is your business." If women do feel this way about birth control, then this product could certainly be empowering for them. 
While the Depo-Provera website is clearly first and foremost about birth control, the capability of the drug to stop menstruation and a focus on bleeding are still prominent. Menstrual suppression is promoted by discussing it as a benefit of the drug. It is never explicitly said that it ought to be a primary motive, but it is certainly made out to be an advantage of using Depo-Provera. For instance, in one of the summary sections of the advantages of Depo-Provera, it is boasted that

With Depo-Provera, you have the freedom to:

Have lighter periods or no periods at all.

Enjoy protection right from the start.

Return to fertility after you stop getting doses.

Another example of the focus on menstruation is evident when one clicks on "The First Year" section of the website. There is a description about what happens in each three month span between doses. Bleeding is mentioned in all of these sections. For instance, with the first time span, women are assured that irregular bleeding is normal and they encourage women to put up with this for the overall benefit of the product -

Irregular spotting and bleeding is normal. These effects generally lessen over time. It just takes time./ Remember that eventually you may not even get your period at all. Depo-Provera has been administered for more than 40 years. Women just like you have benefited from Depo-Provera in many ways. ${ }^{17}$

(www.depoprovera.com)

Menstrual cessation, irregular bleeding, and spotting are all side effects, yet the first is framed and promoted as convenient and the others are minimized because they are inconvenient. This is consistent with social and cultural norms about menstruation. Concerning women's attitudes toward stopping menstruation, it is depicted as something

\footnotetext{
${ }^{17}$ Regarding it being used for 40 years, this is a very misleading statement given that both of the appeals to have it approved in the US in 1978 and 1984 were turned down because of concerns about safety. It was only approved by the FDA in 1992 (Corea 1991:161). Again, it was approved in Canada in 1997. This 40 year time span that they talk about was, as has already been discussed, a time in which they were attempting to exploit the market in 'Third World' countries, as well as targeting "Third World stereotypes" in 'First World' countries (Bunkle 1993:288-289).
} 
that most women would not mind stopping. While they acknowledge that some women might not like the idea of menstrual suppression, they do not elaborate on this. It is significant that Depo-Provera draws on the idea of menstruation as a hassle - one that need not be tolerated, yet the side effects of irregular bleeding and spotting (two potentially disastrous social mishaps according to the feminine hygiene industry) that can occur with the use of this product, are delineated as not that big of a deal.

\section{c) Depo-Provera and 'Expert Knowledge'}

Goldman describes advertising as something that does not come after the production of a product but as something that is part of the production process. It is production in the sense that meaning is produced - or at least there is an attempt to produce meaning, since it will be interpreted differently by various people (1992:33-39). How is medical knowledge presented on this website? How is expertise appealed to? In terms of the language used, the euphemism 'period' is frequently utilized in parts of the website aimed at patients/consumers. The words spotting and bleeding are also used quite often. 'Menstruation words' such as 'menstrual bleeding' and 'menstrual cycle' are terms associated with doctors because they are only used in the section of the website that is a 'consultation' with a doctor (a 'Q \& A' section). Justine Coupland and Angie Williams describe how pharmaceutical advertising uses an authoritative voice - typically presented as a doctor's voice, yet it is often ambiguous whether the writer is a doctor or not (2002:423). Depo-Provera has a 'Q \& A' section in which one can “Meet Dr. Adrias.” It is unclear how real this doctor is since actual medical questions are not to be referred to 
her, but are instead to be directed toward the Depo-Provera phone-line (staffed by nurses) or one's own health-care provider. ${ }^{18}$

Pharmaceutical advertisements are presented in terms of facts and solutions (Coupland \& Williams 2002:422). Statistics are used throughout the Depo-Provera website to appeal to the idea of expert knowledge. Also, in addition to the use of authoritative knowledge, lay people who present testimonials are often presented as experts (Sorofman 1992:379). Depo-Provera uses a video testimonial on its website to do this. On the site overall, the medical knowledge aimed at patients is 'dumbed down' so to speak, while the medical knowledge aimed at doctors (which can be accessed through the 'Important patient information' link) is quite detailed. If one reads the side effects section on the homepage of the website, it is simple and easy to understand. However, if one ventures onto the pages aimed at informing doctors about the drug, she will discover that the information is much more thorough. ${ }^{19}$ It is important to note that the most detailed knowledge is not overly accessible to patients because the scientific language used is somewhat difficult. This is an unfortunate discovery, since it is possible that many people will not wade through this literature to eventually discover that significantly more side effects are intended to be revealed to health-care professionals than they are to patients visiting the main pages of the website. The only side effects that are listed on the main pages of the website are bone mineral density loss, weight gain, headaches, and irregular bleeding or spotting. They also note that Depo-Provera should not be used if one has a history of breast cancer, blood clots, stroke, or liver disease. Moreover, when one clicks

\footnotetext{
${ }^{18}$ Interestingly, when I called the toll-free Canadian Depo-Provera line in the Fall of 2005, I learned that it is entirely automated - at no point is there an opportunity to speak with a real person. With the American toll-free line though, there is the opportunity to speak with a nurse, but only if you are an American citizen. ${ }^{19}$ Furthermore, there is an additional link for doctors but it has restricted access - patients or potential patients would not be able to get to this restricted site.
} 
on the question - "Are there any side effects?" - only two are discussed - irregular bleeding and weight gain. This is nowhere near the number of potential side effects that actually exist. The website is set up in a way that minimizes the negative side effects and prioritizes the benefits of the drug.

\section{d) Consuming Freedom}

The slogan that Depo-Provera uses on their website is "Depo-Provera. Freedom from the everyday." 20 The idea of freedom is prominent throughout the website. They are careful to present the drug as something that can be liberating, rather than drawing attention to the bodily management and self-regulation involved with the consumption of this drug. How do they depict freedom? I interpret their slogan as offering women freedom from their minds and freedom from their bodies - from their fertile bodies and bleeding bodies. Regarding freedom from one's mind - they present the situation as such:

You lead a busy life. Your job, your friends, your family. It can all really add up. And some days it's so easy to forget about birth control. With Depo-Provera, you don't have to think about your birth control every day. That leaves you free to get on with your life.

The Depo-Provera website includes a testimonial video (of an 'expert lay person') for visitors to watch. One can click on "A real experience. Watch Amy tell her story" to begin the video. Amy is young, attractive, intelligent sounding, and is a professional in the health insurance industry. She describes herself as very active, very busy, and she travels a lot for work and in her leisure time. The video is set up so that she is sitting in a room beside some pink flowers (connoting femininity). The video is quite long, thus only an excerpt will be included here:

\footnotetext{
${ }^{20}$ 'Freedom' was not always a major part of their focus. I am not exactly sure when the current slogan developed, but from going back onto old websites (via the 'WayBackMachine' on www.archive.org), as far back as at least 2003, their slogan was "Birth Control You Think About Just 4 Times A Year."
} 
CHOOSING DEPO-PROVERA [text before she talks] ... when I went back to my gynecologist [after being dissatisfied with the pill] he recommended I try the Depo. So I was on Depo for about, um, 1 year or so in college. And um, I went off birth control for about two years. And when I did chose to go back on birth control I choose to go back on the Depo again. CONVENIENCE [text before she continues talking] I'm getting married in two months and I'm pretty much all set for my honeymoon because we're going to Hawaii. Um, we're going for three, three and half weeks. So, I don't have to worry about taking a pill. I don't have to worry about my schedule. It gives me a lot more freedom on vacations, it gives me more freedom over the summer. It doesn't concern me that I get my period less than some other women might. I think of it more as a plus. When the pill is taken incorrectly it decreases the effectiveness. With the shot you don't really, there isn't really, a decrease in the effectiveness as long as you get it once every three months during that two week window that you have. You know, when you do go off Depo, your periods do return and like I said I was on Depo for a period, um, then I went off of Depo. My periods did return. So that right there was testimonial to me that everything, you know that everything goes back to normal. FREEDOM [text before she continues talking]. I do think that I'll keep using it. Eventually when I want to have children, I'll go off of it. Um, but I can see myself in the future, when I don't want to have any more children, or, you know, if I want to kind of take a break from having children, if I were to go on birth control again after that time, I would choose to go on the Depo again. I like it mostly 'cause it, it is, it's convenient ... it's, you know, there's that's really the number one reason. You know, you make an appointment, and you go into your doctor, they take my blood pressure. Um and they administer the shot. It's very quick, um, I'm in and out of the door in fifteen minutes. Um, I think that some people would stick to status quo and would continue on the pill, but I also think there are many women out there who, if they knew as much as I know about this, this form, um, if they knew as much about Depo as I do, I think they'd be willing to switch once they see the types of freedoms that I have that they might not necessarily have. (www.depoprovera.com)

Freedom from both the fertile and bleeding body are emphasized throughout the excerpt.

The idea is also promoted that women who use Depo-Provera are more free and have an advantage over other women. Freedom is framed in several different ways. For example, Depo-Provera offers freedom from presumed social and personal awkwardness with birth control. One need not be put in a position in which they have to use or take their contraception in front of others, as they only have to go to the doctors four times a year to get an injection. The idea of freedom is also promoted by offering that women do not have to worry about the efficacy of birth control. They also offer freedom from the 
presumed social and personal awkwardness with menstruation - if menstruation stops (the optimal result with bleeding that Depo-Provera promotes), then one would not have to worry about the hassle of leaks, smells, pads or tampons. They could have freedom with their leisure time, as well as their work. Also, they could have sex whenever they want. It is interesting how Depo-Provera implicitly draws on the 'taboo' that having sex during menstruation is bad, by telling a story about a woman about to go on her honeymoon. Their advertising overall, encourages women to focus on their rights to freedom of choice with their consumption and also their freedom of choice over their bodies. The other experiences when using this drug - self-regulation and bodily management, are explicit but are framed in a positive light.

It is significant that while Amy discusses menstrual suppression as positive, she does consider the possibility that not bleeding could be a negative experience for some women - that it could be disconcerting to not menstruate. Indeed many of the women in my study expressed numerous concerns about menstrual suppression. Amy rejects this possibility though by drawing on ideas about normalcy when she says, "You know, when you do go off Depo, your periods do return. So that right there was testimonial to me that everything, you know that everything goes back to normal." While she validates what is 'natural' (monthly menstruation) as normal, Depo-Provera tries to produce and present an alternate 'truth' about menstrual suppression as healthy and thus normal. Their power over the production of knowledge about this drug is noteworthy. They attempt to shift the meaning of normality via Amy's testimonial. Thus while she implies some initial hesitancy, in the end she stretches her own personal truth (that monthly menstruation is normal) because she likes the "plus" of not bleeding and because she feels healthy 
(normal) while doing it (Depo-Provera's truth). As we will see in Chapter Five, the women in my study stretch their own personal truths about menstruation, often in the name of effective contraception.

\section{e) Consuming Freedom at a Cost?}

While Depo-Provera attempts to symbolize their product as a pathway to freedom, a closer look reveals that regulation is a significant part of getting to this goal. A basic way in which regulation occurs is that the usage of Depo-Provera instantly means that a certain degree of self-regulation has occurred - one has consumed something that will require going to a doctor for injections. This will also require that one be relatively attentive to changes in their body and be able to convey these when necessary at doctor's appointments. Under the assumption that an individual has taken this drug willingly, it is safe to state that self-regulation and bodily management is happening. But this basic selfregulation that comes along with the usage of Depo-Provera is only part of the story. The idea of regulation manifests itself in other ways on the website. Encouraging women to self-regulate their bodies in socially desirable ways is done under the promise that this behaviour will lead to freedom. If this is the form that self-regulation takes in order to attain freedom, then this raises the question of how free people really are if this is how they plan to achieve it. To reiterate my main research question - to what degree is taking Depo-Provera with the intention of stopping menstruation a form of regulation - that women believe that there is something wrong with their bodies that must be stopped, or, to what degree does it actually provide them with a sense of freedom? It is vital to note though, that for some people, self-regulation might not be a 'cost' - it can be a positive experience, or, costs could be worthwhile for some women, particularly when leading to 
a desired outcome. These are not simple points to address. They are illuminated by the theoretical discussion that shortly follows, as well as by the women's insights from the interviews. It is most advantageous at this point to first present self-regulation in terms of a cost to one's freedom and to reflect on this and scrutinize this in subsequent chapters.

One of the ways that self-regulation is encouraged on the Depo-Provera website is by attempting to get women to feel responsible for maintaining 'good health.' They are pushed to learn as much as they can - "To have the best experience on Depo-Provera, utilize all the resources available to you" (meaning the website, the phone-line, and doctors). The company only takes responsibility for the efficacy of the product (if the injections are taken on time). They attempt to take the burden off of women for the actual use/injections of the product (through an appointment reminder system). Although the four injections a year are framed as something that is convenient, many women might understand this as a disadvantage to have to go to the doctors to administer one's birth control. Interestingly, one of the Depo-Provera users in my study administers the drug herself. I suspect this is not a common responsibility that patients have though.

Depo-Provera recommends that women be responsible for their well-being while using their product. For instance, to displace the blame off of Depo-Provera for the very common side effect of weight gain, women are urged to eat well and exercise to reduce this side effect. When addressing concerns about weight gain, Dr. Adrias (the doctor on the Depo-Provera website) says,

You should know that weight changes sometimes go hand in hand with hormonal birth control. It's different for everyone, though. And leading a healthy lifestyle can really help. Exercising and eating well are things you should be doing anyway. So, if you're already active and have a healthy diet, then by all means keep it up. If your lifestyle could be healthier, being on Depo-Provera is a great time to change some of your habits. Try different forms of exercise and see what 
you like best. Yoga, jogging, and swimming are some examples. Or visit www.PfizerForWomen.com Health Center for articles and suggestions for healthy living. (www.depoprovera.com)

An attentiveness to maintaining 'good health' fits well with how Depo-Provera's 'modern woman' ought to behave. To reiterate, they present the modern woman as strong, beautiful, intelligent, and in control - the possible weight gain brought about by this product threatens this image, thus women ought to 'step up' their attention to their body management. In their effort to responsibilize patients for their own 'good health,' Depo-Provera outright removes the blame off of themselves and places the problem of a common side effect on the user.

Regarding menstrual suppression, it is possible to frame Depo-Provera as regulatory because of its reliance on negative social and cultural norms about menstruation. ${ }^{21}$ As discussed earlier, the website depicts menstruation as an inconvenience - bleeding need only be tolerated (the side effects of irregular bleeding and spotting) if leading to its eventual lessening or eradication. Depo-Provera promises women that dedication to the product can eventually lead to freedom from menstruation. After using the product for nine to twelve months, one can expect that - "For you, as for many women, your periods have stopped completely by now - or they may stop within the next few months." In our society, menstruation is treated as inconvenient (when trying to be active, when at work, with sexual intimacy), uncontrollable (messy, smelly, the threat of leaks and spotting), and something that women ought to hide, so as to not be offensive to men and other women. By offering to stop menstruation, one could argue

\footnotetext{
${ }^{21}$ While I think that the 'regulation vs. freedom' question would be interesting to analyze regarding the contraceptive aspect of Depo-Provera, that is a whole other topic that cannot be dealt with here. Studying any drug that can stop menstruation instantaneously means that this drug is also a form of birth control. While I do not mean to ignore the birth control aspect completely, the focus here needs to remain on the topic of menstrual suppression.
} 
that Depo-Provera is simply extending a dominant discourse that menstruation is problematic and in need of strict bodily management by women. Furthermore, one could propose that regardless of the drug manufacturer's intentions - the end result of using this product contributes to encouraging women to self-regulate their bodies in socially appropriate ways. Thus, if one feels free by using this product - has it come at a cost? What has this cost been? It is conceivable to argue that by using this product, and doing so knowing and accepting that it can stop menstruation, one is (intentionally or not) validating the social and cultural values which dictate that there is something wrong with women's bleeding bodies which requires management and regulation.

In the time that I have been doing my research a new injectable contraceptive has developed. When attempting to access the Depo-Provera website, the existence of this new product - depo-subQ provera 104 (herein after subQ) becomes glaringly obvious. A large advertisement with a link to the official subQ website pops up (blocking much of the content of the Depo-Provera site). Like Depo-Provera, it is a highly effective injectable contraceptive with which menstruation could also become light or stopped. It is different in that the dosage of hormones is lower and a smaller needle is used to administer the drug (www.depo-subqprovera104.com). Now, not only do women have the freedom to choose or not choose a product, they actually have choices of products when it comes to injectable contraception.

Although I do not intend to analyze the subQ website, a few points about its content are noteworthy. Similar to Depo-Provera, subQ emphasizes the idea of choice, it minimizes side effects overall, it addresses the advantage of menstrual suppression, and it 
pushes for self-regulation of 'good health. ${ }^{22}$ It also utilizes the 'modern woman' but alters it in one major way - rather than focusing just on work, the subQ modern woman highly values her leisure time. The slogan for subQ is not about freedom. It is about lifestyle and leisure. Thus with Depo-Provera, the idea of freedom is explicit and the 'payoff' of an enhanced lifestyle is implicit, whereas with subQ, lifestyle is explicit and freedom becomes the implicit assumption of an enriched lifestyle. Why did the marketing of such a similar drug shift like this? I am not sure why this happened - was it something as simple as presenting leisure and lifestyle because they are enjoyable and thus make the drug enticing? Regardless of why it happened, the loss of the explicit promise of freedom is interesting. Still, the assured benefit of the lifestyle that subQ promotes is, as with Depo-Provera's 'freedom,' something that is attained through self-regulation.

\section{THEORIZING FREEDOM}

Freedom is a complex concept. Zygmunt Bauman observes that the idea of freedom is quite often taken for granted. We use the term frequently, but typically scrutinize it only when we feel we have been denied it (1988:1). Rather than seeing freedom as a given afforded to everyone, Bauman draws attention to how the concept is socially constructed. An analysis of freedom, when viewed as a social construction necessitates considering historical and other contexts (30). Power is also a part of comprehending freedom. Bauman argues that our current social conditions are saturated by consumerism and thus our understanding of what freedom is, is shaped by a consumerist logic (10), or, as

\footnotetext{
${ }^{22}$ I mentioned earlier how Depo-Provera asks women to be responsible and counter the side effect of weight gain. Interestingly subQ does this as well, but also asks women to counter the side effect of bone mineral density loss - "You should be exercising, including weight bearing to keep your bones strong. Talk to your health-care provider about a diet and exercise plan that may be right for you." It is also promoted to "Keep on pursuing your active and busy lifestyle. Including weight-bearing exercise and calcium supplements which can help keep your bones healthy" (www.depo-subqprovera104.com).
} 
Conrad Lodziak describes it - "the ideology of consumerism" (2000:112). To illustrate this Bauman describes that,

The capitalist economy is not only the territory where freedom may be practiced in the least constrained fashion, uninterfered with by any other social pressures or considerations; it is also the nursery where the modern idea of freedom was sown and cultivated, to be later grafted on other branches of increasingly ramified social life. (45)

He maintains that our ideas about freedom are skewed by the influence of capitalism and the legal system - which employ the premise that when a person is motivated by a particular outcome - they are free to act, but are then responsible for the outcome (2-3). He depicts consumer society as promoting the mentality that freedom is no longer relational (one can be free only if someone else is not free) - that with consumption, everyone can gain and attain freedom (63). I, like Bauman, find this 'logic' suspect. Bauman acknowledges that not everyone has the means to participate fully in consumption (67). To this I would add that not everyone wants to participate and 'gain' via consumption.

As has been illustrated, Depo-Provera promotes the idea of freedom of choice to its potential consumers. It attempts to produce, through its construction of knowledge and 'truths' about menstruation, a desire to choose to be free via menstrual suppression. James Miller asserts that in our society, there is what he describes as a modern liberal idea - that more choices will make our lives better (1999:1121-1122). Nikolas Rose further elucidates this idea that,

modern individuals are not merely 'free to choose', but obliged to be free to understand and enact their lives in terms of choice. They must interpret their past and dream their future as outcomes of choices made or choices still to make. Their choices are, in their turn, seen as realizations of the attributes of the choosing person - expressions of personality - and reflect back upon the person who has made them. (1999:87) 
Bauman suggests that the freedom to choose what one buys is a privilege (1988:70). Freedom of choice, in the context of birth control, is something that many women demand or desire to be a right. However, it is not recognized as such. Thus it is a privilege and unfortunately, not all women have the resources to exercise this privilege.

Bauman recognizes freedom and consumption as having external restrictions, such as money or resources. He also argues that we often internalize restrictions such as social and cultural values when considering what to consume (5-6). When trying to understand freedom and freedom of choice, I contend that it is important to recognize the possibility that people might feel both free and unfree simultaneously. Bauman, while quite focused on describing arguments about freedom through consumption, also acknowledges regulation with consumerism.

A basic explanation of freedom that he offers is that we are free to act or not act and that we are responsible for our actions (28). This responsibility however, he describes as a potential source of anxiety. He argues that a significant aspect of consumption is that we create and convey identities through it - but this can often be a difficult pursuit, as we might get anxious about our choices and thus might want to regulate ourselves to behave in 'appropriate,' normative ways (39-41). Thus one might experience regulation in their pursuit of freedom.

Bauman shows that much advertising aims to alleviate the perceived anxiety derived from our freedom of choice (and thus responsibility) (Warde 1994a:63; Warde 1994b:877). Depo-Provera does this by trying to convince consumers that their product is effective, has many advantages over other types of hormonal contraceptives, and that it is the best product available. Joy Fuqua argues that with prescription drug advertising in 
which the manufacturers present themselves as consumer advocates - the assumption is made that patients need to be told what is good for them. They are simultaneously constructed as passive and in need of advice and as active regarding their choices and decision-making (2002:663).

Alan Warde is apprehensive about Bauman's conception of consumption as anxiety provoking (1994b). For many people, consumption can be a positive, worry-free experience. If one does experience anxiety it could be for financial reasons, not because of fears of making incorrect decisions (890-891). Warde maintains that,

Bauman's initial hypothesis, that consumption is characterised by anxiety has, I think been found almost totally wanting. In fact, consumption is a disciplined practice for those who might have grounds to feel anxious; and the rest would not be troubled. One implication of this is that a distinction should be drawn between choice and selection. I believe that Bauman is deceived because most purchasers do not perceive that they have a responsibility in his strong sense; and that is because they do not have a real and meaningful choice. (895-896)

Can one be free through consumption when they do not like the choices available to them? Lodziak insists that "consumer choices cannot be equated with individual freedom" (2000:116) - motives and reasoning for the multitude of ways in which we consume are too complex to be boiled down to a simple premise - that the market can provide us with a space to experience freedom just by consuming and mediating our anxiety (115-116).

Another part of Bauman's work that has received criticism is his representation of the majority as consuming for identity-building. Bauman argues that because we are no longer 'defined' by lineage or caste, we are left to build our identities on our own (Warde 1994b:881). Warde explains that Bauman cites the market as a space that purposely tries to provide us with identities and lifestyles (1994a:67-68). The Depo-Provera website attempts this through its utilization of the 'modern woman.' Bauman preoccupies himself 
with theorizing identity-formation and consequently, Warde accuses him of having too narrow of a conception of the consumer. Consumers could have multiple motives with regards to their purchases (1994a:64-65). Use-value is often overlooked by these theorists due to an overconcern with identity-value (Lodziak 2000:120). This is an important point to consider when applying these ideas to the context of the consumption of prescription drugs. While some drugs might be consumed for lifestyle or identity purposes, many are consumed for use-value. Both Lodziak and Terri-Anna Wilska attest that while some people might consume to create and reinforce an identity, we are generally not as aware of our identities as some theorists think $(2000 ; 2002)$.

Lodziak is critical of Bauman's assertion that consumption is such a primary aspect of our lives that freedom ought to be defined primarily in light of it. Lodziak argues that Bauman's work emulates and reinforces 'the ideology of consumerism' (2000:112). While I agree with Lodziak that too much focus has been put on consumerism and its relationship with freedom, perhaps he has misunderstood Bauman's overall goal to show a depiction of consumer logic in our society rather than advocate the beliefs of such logic. Bauman's work is disappointingly unclear at times concerning whether he is describing the opinions of others, whether he is describing how consumption and freedom 'ought' to work according to capitalist or consumerist logic, or whether he is voicing his own opinions. Some shortcomings of Bauman's work are that in his depiction he certainly does overemphasize the role that consumerism plays in our lives and he does get caught up in illustrating a somewhat narrow description of consumers as choice-hungry, anxiety-ridden, and identity-obsessed characters (Lodziak 2000:122; Warde 1994b:895-896). However, he does maintain that while we are offered 
freedom and choices from the market, we have to make these choices in a regulated environment (in that we cannot escape the influence of social and cultural norms although we might resist them, they are still a regulatory presence). The regulatory aspects of his argument (particularly in the latter half of his book Freedom) are at times lost amidst his colourful portrayal of consumerism, but they are nonetheless a crucial part of his work to consider. He is careful to note that no one can have absolute freedom (1988:47-48). Furthermore he questions whether we actually have more freedom now because of consumption, or if it has caused us to be more regulated (54).

Is the manufacturer of Depo-Provera intentionally trying to regulate women? Help women? Are they simply trying to make money? While economic motivations are the most obvious, motivations are potentially complex and can only be assessed indirectly. Motivations aside, it is nevertheless clear that they are using dominant discourses about what is socially appropriate regarding gender and menstruation to validate and make appealing a promise of freedom, in the hopes that women will feel compelled to use their product. The use of 'freedom' to entice women to use the product and engage in management of their bodies is interesting and deserves the analysis that it is being given, but it is by no means a unique tactic for trying to secure conformity.

The work of Nikolas Rose is useful for exploring this last point. His work is also helpful for pushing our theorizing about freedom beyond just consumption. In his work, he considers governmentality, particularly how people are governed through the idea of freedom. He is influenced by Foucault's work on governmentality. McLaren describes Foucault's ideas as follows,

Power is a relationship that can direct or determine behavior, Foucault calls these relations of power and the techniques that allow them to be exercised 
'governmentality.' Governmentality can apply to a society, a group, a community, a family, a person ... It aims to manage populations from within, unlike state power, which imposes control from above. Governmentality targets the interests, needs, aspirations, and consciousness of individuals, as well as of the population as a whole. (2002:167)

Thus, the concepts of 'governance' and 'governmentality' developed largely from trying to understand power and politics in a way that was less state-centered. Rose affirms that "At its most general, the term 'governance' is used as a kind of catch-all to refer to any strategy, tactic, process, procedure or programme for controlling, regulating, shaping, mastering or exercising authority over others in a nation, organization, or locality" (1999:15). Consistent with Foucault, Rose argues that governing can take the form of the encouragement of self-regulation. Hence their ideas about governing can be applied to innumerable activities in our society - and work well here with the topic of medicine and consumerism.

Rose contends that freedom is a large part of how we understand our government and our everyday lives. We wish to be 'free' and thus are often willing to accept and engage the activities that promise to lead to freedom. Like Bauman, Rose interprets freedom as something that is socially constructed and requires contextualized analyses. He suggests that freedom can be understood

as a set of practices, devices, relations of self to self and self to others, of freedom as always practical, technical. Contested, involving relations of subordination and privilege, opens freedom itself to historical analysis and historical criticism. (1999:94)

Accordingly, recognizing power is an integral aspect of fathoming freedom.

The control that exists with today's government, Rose argues, is largely exerted in a way that emphasizes freedom. Coercion and exploitation are framed and justified in a way that puts the (mis)apprehension of freedom at the forefront - "To govern humans is 
not to crush their capacity to act, but to acknowledge it and to utilize it for one's own objectives" (1999:4). We are told that regulating ourselves in normative ways is positive and 'good' for us, as well as for society in general. It is through the idea of freedom that people are encouraged to regulate themselves according to social norms. Rose defends that,

To be free, in this modern sense, is to be attached to a polity where certain civilized modes of conducting one's existence are identified as normal, and simultaneously to be bound to those 'engineers of the human soul' who will define the norm and tutor individuals as to the ways of living that will accomplish normality. (76)

Rose acknowledges though that freedom does not always exist like this. For example, there are struggles and resistances - he is aware of the "messy realities of power relations" (274). Nonetheless, his work helps to illustrate that both regulation and freedom can coexist with practices of governance in countless spaces of our lives.

A look at Foucault's later work helps to further discuss some conceptual aspects of freedom and governance. There are several shifts throughout Foucault's work. Rose describes these as changing from sovereignty, to discipline, to governmentality (1999:23). Another way of characterizing these changes is, as McLaren demonstrates, from archaelogical to genealogical to ethical, or from a focus on knowledge to power to the subject (2002:3-5). Although many people interpret these changes as breaks in his work, both Rose and McLaren perceive all parts of his work as connected with and informing one another $(1999: 23 ; 2002: 3-5)$. For instance, McLaren explains that his later work on ethics builds on his previous work and challenges his own, as well as general, ideas about the subject (4-5). Jana Sawicki suggests that,

Foucault's turn to Ancient Greek ethics can be understood as his effort to establish a normative basis for practices of self-formation and invention (that is, 'practices of liberty') which avoid the universalism of the Kantian 'science of 
morals' and its inquiry into the necessary structures of morality, and which, in so far as they operate at the practical and not the theoretical level, might provide us with a practice aimed at the concrete realization of our ideals. (1998:103)

His concern with the subject in his final work is informed by his belief in the connectedness of ethics and aesthetics (McLaren 2002:70).

Foucault also emphasizes that a meticulous analysis of 'freedom' necessitates being aware of its connection to knowledge and power (Foucault 1978). McLaren articulates Foucault's thesis that "Power does not exclude freedom, but implies it. Nor does domination exclude freedom, although freedom is more limited under states of domination" (2002:40). He understands freedom as something that is practiced, rather than being a universal given (Sawicki 1998:102; Ivison 1997:44). ${ }^{23}$

The ethical element of freedom was crucial to Foucault in his later work. To develop this ethical aspect of freedom, one needed to work on oneself. This 'care of the self' or 'cultivation of the self' was "an exercise of the self on self" - ensuring that one is behaving and taking care of oneself properly (Foucault 1984:282). Foucault contends that with the Greeks, "concern with the self and care of the self were required for right conduct and the proper practice of freedom, in order to know oneself" (1984:285). He further argues that it is a lifelong project of taking care of oneself, ensuring that others are doing well, and accepting help from others (1984:286; 1986:52-53). The care of the self is linked to medicine and thus to the body. Therefore, it is not just a project of taking care of the mind - a well-kept body is maintained by a person with a good care of the self (Foucault 1986:54-56). Foucault acknowledges that this depiction of how to take care of

\footnotetext{
${ }^{23}$ Foucault argues that liberation and freedom are not interchangeable. He explains - "Liberation paves the way for new power relationships, which must be controlled by practices of freedom" (1984:283-284). Thus, while they are different, he understands liberation as a practice as well - not a given (Foucault 1982:354-355; 1984:283-284).
} 
oneself is limited - not everyone is able to work on themselves the same - thus not everyone has the same access in the pursuit of experiencing freedom (1986:45).

Must ethics be a part of understanding freedom? According to Foucault, "Freedom is the ontological condition of ethics" (1984:284). He is quite aware that selfregulation is occurring with the care of the self (Foucault 1986:54-56). Jean Grimshaw explains that Foucault sees self-discipline associated with ethics and the care of the self as positive because it helps to develop oneself (1993). Interestingly (in comparison to his earlier work anyway), Foucault understands self-discipline as power, rather than regulation (Grimshaw 1993:64-65). Perhaps he does not convey this self-regulation in a harmful fashion because of how he understands ethics. Duncan Ivison explains that we typically think of ethics as something broad - it "usually denotes a set of standards" (1997:48). The way that Foucault understands ethics however, is more at the level of the individual - how one regulates their own behaviour based on how they will perceive and create their self (1997:48). Ivison questions if Foucault is wrongly disconnecting personal ethics from broader social influences, given that we cannot extract ourselves completely from the social. He emphasizes though that for Foucault, the care of the self is not about following a broad moral code, rather it is about individuals shaping themselves (48-49). Ivison explains that "this kind of ethics Foucault discovers ... does not seem to involve any attempt to 'normalize' the population, to prescribe a pattern of behaviour for everybody, since its principal aim is an intensely personal and aesthetic one" (1997:50). Foucault affords the ethical subject a great deal of agency.

There is disagreement amongst feminist scholars of the value of Foucault's work on ethics and freedom. In Foucault's defence, McLaren attests: 
Concern for the body and the relationship of self-mastery were crucial to the formation of oneself as an ethical subject. Foucault's later work offers a way to think about bodily practices not as normalizing disciplines, but as practices of self that are necessary for ethical subjectivity. Practices of the self can lead to selftransformation and to new nonnormalizing ways of being and relating. So, practices of the self provide another avenue for resistance, along with competing claims of power and discourses. (2002:99)

She, like Foucault, interprets self-mastery in a positive way. Also, since she examines the care of the self primarily in the context of resistance, she defines self-mastery as nonnormalizing. With the example of feminist consciousness-raising she says,

Consciousness-raising exemplifies the type of self-transformation that Foucault refers to in his discussion of practices of the self. One engages in praetices of the self to produce self-transformation within a social context. Practices of the self draw upon the rules, methods, and customs of one's culture, but are also practices of freedom, that is, they create new nonnormalizing modes of existence and relationships. (McLaren 2002:159:emphasis added)

She is depicting this care of the self as a means of resistance. Is it not possible though, that the care of the self could involve both normalizing and non-normalizing behaviour? Grimshaw insists that Foucault's emphasis on the positive aspect of the care of the self causes him to overlook the possibility that self-regulation can be oppressive. She suggests that,

In much of his earlier writing, he noted the ways in which disciplinary practices and techniques operated by means of internalized self-surveillance, such that external sanctions or forms of control were no longer necessary to bring the subject into line. Suddenly, in his last writings, these practices of self-discipline and self-monitoring are no longer seen as disciplinary practices which undermine all notions of the autonomy of the self; they are seen, rather, as constituting autonomy. (1993:66)

She is frustrated with what she believes is a lack of consistency in his work. She asks, "When should we see a concern for one's body, a programme of monitoring of one's fitness or concern for one's appearance, as an exercise of creative self-mastery rather than as the result of the internalisation of norms of bodily appearance which serve to 
undermine other forms of autonomy?" (Grimshaw 1993:67). She is concerned that because we tend to internalize social norms, the ethics and care of the self cannot be an exclusively individual act.

Furthermore, Grimshaw is uneasy about how androcentric his work is. She argues that when theorizing self-regulation - one should be more attentive to gender. The subject that Foucault uses in his work on ethics is an affluent male subject. Grimshaw expresses that

Foucault's late work on ethics is disappointing, and somewhat depressingly unaware of anything that feminists have written about ethics or morality. It seems trapped in a highly masculinist view of ethics as the concern of a male elite to stylise their own lives. It sees this stylised of life as the only alternative to a morality based on adherence to a rigid or universal code. (1993:70)

Indeed he did only consider the affluent male subject but the context which he was researching only recognized this as a subject. Foucault was not attempting to create a broad theory of ethics that could be applied to everyone. His exploration of ethics was of a very specific context - examining ethics in Ancient Greece, and thus specific conclusions were made. Foucault would not want, nor do I, to have his ideas 'fit' and apply perfectly to other concerns. The debates that arise from his later work instigate one to consider self-regulation and normative behaviour and how they come to be perceived as positive, negative, or both.

From all of the theorists discussed in this chapter, there are aspects of their work that are relevant to draw on to better understand Depo-Provera's proposition of freedom. Bauman's ideas about gaining freedom via consumption are useful for understanding Depo-Provera's marketing, as they utilize this 'logic.' The criticisms against the consumerist logic are useful for illustrating that consumer choice does not necessarily provide consumer freedom. This is evident with the women's responses - several of them 
rejected the idea of freedom of choice as a 'good thing.' Furthermore, both Bauman and Rose's work helps to illustrate the possibility that when freedom is promised (through consumption or governance) significant amounts of regulation are potentially attached to this promotion. This illuminates one of my main research questions concerning if the usage of Depo-Provera could mean that one simultaneously feels regulated and free. Foucault's care of the self instigates me to raise questions about whether or not selfregulation is a 'good' or 'bad' thing. As well, when trying to understand his ideas on the care of the self, I question if freedom should be conceptualized as an individual project, a collective project, or both. All of the theorists draw attention to how freedom is a social construction imbued with power. This encourages one to be critical of how Depo-Provera creates and presents truths about their product. The ideas of these theorists continue to be explored in Chapter Six, when discussing my findings.

It is important to now turn to these findings to begin to reflect on how DepoProvera's truths about menstruation and freedom are received. It is important to not only theorize the concepts of regulation and freedom, but one's approach to research in general must be theorized. Thus first, I engage a short discussion about methodology. Examining how my research developed and was carried out is a relevant aspect of my overall exploration about women's perceptions about menstrual suppression and freedom. 


\section{CHAPTER FOUR: \\ ETHNOGRAPHIC RESEARCH WITH WOMEN: THEORETICAL FRAMEWORKS AND METHODOLOGY}

To explore women's attitudes toward stopping menstruation, a qualitative approach is most suitable. Qualitative researchers are able to examine processes and meanings with their data - my goal is not to look for the truth but to seek out truths and how these come to be formed and articulated (Denzin \& Lincoln 1998:8). A qualitative approach allows me to compile detailed, rich data on complex concepts like freedom, regulation, and choice. A quantitative posture would not allow for this. The term 'qualitative research' is not transparent, thus before presenting my research findings, it is imperative to first examine how the data were gathered and analyzed.

It is not a simple task to define what qualitative research is - its meaning, methods, and history are quite varied. Norman Denzin and Yvonna Lincoln explain that there have been many shifts in qualitative research and how it is used and theorized. They describe a number of phases that it has gone through over the past several decades. It is only of relevance here to articulate that our current understanding of qualitative research is postmodern or "present moments" as they label it (1998:2). With this current approach, researchers take a critical stance toward previous conceptions of what qualitative research ought to be. They describe a qualitative researcher as a bricoleur and the research as bricolage. One could be a bricoleur in the sense that they use multiple methods. I conducted interviews as the main research component in my study. In addition to this, I did a qualitative content analysis of the Depo-Provera and depo-subQ provera 104 websites. The practical and theoretical aspects of the latter are not focused on here 
though, as it is more of a supplementary (yet still very important) piece of my research (see Appendix Two concerning my content analysis).

In the following sections, I explore theoretical concerns about my main research component. I concur with Raymond Morrow who emphasizes that it is necessary to go beyond just examining the practical element of one's research, since the theoretical influences the practical (1994). To return to Denzin and Lincoln's bricoleur, they explain that he or she is reflexive and tries to be as aware of their context as possible. This entails being aware that one's interpretations are created in paradigms - one's ontology, epistemology, and methodology need to be scrutinized. I take a critical theory approach with these. Connected to this is my method of the interview, as well as my methodology of discourse analysis for interpreting the data. I show how critical theory and more specifically, discourse analysis coalesce with aspects of both Foucaultian and feminist theory. Furthermore, I discuss how I treat women's experiences in my analysis. This includes addressing the idea of 'false consciousness' and how experience is validated or interpreted. In the final section of this chapter, I discuss the characteristics and basic findings of my sample.

\section{REFLEXIVITY}

Not only do researchers need to expose their theoretical perspectives, there are also often features of one's personal experiences that might influence how they approach their study. Andrea Doucet and Natasha Mauthner describe -

Our understanding of how our data analysis processes, and projects as a whole, were influenced by such epistemological, ontological, and theoretical assumptions as well as other personal, interpersonal, emotional, institutional and pragmatic influences has deepened over recent years. (2003:415) 
I feel it is relevant to divulge some personal aspects of my life which influence how I approach the topic of menstruation. For instance, I have a very unproblematic menstrual cycle. Before using the pill, it gave me very little grief, and now, my hormonally manipulated cycle gives me even less troubles. I undertook this study because I wanted to know why someone with a non-problematic cycle might want to stop it. I am not embarrassed or 'grossed out' by menstruating. I deeply resent the social norms that exist about women's bleeding bodies, yet I also ensure that I manage my bleeding with feminine hygiene products each month. Thus while I find myself falling prey to worrying about whether or not my menstrual management is going for the most part, flawlessly, I simultaneously act out instances of resistance (for example, by challenging normative depictions about menstruation and pushing myself and others to ask how and why these exist). I enjoy menstruating, yet am aware that I, like many of the women in my study, am quite conflicted about it. Without a doubt, my awareness that I am conflicted about the meaning of menstruation in general has developed by examining other's attitudes about menstruation. Before I started doing this research, I thought I personally knew what menstruation meant to me - I thought it was socially complex, but that personally my experiences were relatively simple. Now, I think that I am wrong.

Whether they are aware of them or not, researchers have ideological assumptions (Kincheloe \& McLaren 1998). Morrow further elucidates that not only is one's choice of methodology tied up with ideology, it is also connected to society and politics (1994:200201). Reflexivity is a central part of both critical theory and discourse analysis (Denzin \& Lincoln 1998:19; Potter 1997:202). I now turn to exploring in detail my interpretive 
framework - to do as Mats Alvesson and Kaj Sköldberg suggest - “[think] about thinking" (1999:5).

\section{INTERPRETIVE FRAMEWORK}

Egon Guba and Yvonna Lincoln attest that it is important to discover and analyze how your own beliefs are part of the research process. They say - "Questions of method are secondary to questions of paradigm, which we define as the basic belief system or worldview that guides the investigator, not only in choices of method but in ontologically and epistemologically fundamental ways" (1998:195). I utilize a critical theory paradigm to illustrate how I approach my research. It is important to emphasize that I do not have an entirely strict adherence to this paradigm, as is also the case with other theories that I utilize in my work. Denzin and Lincoln comment that "the researcher-as-bricoleurtheorist works between and within competing and overlapping perspectives and paradigms" (1998:4).

Like 'qualitative research' - 'critical theory' is also difficult to define. For instance the word critical could apply to a lot of theories, but not ones that necessarily fit under 'critical theory' (Morrow 1994:7). Many feminist approaches can be considered critical theory (Denzin \& Lincoln 1998:27). ${ }^{24}$ In addition, Foucault's work fits quite well with critical theory (Kincheloe \& McLaren 1998:262-263). Loosely defined, critical theory can generally be understood as follows:

We are defining a criticalist researcher or theorist who attempts to use her or his work as a form of social or cultural criticism and who accepts certain basic assumptions: that all thought is fundamentally mediated by power relations that

\footnotetext{
${ }^{24}$ Some feminist theorists would not want to be categorized as critical theory though. For instance, Kitzinger is concerned about feminist theory being put under this label because of her concerns about what experience is and how it ought to be examined. Her perspective of validating women's experiences as 'real' does not fit well with critical theory (2004).
} 
are social and historically constituted; that facts can never be isolated from the domain of values or removed from some form of ideological inscription; that the relationship between concept and object and between signifier and signified is often mediated by the social relations of capitalist production and consumption; that language is central to the formation of subjectivity (conscious and unconscious awareness); that certain groups in any society are privileged over others and, although the reasons for this privileging may vary widely, the oppression that characterizes contemporary societies is most forcefully reproduced when the subordinates accept their social status as natural, necessary, or inevitable; that oppression has many faces and that focusing on only one at the expense of others (e.g., class oppression versus racism) often elides the interconnections among them; and, finally, that mainstream research practices are generally, although most often unwittingly, implicated in the reproduction of systems of class, race, and gender oppression. (Kincheloe \& McLaren 1998: 263:emphasis added)

Kincheloe and McLaren value critical theory as it enables them to create "dangerous knowledge" - which they understand as a positive thing (260). There is an emphasis, with critical theory, that researchers attempt to be transformative with their work, that they promote advocacy or political change (264). Given critical theory's stance on reality, this idea of emancipatory research emerged - one could create or encourage people to create new, less oppressive 'realities' (262). Clive Seale cautions that research be "informed" by transformative and political qualities, rather than completely "over-determined" by them (2004:210). This is the case with my research.

Ontology, epistemology, and methodology are all connected - answering one depends on how another is articulated. Understanding one's ontology is the most logical place to begin. To develop this - the researcher must ask questions about what they think reality is (Denzin \& Lincoln 1998:26). I believe that reality is socially constructed. I think that the construction of our realities are influenced by beliefs about gender, race, class, sexual orientation, social structures, and more generally, by power relations in our society. Furthermore, I do not think that there is $a$ truth or reality in our society but that 
multiple truths and realities exist. I perceive reality to be an interpretation that can be plural, changing, and even contradictory.

My beliefs about reality are consistent with critical theory, although it is also evident that I am influenced by a constructivist paradigm. Guba and Lincoln describe that the ontology for critical theory is historical realism. They explain this stance on reality:

A reality is assumed to be apprehendable that was once plastic, but that was, over time, shaped by a congeries of social, political, cultural, economic, ethnic, and gender factors, and then crystallized (reified) into a series of structures that are now (inappropriately) taken as 'real,' that is, natural and immutable. For all practical purposes the structures are 'real,' a virtual or historical reality. (1998:205)

Critical theorists tend to believe that what influences our construction of reality changes over time. Sometimes, knowledge can transform by "erod[ing] ignorance and misapprehension" (212). They note that the paradigms are not fixed and that their meanings are still being negotiated (1998:203-204).

To understand one's epistemological approach with research, one must ask based on my beliefs about reality - what can be known (Guba \& Lincoln 1998:201; Denzin \& Lincoln 1998:26)? With my research - when I speak of 'truths' - I understand these as accounts or interpretations. I believe that it is useful and vital to look for meaning in the data - but one must be cautious of how it is socially contingent. The participant's accounts are influenced (positively, negatively, or both, or conforming, resisting, or both) by social values, their own values, and possibly by their perceptions of what my values are. With critical theory, it is important to recognize that one's findings will be "value mediated" (Guba \& Lincoln 1998:206).

Lastly, to determine how one understands methodology, it is crucial to ask questions about how we think that we can learn and know about the world (Denzin \& 
Lincoln 1998:26). Since I consider 'reality' and 'truth' to be constructed interpretations, I examined how people create their truths. I used discourse analysis to interpret my data. While there is no rigid definition of what discourse analysis is, or how it ought to be conducted, there are several general qualities that describe it. For instance, there is a focus not only on what people say, but also on how they say it. Jonathan Potter describes that with discourse analysis there is "a dual focus on the practices themselves and on the resources that are drawn on in those practices" (1997:205). Researchers need to consider how people organize and justify what they say - what discourses do they utilize to understand the world and their own experiences (Potter 2004:609-610)? This approach fits well with Foucault's work. Both focus largely on how things happen rather than getting stuck on trying to only figure out why (Kendall \& Wickham 2004:144). When reflecting on Foucault's work, Potter says,

Another very different tradition of discourse analysis comes out of poststructuralism and particularly the work of Michel Foucault. His work rarely considered discourse in terms of specific interaction. Rather its focus was on how discourse, or a 'set of statements', comes to constitute objects and subjects. (2004:608)

While I value focusing on and asking 'how,' with my own research, I coincide with Clarissa White et al., who contend that it is important to also achieve a balance between being descriptive, explanatory, and interpretative (2003:289).

\section{III. 'EXPERIENCE' AND 'FALSE CONSCIOUSNESS' - SOME RESEARCH DILEMMAS?}

As was mentioned earlier, for some, feminist theory falls under the label of critical theory and also goes well with discourse analysis. For some feminists though, critical theory is a perilous approach because of its conceptualization of experience. Celia Kitzinger explains that some feminist researchers believe that their role is to act as a conduit for 
women's experience. They adhere to the idea that women are their own experts, based on the premise that women's experiences, as they personally depict them, have to be validated because women are so often silenced or invalidated because of their social status. She describes that many feminists are hesitant to accept critical theory because experience is depicted as something that is entirely a social construct - which to some, means that women's experience is void of agency - "we merely animate socially constructed discourses" (2004:128). First of all, in regard to these concerns, I do not think (and neither does Kitzinger) that it is possible for a researcher to be an objective conduit for experience. Also, the last concern about lacking agency is, I believe, based on a misunderstanding. Viewing experience as socially constructed does not mean that women lack agency. Indeed women can knowingly or not, conform, resist, or manipulate social norms and influences. I understand that for the women in my study, just as with myself, our interpretations of our experiences are quite real to us, but it is important to recognize how we come to understand and justify our experiences. When talking specifically about discourse analysis, Potter "considers the way participants make institutional activities and identities relevant to themselves, by invoking them, orienting to them or, sometimes, subverting and ignoring them" (2004:610).

Kitzinger raises questions about how feminist researchers should hear women's voices. Connected to this discussion about experience is the idea of 'false consciousness' - what do we do when we hear voices that seem anti-feminist to us? I think that it is important to remember that there are numerous interpretations of what feminism and empowerment are. While there might be some accounts that women offer that are quite different from my own understanding of the world, rather than discount it as 'false 
consciousness,' it is better to try to understand how women develop their interpretations. There are times though, when I do question how aware women are of their 'reality' - for instance whether they are aware of their contradictions or how much they bend their own truths about menstruation. I do not think that challenging women's truths (based on their own accounts of their actions and beliefs) should be equated with accusations of 'false consciousness.' It is relevant to divulge how one's interpretive framework influences one's analysis, as I have done here. Doing this can potentially clarify how I come to many of the findings and conclusions that I present shortly.

\section{METHODS}

The method that I chose for this study is the semi-structured interview. I had specific questions set up in advance (see Appendix Three). Russell Bernard refers to this as a guide (1988:204-205). Although my guide appears to be quite structured, in practice it was not used rigidly. ${ }^{25}$ While I do not think that it is necessary to justify my interview method, there are a couple of points about interviews in general, that need to be mentioned. Some problems with interviews are that there is a reliance on memory, respondents might selectively report, or might use deception (Mason 2002b:237). These do not concern me too greatly though, given that I understand their truths as constructed accounts. Of more concern to me is that $I$, and the readers, be aware of how the interview itself is a social process. The participants and the researcher are generally aware of the 'structure' of an interview and what the behavioural expectations are (Gubrium \& Holstein 2002:3). Not only might interviewees shape their answers based on what they think they ought to say, or what they think the researcher wants to hear, but they might

\footnotetext{
${ }^{25}$ Part of the reason why my guide is so structured is because of the requirements that I had to meet, which were set out by the ethics board.
} 
also convey their answers based on the assumed audience of the research (Briggs 2002:914; Rapley 2004:16). The interview is not an isolated event. It is a social process that is connected to a broader social level. Jaber Gubrium and James Holstein describe the pervasiveness of the interview in our society and comment that it "is part and parcel of our society and culture. It is not just a way of obtaining information about who and what we are; it is now an integral, constitutive feature of our everyday lives" (2002:11).

I interviewed fifteen women for my study. This sample is not intended to be representative; rather I aim to draw analytical and theoretical ideas from it. This type of sample is a 'theoretical sample' (Strauss \& Corbin 1998:214). It allows the researcher to generate theories when analyzing the data instead of beginning with an existing theory (Curtis et al. 2000:1002). A theoretical sample is created in a way that is most suitable for exploring one's research concerns (Strauss \& Corbin:201).

The women in my sample were recruited in two different ways. I first spoke to Introductory Sociology classes at a small university in Atlantic Canada, anticipating that several women would volunteer (see Appendix Four and Five). I asked the males to leave the classroom, I passed around a pamphlet about my research (see Appendix Six), and described to the women what my research was about and how they could be a part of it. Due to the small class sizes at the university though, this approach did not generate enough participants. I then turned to using snowball sampling for my recruitment. Women who were interested were able to forward emails with my recruitment pamphlet to other women they knew, and these women in turn forwarded this to other women, and so on and so forth. I am aware that a shortcoming of this type of recruitment is that my sample could potentially be somewhat homogenous - the women who are friends might 
have similar perspectives on menstruation and in general, similar outlooks on society and life. Again though, I am not trying to generalize with my sample - I am trying to explore different ways to approach a complex theoretical topic.

I recruited women between the ages of eighteen and twenty-five. The majority of these women grew up in Atlantic Canada. They were all quite well-educated - one woman was working on a college degree, nine women were working on an undergraduate university degree, four were working on a second university degree, and one woman finished an undergraduate degree and was working. Their areas of education were in the Arts, Sciences, Education, and Hotel and Restaurant Management.

Before delving into the detailed findings of my study, I offer a quick synopsis of the sample in terms of their contraceptive knowledge. All of the women had heard of Depo-Provera before the interview. The majority of women in my sample knew someone that was using or has used Depo-Provera. Few of them had extensive knowledge about it though. In fact, only those who were using it or had used it had substantial knowledge about it. Two women were currently using this drug and one had in the past but discontinued its use because of complications and hesitancy about menstrual suppression. The two Depo-Provera users felt that the use of condoms was also important if in a noncommitted relationship. As for the remainder of the women, six of the women were using the contraceptive pill and condoms; five women were using just the contraceptive pill (but four noted that they would use condoms in a non-committed relationship); one woman was using the contraceptive patch (and condoms if in a non-committed relationship); and one woman was not using anything. Overall, the majority of the 
women had average or above average knowledge about different types of contraception. ${ }^{26}$ I suspect that there were a lot of women with above average knowledge of contraception because they value and enjoy learning about the topic and were drawn to be a part of a study about contraception.

None of the women in the sample had any serious health problems with menstruation. I specifically requested that those who volunteer do not have any major problems, as I felt that they might be more inclined to want to stop menstruation. I wanted to know why someone with an unproblematic menstrual cycle might want to stop it. About half of the women had stopped menstruation before with hormonal contraceptives (either with the pill, Depo-Provera, or the patch). For two of these women, this happened accidentally. Also, two other women attempted to stop menstruation but were not successful. Both the findings about the women's general attitudes toward menstruation and their attitudes toward stopping menstruation need to be revealed. The findings with this data are quite complex though and thus we need to shift over now to more detailed explanations.

\footnotetext{
${ }^{26}$ Assessing their contraceptive knowledge included giving them a chance to talk about withdrawal, spermicides, the diaphragm and cervical cap, female condoms, male condoms, IUD (intrauterine device), the pill, Norplant, Depo-Provera, plus any other types that they brought up. 'Below average': very limited knowledge, inaccuracies with the descriptions that were given, uncertain about a large percentage of the methods on the contraceptive list. 'Average': has general knowledge of what the different types are, generally aware of how they work, fairly knowledgeable about common types, is able to express what she does and does not like about most of them. 'Above average': very detailed knowledge about most of the types on the list, can clearly state advantages and disadvantages of different methods, clearly understands which ones are most and least effective and why.
} 


\section{CHAPTER FIVE: \\ WOMEN'S PERCEPTIONS OF STOPPING MENSTRUATION: SOME FINDINGS}

In this chapter, I begin exploring my findings by first examining the women's general attitudes toward menstruation. This includes discussing how they personally felt about menstruation, as well as their thoughts on how menstruation is treated in our society. I then explore my findings concerning their attitudes toward actually stopping menstruation. Some significant conceptual implications arise concerning how malleable the women's truths were, and how they felt about Depo-Provera's enticement of freedom.

\section{GENERAL ATTITUDES TOWARD MENSTRUATION}

When trying to evaluate how women feel about stopping menstruation, it is vital to first assess their general attitudes toward menstruation (Rosenberg 2003). Johnston-Robledo et al. argue that those who hold the most negative attitudes toward menstruation are typically men, younger women, and women with menstrual problems (2003:61). Furthermore, they argue that those women who have a higher tendency to self-objectify and who internalize and accept a lot of the social norms about menstruation are going to be more willing to stop it (63). I do not feel that I am able to assess how the women in my study do or do not self-objectify. Generally though, when trying to link attitudes toward menstruation with attitudes toward stopping it - it seems quite logical that if you do not like something, you would be more inclined to favour its elimination. My findings are not so straightforward however.

Most of the women in my study accepted and embraced menstruation but also problematized it. Amongst the women, the most common way of accepting menstruation was by describing it as something natural. Yet all of the women also expressed 
displeasure toward it (it is a 'nuisance' or 'annoying') and highly valued having some control over it. Tamara's comment about how she currently feels about menstruation is quite typical of the sample:

yeah, it's still a nuisance, but I'm not bothered by it so much, like I know pretty much the exact day and time it's gonna come and the day and time it's gonna end and now - so it's just, more of a - I guess it is an inconvenience when it comes to it I'm not as bothered by it, I'm just used to it now. It's been 12 - yeah 12, 13 years now so it's kind of a part of me. There's times when I wish I didn't have it and such, but there's also times when I'm very excited when it has arrived! ((laughter)) at this age ((laughter)).

She values the sense of control that using the patch has given her. Like many of the other women, she expressed mixed feelings toward menstruation - she conveyed both positive and negative things about it. It is important to note that all of the women but one, were careful to not define their experiences as largely negative - they tended to minimize the negativity that they disclosed. They found aspects about menstruation that they could define as positive and could accept while simultaneously noting things about it that they did not really enjoy. Only Tara explained that her current conceptions about menstruation are less positive now than in the past because she now experiences pain when menstruating. The rest of the women expressed that their current conceptions of menstruation are more positive than in the past or that they have remained able to find positive aspects about it. Even the women that are using Depo-Provera had come to see menstruation in a more positive light before they started using the drug.

A 'natural' discourse was utilized by most of the women to describe menstruation. This natural discourse that they drew on is based on the idea of menstruation as biological. They were all taught from a young age, from mothers, friends, and in health classes that menstruation is a natural, biological process. Despite all encountering negative depictions of menstruation throughout their lives, they framed the 
natural discourse in a positive way. For instance, several of the women talked about menstruation as something that is part of being a woman. They accepted this and Sheila and Liz in particular said that they appreciated it because they linked it to reproduction. The natural discourse was also drawn on in terms of health. Monthly bleeding was equated to feeling healthy and normal. Robyn in particular said how this makes her feel connected to her body. Several of the women also depicted menstruation as something that is cleansing. For instance, Becky commented,

it seems like (...) your body is made to get rid of this stuff for a reason, like it's supposed to (...) empty itself of this and then if it's not, like where? - it's got to change your body in some way on a larger scale.

Also, of great importance to many of the women is the 'pregnancy test' that monthly bleeding provides them with. It is interesting to note that many of them also described 'natural' to mean that menstruation is something that women have to go through - it is something that our bodies do and that we have to deal with, thus we might as well accept it. They were all aware though of how much menstruation can be regulated and even stopped. They all understood menstruation as something that they had to actively manage.

When looking at changes in the women's attitudes from adolescence to adulthood, the most common reasons cited for positive changes in their attitudes were general maturing and having a greater sense of control. They got used to their bodies but also learned about different ways to manage menstruation. Discovering products like tampons, different pain-alleviating drugs, and especially the pill, caused the women to feel a greater sense of control. For instance, Melissa went on the pill for contraceptive reasons but then realized that this gave her more control over her menstrual cycle. She said: 


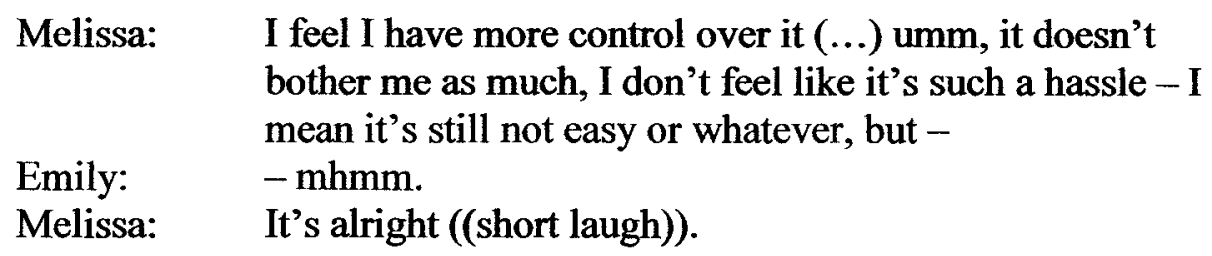

I argue that by valuing control over menstruation, the women problematize (whether knowingly or not) their bodies to a certain degree. The women gained a sense of control via how they manage menstruation. For instance, using 'feminine hygiene' products gave many of the women a sense of control. In addition, all of the women on the pill and the one woman on the patch valued how these methods regulate their menstrual cycles. They experienced reduced menstrual symptoms and increased predictability of when menstruation would start. Even those women who did not go on the pill or patch with the intention of regulating menstruation, as well as those who felt conflicted about manipulating their hormones with these drugs, still described their increased sense of control as an advantage. Also the two Depo-Provera users embraced the feelings of control that they have over menstruation, especially Joyce.

All of the women defined normal menstruation as something that occurs on a monthly basis with the exception of Joyce. She explained that she felt that menstruation is "an absolute pain in the butt, it really is." She said, "I don't know I guess from being on Depo, I don't feel that it's necessary, like, I don't feel that I'm less of a person because I have - I don't have a period every month." Menstruation was something that she got used to in the past, but now that she does not menstruate, she rejects the dominant discourse that monthly menstruation is necessary.

\section{a) Social Perceptions of Menstruation}

Before analyzing how the women felt about stopping menstruation, I feel it is worthwhile to understand how they think that the topic is treated in our society. I argue throughout 
my work that socially and culturally, menstruation is treated quite negatively - but how do other women perceive this? Overall, there is a split between the women regarding how they thought that the topic of menstruation is treated. One group concluded that it is treated negatively, and the other, positively. What is significant is that both groups drew on a 'discretion' discourse and the 'natural' discourse to explain their opinions, yet the women in the first group characterized the discretion discourse as predominant and the latter felt the natural discourse prevails.

The first group of women, help to illustrate what the discretion discourse is. They maintained that negative stereotypes about menstruation are predominant in our society. They cited that menstruation is depicted as a sign of weakness and over-emotionality, and something that ought to be hidden and kept silent. The idea that menstruation is something that women need to be discrete about contributes to a lack of communication, and in turn, this lack of communication means that it is difficult to quash negative stereotypes. In particular, Joyce suggested that menstruation has been masculinized. She explained to me that she uses a feminist perspective to understand how menstruation is treated by our society. She said,

I just think it's been-been taken by (...) the general society and shown to be a weakness and it's the butt of $a$ lot of jokes and um it is not treated as a means to procreation, like, it's not treated as a way - a way of having children, it's treated as something that women go through because we're the lesser sex (...) and it really outli-outlines the differences between the sexes because it shows that we have (...) fluctuations in our hormones that cause changes in our bodies on a monthly basis.

Her comments prompt me to ask - does Depo-Provera masculinize or feminize women? By stopping menstruation, does it make us more like men? Arguably, Depo-Provera also 
helps to preserve traditional notions of femininity. By being able to suppress menstruation, we can remain clean and attractive (no leaks, no smells).

The women in this first group understood menstruation as something natural but did not think that it is acknowledged this way on larger, social scale. Thus, they depicted the discretion discourse as predominant but also identified a competing discourse - the natural discourse. A couple of the women suggested that this natural discourse is more of a younger mentality, whereas the discretion discourse might be taken up more often by older women. Several of the women in this group articulated that a natural discourse could be used as a means of resistance. For instance, Chantal said:

I would love for it to be just (...) another event in life, you know, without the secrecy or such discretion, I just think, well sexual health all over, not just menstruation, needs to be more natural umm and I think it'll lead to more, you know better body um awareness and more self-esteem especially in teenage years.

It is relevant to note that although there is a split between how the women perceived menstruation to be treated by society, almost all of the women emphasized that there is still room for improvement, even those, in the next group, who labeled social norms as positive. Also, almost all of the women stressed the transitional nature of the subject of menstruation in our society.

The other group of women contended that menstruation is treated positively. They argued that menstruation is treated this way in our society because it is recognized as just something natural that women experience. They also reasoned that the topic is socially accepted because it is openly talked about. For instance, they explained that feminine hygiene product advertisements keep the topic out in the open. As well, several of the women believed that society is more open about everything at the present time - nothing in our society is private. Kim in particular associated women's rights with positive social 
changes. She proposed that topics which are more woman-specific are possibly now more talked about because women are increasingly active and involved in society. The women in this group illustrated that the discretion discourse, which was once prominent, has been defeated by the now dominant natural discourse. Yet a few of the women in this group Becky, Jocelyn, and Tamara - questioned if their perceptions were accurate or not. They brought up the idea of false consciousness. They wondered if they were describing social perceptions as positive because that is how they want it to be. As well they questioned if their own experiences, which are for the most part positive, were causing them to label social perceptions accordingly. Becky and Tamara speculated even further that perhaps their age was influencing their answers - that it was a big deal when they were adolescents but now it is just something natural that they can openly talk about because of their maturity.

Although I have shown that the women's responses fall into these two groups, there were a couple of exceptions. Melissa and Tara recognized that the topic of menstruation is predominantly silent in our society; however, they did not depict this as negative (unlike the first group which argued that the discretion discourse is negative). Tara reasoned that this silence exists simply because menstruation is not a big deal - it does not need to be talked about. In addition, Melissa contended that there are bigger things to be talking about in society than menstruation (for example, sexually transmitted infections). She deduced that talking about menstruation is something that adolescent girls do because they have nothing better to talk about. 


\section{ATTITUDES TOWARD STOPPING MENSTRUATION}

There is a lack of research on women's attitudes toward menstrual suppression, particularly via the drug Depo-Provera. Of the literature that is available, most of it is based on stopping menstruation with long-acting oral contraceptives (thus with many of these, for instance Seasonale, there is still bleeding four times a year). F.P Anderson et al. assert that "many women, regardless of age, express a desire for less frequent menstruation, with cycles occurring every 3 months often cited as optimal" (2003:89-90). Furthermore, Kaunitz believes that menstrual suppression is what women want. An advocate of it himself, he argues that we need to give women what they want (2000:282283). The majority of the women in my study however felt that other women have mixed feelings about stopping menstruation. They expressed that although women find the idea of stopping menstruation appealing, most of them will not actually follow through with this in practice. The women drew primarily on experiential knowledge to develop their answers. Many of them also drew on assumptions that they have about other women. Interestingly, the two Depo-Provera users did not draw on any personal experiences at all. Andrist et al. also found that many women like the idea of stopping menstruation but disliked the idea of doing this in practice. They question if women are hesitant because the idea of menstrual suppression is new to them or if "they are opposed to hormonal manipulation or that they need more education" (2004a:35).

When I asked them why they thought that other women might want to stop menstruating, their answers fell into two categories - health reasons and lifestyle reasons. Health reasons include not having to deal with pain, premenstrual syndrome (PMS), heavy bleeding, and irregular bleeding. Lifestyle reasons include, not wanting to have 
children, having an active lifestyle/involvement in sports, having a busy life, and traveling a lot. As well, many thought other women might like the convenience of not taking the pill and not having to use pads or tampons. Some further lifestyle reasons that they suggested others might adhere to were - to save money, sexual activity (meaning one would feel that they could have sex more often?), thinks menstruation is gross, and that menstruation is perceived as generally inconvenient. Also Carla thought that younger women might be more inclined to want to stop menstruation as they might not see it as something that one has to deal with.

It is important to note that all of the women who cited health reasons agreed with them as justifications, whereas, of those who mentioned lifestyle reasons, they seemed to be split down the middle as to whether they agreed or disagreed with these justifications for others' actions. J. Rosenberg reports that for women who want to suppress menstruation, one of the most common motivators for using a long-acting oral contraceptive is because menstruation is perceived as inconvenient. She conveyed that more women today desire menstrual suppression than has been found in past studies. She explains though, that this could be because younger respondents were involved in the recent study (2003:95-96).

The majority of the women expressed a lot of concerns about stopping menstruation and their concerns generally intensified when talking specifically about stopping it with Depo-Provera. Their concerns about stopping menstruation included: it is unnatural, they find comfort in the normalcy of menstruating, and that they find comfort in monthly bleeding because it acts as a monthly pregnancy test. They also expressed health concerns, and concerns about a loss of womanhood. When looking at their 
concerns with Depo-Provera, these same ones arose, as well as some additional concerns - about side effects (particularly irregular bleeding and spotting and depression), about fertility, about how long the drug might stay in the body after discontinued use, about needles, about the inconvenience of going to the doctors for injections, and concerns about not trusting the scientific knowledge available on the drug at this time.

Despite all of these concerns, the majority of the women have mixed feelings about personally stopping menstruation. Several of them would likely not label themselves as having mixed feelings, yet from analyzing their attitudes and opinions, as well as recent and anticipated actions that they conveyed to me, few of them maintained a consistent opinion. Many of the women flip-flopped, contradicted themselves (knowingly or not), and were conflicted about how they felt about stopping menstruation. The intensity of this conflict varied amongst the women. Sheila said,

I like the thought of not having it ((laugh)), but I don't think that I would (...) actually want to not have it - I know that I do complain about it once and a while but, the thought of erasing it altogether I don't know.

Kim also expressed mixed feelings and was quite explicit about it. I asked her to reflect on a hypothetical scenario in which women do not menstruate - they were born not menstruating yet could still get pregnant if they wanted to. She commented,

I think I'd be conflicted. It - like - umm, on the one hand, it seems like a really nice deal ((laughs)) umm and it seems like a good idea because it would just create less hassle and be easier and make life easier and if it's not going to affect whether or not you get pregnant then, I mean, if you could choose to get pregnant, then, umm, yeah, then there's not any other - or not a reason that I can think of except for the fact that it - we were born with it so there's got to be some reason why it's beneficial to us. Umm I think (...) but who knows?

Tamara also remarked that she feels a sense of "internal conflict" when thinking about whether or not it is good or bad to stop menstruation. 
Two of the women were completely against stopping menstruation. Tara, despite currently having a difficult time with pain when menstruating, is against the idea of altering her body with drugs to stop menstruation. She did not like the idea of "messing with" her body since "you are putting chemicals that aren't naturally in your body." Another woman, Robyn, used to have mixed feelings about stopping menstruation but is now very clear on how she feels about it due to her past negative experiences with DepoProvera. She experienced a serious adverse reaction of depression while using the drug. As well, she felt very uncomfortable about not menstruating. Robyn commented, I felt like less of a woman not having my period. I felt like an alien. (...) No, and I knew what was going to happen and I thought it was going to be great when I first went on it, but I was happy to see my period come back.

Her reference of feeling "like an alien" highlights how abnormal she felt.

Two women, the Depo-Provera users, were personally in favour of stopping menstruation. Joyce did have some concerns about Depo-Provera specifically (for example about bone mineral density loss - this research was not out when she started using Depo-Provera), but had no concerns about stopping menstruation. She only saw stopping menstruation as a benefit and said "I'm quite happy to be without it." Carla was also comfortable with stopping menstruation. While she does not understand menstruation as something that is a huge hassle, she is fine with it stopping, as she is using Depo-Provera primarily for contraceptive reasons. She did express some concerns about side effects but said she would be concerned about this with any hormonal contraceptive.

For those women who are currently stopping, or have stopped, menstruation, some felt that it is/was positive, some felt that it was a negative experience, and a couple of women were uncertain about how they feel about it. When Alana stopped menstruating 
while on the pill, she enjoyed it because she felt that it was convenient. Melissa also had a positive experience of stopping menstruation with the pill. It worked out well for her and she did not worry about not menstruating because she said that her body still mimicked a cycle (she got symptoms when menstruation should have occurred so this made her feel normal). Joyce, who stops menstruation with Depo-Provera, enjoys it because of her active lifestyle, she is able to save money, she has reduced pain, and she does not experience any side effects. She was taught at a young age, in her health class that menstruation was not to be talked about, especially with males. For the first couple of years that she was menstruating, it was very embarrassing to her - "I always thought that like, you know, going to the bathroom that somehow people could see with $\mathrm{x}$-ray vision in their minds." When asked specifically what she likes about not bleeding she said:

Joyce: $\quad$ It's really the cleanliness. I hated (...) feeling so gross for 5 to 7 days. And you just never feel like you can shower enough or (...) and it smells, and I know that they - people say that other people can't smell it, but it's just disgusting

Emily: $\quad$ hmm

Joyce: $\quad$ There's nothing worse than (...) than that stench I don't think.

Carla also explained that she enjoys not bleeding via her use of Depo-Provera. She commented,

Carla: $\quad$ Uh, the cramps (...) and just like not having ...Umm, I don't feel gross. ((laughs)) Umm, I don't know, when I think about it, it wasn't really that bad, like having to go to the bathroom to change a tampon 'cause like, you have to go to the bathroom anyways, like Emily: $\quad$ mhmm

Carla: $\quad$ It's not - but I mean I'm not like - if I was to start menstruating again, I wouldn't be like 'Oh God.'

Emily: ((laughs))

Carla: $\quad$ It's just kinda like an added bonus so. 
She told me that she still spots sometimes which can be annoying. Overall though, in terms of stopping menstruation she said "I don't really know why stopping menstruation would be bad." She told me that if she learned otherwise, then she might "think twice about it."

As was mentioned, Robyn had a very negative experience with stopping menstruation with Depo-Provera. Kara also had a negative experience when she accidentally stopped menstruating. She did not start one of her packs of pills on time which threw off her menstrual cycle. This was "scary as hell" to her. She was concerned that her body would not function naturally again. When she did start menstruating again she was relieved and described this as "back to normal again." This was no doubt a bothersome experience for her because she did not intend to stop it.

Liz also felt concerned when she stopped menstruating with the pill but was also pleased that it had worked for her (she was going on a romantic trip and did not want to be menstruating). She said - "I felt pretty bad about it, like I was pretty scared ((laughter))." She was relieved when it came back. As well, Tamara thought that stopping menstruation with the patch "was great" and thought that she might like to try to stop it again during the summertime. She did express concerns though about how her body will function when she decides that she wants to menstruate again. She likes having the choice and control but at the same time feels uneasy about this. Thus there is a bit of dissonance between her beliefs (that it is natural) and her actions. 


\section{CONCEPTUAL IMPLICATIONS}

\section{a) The Malleability of Menstruation}

The women treated menstruation as something that happens naturally but also as something that can be manipulated and controlled through different types of bodily management. All of the women were aware of how malleable menstruation is and that they could choose to manipulate it with varying degrees of intensity. As was noted earlier, the majority of the women in this study use the pill. They consider its regulation of menstruation to be either their primary motivation for using it or a bonus to using it (their primary motivation being contraception). Two of the women exert intense control and management over menstruation by using Depo-Provera. Again, the idea of control is highly valued amongst the women, with the exception maybe, of Tara.

Only one of the women in this study actually experiences naturally occurring menstruation. The rest of the women who 'menstruate' experience something symbolic of menstruation - 'withdrawal bleeding.' Thomas and Ellertson explain,

the bleeding that oral-contraceptive users experience each month bears little biological resemblance to a menstrual period. Indeed, there is scarcely any builtup uterine lining to be shed for these women. Rather, the bleeding results from a drop in the hormone levels after the $21^{\text {st }}$ day when the woman stops taking active tablets and switches to placebo. Women who use oral contraceptives and feel that they are maintaining a 'normal' or 'natural' cycle are being duped. (2000:923)

Furthermore, Anderson et al. argue that keeping monthly bleeding around with the pill was only done because of "a historical desire to mimic the natural cycle" (2003:89). Many of the women know that they are regulating menstruation with the pill, yet still described their bleeding as something natural and utilized the natural discourse when reflecting on how they felt about stopping menstruation. Perhaps these women were unaware that their bleeding is not occurring naturally. Others know that they are controlling their menstrual cycles and noted their contradiction of manipulating it and 
maintaining that they value it as something natural. For instance, Liz accepts and embraces menstruation as something natural and is deeply conflicted by her use of the pill. She described that after being pregnant and then eventually going on the pill, the hormones from the pill made her feel like she did when she was pregnant - she felt "crazy again." She explained though, that she had to decide - "do I want to be crazy or do I want to have another baby? Ok, I'll be crazy." Not only is she aware that the pill is unnatural, she is aware that it makes her feel differently - it is different from how she feels when things are natural. Despite all of this, she continued to frame her opinions and arguments utilizing the natural discourse.

There are a couple of women who explicitly drew attention to their bleeding as something that is symbolic. Rather than describing it as something natural, they were aware that the comfort that they find in menstruating is based on the symbolism of something natural. Both Laura and Tamara take comfort in their birth control methods (the pill and the patch) at least mimicking monthly bleeding, since they understand this as natural and normal. Laura acknowledged her contradiction of simultaneously valuing menstruation as something natural and as something symbolic of the natural. Tamara also described menstruation as something natural, yet once asked specifically about stopping it, she made it clear that she knows that the bleeding that she experiences is unnatural. She has purposely stopped menstruating before with the patch and expressed concerns about if it was unhealthy to not at least mimic monthly bleeding. Not only does she have concerns about her health when stopping menstruation, she also appreciates the symbolism of menstruation as a monthly pregnancy test. 
Sexual activity caused many of the women to view menstruation differently compared to when they were adolescents. For some, they described that it got in the way of having sex. Robyn framed this as something that she could use to her advantage though - it could give her a "break." The majority of the women however discussed sexual activity and menstruation in terms of the pregnancy test. For many of them, part of their conflict and hesitancy to stop bleeding completely had to do with their reliance on this. For instance, Jocelyn explained how she is purposely on the pill so that she will know that she is not pregnant each month. She said,

Jocelyn: $\quad$ Um (...) I think now it's more of - for me personally it's more of a relief factor in terms of 'my birth control pill is working and I'm not pregnant.'

Emily: $\quad$ mhm

Jocelyn: So, that for me is important -

Emily: $\quad-$ yeah

Jocelyn: that's why I chose to be on the type of birth control pill that I'm on. So, that's important to me right now.

She is aware that bleeding can occur with the pill - it is something that she needs to affirm that scientific knowledge has not failed her. Robyn remarked that the loss of this pregnancy test, when on Depo-Provera, was very bothersome to her. She reflected, "it had a real impact on me. I was worrying whether I was pregnant or not, you know and not knowing, not having that extra security about it." The women in this study are working on getting their education and starting their careers. Pregnancy is likely not an option for most of them right now.

Not only did the women understand actual menstruation as something that is malleable, but it is evident that when trying to convey how they feel about stopping menstruation, for most of them, their truths and perceptions about menstruation are malleable as well. The majority of the women have mixed feelings about stopping 
menstruation and many of them experienced inner conflict when trying to sort out their thoughts, actions, and predicted future behaviour. Most of these women hold a 'truth' of menstruation as something that is natural but are also pulled in another direction of trying to regulate it because of their 'truth' that it is problematic. The topic of what menstruation is and how they feel about regulating it is complex for many of them and thus at times, they bend their truths (knowingly or not). While this bending of one's truths might cause inner conflict, if it is believed to be done for a valid reason, then the stretching of one's truths can be seen as a means of trying to minimize possible contradictory thoughts and actions.

A large portion of the women bended their truth that menstruation is natural (and validated their truth that it is problematic) in order to have a sense of control and regulation over it. ${ }^{27}$ Many of the women went on the pill to control their menstrual cycles and several, who went on it initially for contraceptive reasons, wanted to stay on it because of the advantage of regulating menstruation. Also, many of the women knowingly bent the 'natural' truth to gain control in terms of effective birth control. For instance, Liz feels that she has little choice in terms of consistently maintaining the 'natural' truth that she values. When talking about pregnancy she said,

Liz: I think it's like a fear thing, you know? And it's - I don't - I'm not comfortable with the fact that I'm putting drugs into my body for that. Umm, like a-first of all I think there's some sort of dissonance between what I'm doing and what I believe.

Emily: $\quad$ mhmm

Liz: $\quad$ if you know what I mean?

Robyn also expressed dissatisfaction with her options - "I just wish there was another way, like, other than sticking drugs in your body and (...) these (...) kind of, either

\footnotetext{
${ }^{27}$ While all of them might not be aware of the withdrawal bleeding as something symbolic, all of the hormonal dnug users are aware that they are regulating their cycles.
} 
intrusive or very uncomfortable ways, you know?" Kara was more comfortable than Liz and Robyn with bending her 'natural' truth for effective contraception, but she was really uncertain about the idea of bending this truth just to stop menstruation. She commented, personally, I wouldn't be on the pill if I wasn't having sex. So I don't think people should be going out and trying these new drugs just not to have a period (...) You have to remember it is a contraceptive.

She believes that only contraception or medical problems are legitimate reasons for using Depo-Provera.

Another instance in which many of the women were willing to bend their truths about menstruation was if they knew, with certainty, that they would be healthy if they stopped menstruating. They were willing to shift their conception of what is normal. Currently most of them think that monthly bleeding is natural and thus normal and healthy - but if they were shown and convinced otherwise, then many of them would come to only define normal in terms of being healthy. For example, Sheila commented at one point that stopping menstruation is unnatural. She said, "I don't really like playing with my body, and like, I mean, it's made to work a certain way." However, then she mentioned that if more research was done on Depo-Provera and they "perfected it more," then she might consider it. Thus scientific knowledge would need to be more convincing. I presented the women with a hypothetical situation in which all women in society stopped menstruating - it was no longer naturally occurring. I asked the women how they would feel in this situation. Only a few of the women were willing to bend their personal truths in this situation. Kara began to, but then hesitated because she realized it was conflicting with her beliefs. She stated, 
if there was research done, and we know that we're still going to be women, without having a period. I - 'cause I just - that's (...) what makes you a woman I think, that's, you know it's just what happens, it's who you are.

She said that there would need to be $a$ lot of research done though - "I'd be afraid I'd turn into a man! ((laughter))" Most likely the women were not interested in embracing this situation as it seems quite suspect and possibly unhealthy that all women would just stop menstruating.

I also posed a situation to the women in which there was an option to take a 'fantasy drug.' This drug was like Depo-Provera, except that there were no risks involved - it was completely safe and flawless (no such drug actually exists). Many more of the women were willing to bend their truths about menstruation as natural with this scenario. Kim thought that it would be more convenient to not menstruate and described this fantasy drug as an "ideal solution" because one could be healthy while doing it. Also Laura, who at one point described menstruation as "no big deal, it's just kind of natural, a part of life," bent this truth in the name of health. She said,

Laura: I'd rather have my period and deal with a little bit of inconvenience

Emily: $\quad$ right

Laura: thennn, potentially have (...) regret -

Emily: $\quad-$ mmm -

Laura: - - down the road. Umm, but if it was completely risk-free, I'd like, there's (...) I don't see anything wrong with stopping it.

Becky, Melissa, and Tara were unwilling to compromise their beliefs in this particular situation - they would want to keep menstruating. Perhaps, many of the women were willing to bend their personal truths with this scenario because it is not a foreseeable possibility. It is safe to say that you would compromise some of your own values in a situation that is, without a doubt, impossible. However, it is interesting that if the scientific knowledge about stopping menstruation with hormonal contraceptives 
constructed a truth that said otherwise - that it is safe - conceivably a lot of women would then bend their own truths and values.

Lastly, it is interesting to note that although most of the women were not willing to use Depo-Provera long-term, many of them considered its short-term usage an option. ${ }^{28}$ Conceivably, they were more open to this idea because it is seen as temporary. The lack of permanency might seem less risky to them and less of a violation of their beliefs.

The women's truths about menstruation are quite malleable. Yet for many, it is clear that their own truths are conflicting with those promoted by Depo-Provera. The company presents a truth that monthly menstruation ought to be managed and that it is unnecessary. While the women did agree with the sentiment that menstruation ought to be managed, for many of them, the bodily management that occurs with Depo-Provera is too extreme - they were uncertain about stopping it. Furthermore, most of the women held onto a truth about monthly menstruation as natural (although as I just illustrated, this truth gets bent around). Thus, because of this dissonance between Depo-Provera's truths and their own, many of them were also unable to accept the truth Depo-Provera purports about freedom.

\section{b) Depo-Provera's Misleading Proposition of Freedom}

The women's thoughts on stopping menstruation were not clear-cut. In addition, their ideas about whether or not stopping menstruation provides them with freedom were not simple and straightforward. Rightfully so - 'freedom' is a very complex concept. The women thought that the slogan "Freedom from the everyday" could mean a variety of

\footnotetext{
${ }^{28}$ I presented them with an example scenario of going on a back-packing trip for several months.
} 
things (not all of which they agreed with). ${ }^{29}$ Many of them thought that it could mean freedom from having to remember to take the pill every day. Other interpretations included freedom from having to think about menstruation, freedom from menstrual management (having to use pads and tampons), freedom from the inconvenience of menstruating, freedom from having to take a pill in front of others, and freedom in the sense that you only have to go to the doctor's office four times a year. Interestingly, Sheila commented that freedom could also mean being free from being a woman. She said it could make us "kind of like men in a sense." Here, she utilized males as a symbol of freedom - as a symbol of what a liberated body is. Conversely, when asked to interpret the slogan, Joyce urgently asked me "are they implying that men are free because they don't go through it?" Although she felt that she was unable to address this question of hers without putting significant time and thought into it, it was clear that there was resentment in her tone of voice when asking this question. Although many of them did not agree with the slogan, they felt that it was clever because the idea of freedom is enticing and can be understood in an assortment of ways. Sheila and Jocelyn in particular drew on the idea that in our society, we always want to be free, and this product plays to this idea.

Even though the women value control over menstruation, most of them were not completely open to stopping menstruation and were not willing to embrace the proposal that stopping menstruation with Depo-Provera could provide them with freedom. To answer my research questions that I initially posed, only one woman felt that DepoProvera could provide women with freedom. The rest of the women fell into two groups.

\footnotetext{
${ }^{29}$ It is important to point out however, that with the interviews, I did not actually show the women any of the Depo-Provera advertising, rather I told them how they advertise that they can stop menstruation on their website. As well, I told them about the company's slogan and how freedom is a part of their marketing.
} 
They either felt that Depo-Provera was sending out negative messages that women's bodies are problematic, or that women could not feel completely free, since bodily regulation is still occurring and potential health risks could arise. Many of them felt that 'freedom' was an inappropriate word for the company to be using.

One woman, Carla, who is using Depo-Provera, felt that it could bestow freedom. In a very matter-of-fact tone, she said,

Carla: I think (...) I-I think it's good 'cause it is kind of is like freedom cause you only have to go to the doctor like every (...) so often.

Emily: $\quad \mathrm{mhm}$

Carla: But I mean with the Norplant or the IUD it would probably be the same.

Emily: $\quad$ mhm

Carla: $\quad$ Especially like freedom in that you don't have to remember every day (...) I don't know maybe it could mean because you don't menstruate.

Emily: $\quad \mathrm{mhm}$

Carla: But like not all women stop menstruating, so.

Here she framed freedom in a couple of different ways - in terms of contraceptive use and regarding menstruation. She does not want to make Depo-Provera seem unique. This is something that she commonly did throughout the interview (for instance when asked about side effects she would respond how other hormonal drugs have side effects as well). I think that because she did not go on Depo-Provera to suppress menstruation, perhaps she just wants it to seem like other types of contraception. She does think that freedom from menstruation could be a possibility but is quick to note that this would only be the case if it was working as promised. Thus while she thinks that Depo-Provera could potentially provide women with freedom from their bleeding bodies, it is not an overly enthusiastic or strong conviction. 
In Chapter One, I initially raised the question - by stopping menstruation with Depo-Provera, to what extent do women feel like they are admitting that there is something wrong with their bodies - that there is something wrong with menstrual bleeding and that it needs to be regulated and controlled? Many of the women expressed resentment toward Depo-Provera, as they believed that the company is depicting women's bodies as problematic. Furthermore, they questioned the usage of the term freedom - they thought that this proposal wrongly implied that women are not free simply because they menstruate. When I asked the women how they felt about DepoProvera's slogan, these were some of their responses:

Becky: I wouldn't call it freedom I don't think. (...) Emily: why not?

Becky: $\quad$ 'cause you - like - when you use the word freedom it's like you've - you're being relieved from something - like you're being trapped or enslaved. But I don't think of having your period as such a negative thing.

Laura: I guess - I guess I do kind of have an issue with them saying that umm (...) that they're offering freedom because I'm not not free right now ((laugh)) so, they're kind of implying that I'm not free because I have a period but I don't think I'm not free.

Kim: but I don't know if - I don't know if we have to look at menstruation as a prison ((laughter)) necessarily (...) umm (...) maybe for some women it is and so that would be a good choice, but I think for the large majority of women, it's umm, not that melodramatic really ((laughs)).

There is a clash between the perceived truth that Depo-Provera is offering and these women's own truths about their bodies and experiences. Although (as I illustrated in the previous section) these women bend their own truths and have mixed feelings about stopping menstruation - this claim that they are not free is too much for them to accept. 
These women resisted and rejected having their bleeding bodies depicted as so problematic.

Kara and Becky further illustrated that the slogan problematizes women's bodies in the sense that it makes them seem abnormal. Kara commented on what 'freedom' might mean:

Kara: I guess being different. Umm not being a typical woman - maybe a little step up, as if it's a burden being a woman (...) it's a curse they make this normal thing that happens to you seem like it's just a curse, it's an inconvenience, and it's making it sound like um not a contraceptive but like a gateway or an escape from 'normal.' (...)

Emily: $\quad$ so do you think that message is positive or negative, like if you understand it that way?

Kara: If I understand it that way I think it's negative.

Here, she drew on and rejected social norms and ideas that conflict with her own perceptions of her body. She wondered if the company is trying to convince women that not menstruating is normal. Becky in particular drew attention to menstruation as something that is medicalized - it is turned into something problematic that needs to be intensely managed:

Becky: $\quad$ well, if they're making drugs to - I don't know if their purpose was to stop menstruation - I mean it's birth control too -

Emily: - yeah

Becky: umm, but if that's going to be a selling point then, it kind of - it's a drug and drugs are normally to stop something from happening, so in that sense, you could look at it as being a disease for some people (...) it's not (...) known as a disease, people might - there could be some women who, that, think of it that way.

She thought that they were using freedom to try to convince women that there is something wrong with them, and to then offer them a product to alleviate this.

It is interesting to note that Robyn disagreed with the slogan because she felt that the 'everyday' is not something that we need to be freed from. She attested, 
Robyn: $\quad$ you're advertising something that's a lie, you know? Like if you're not going to save me from the everyday, then you're going to have to start worrying about other things, like, you know, depression, and breast cancer and different types of cancer, and you know, what does this do to your uterus, you know, what is this going to do to your chances of getting pregnant afterwards, your, you know and these are bigger concerns than - am I getting my period today or [tomorrow]

Emily: [mmhmm ]

Robyn: and uhhh did I remember to take my pill this morning. These are bigger concerns - they're life threatening.

Robyn is passionately against the drug and any claims that it could provide women with freedom. Chantal, who has mixed feelings about the drug, wondered if 'freedom' is an inappropriate word to be applying to something so everyday like menstruation. She compared menstruation to another necessary bodily process, eating, to illustrate her point:

Umm, I'm not sure if I would consider it freedom or just more convenient. Umm (...) I don't know it's kind of like if they invented a pill where you don't have to eat - you know 'cause it's a necessary life thing ((laughter)) Uh freedom from having to go to meals, I'm not sure if that would just cut down on time you take eating in your life or if it would actually be freedom - it would kind of be the same thing.

She thought that possibly the drug could be convenient but maybe should not be described as leading to freedom.

With my research questions, I also posed the possibility that women might express that using Depo-Provera could involve both regulation and freedom simultaneously. Many of the women did have mixed feelings about the message of freedom because they felt that there are limitations and restrictions that come along with it. For instance, several women felt that one might not experience complete freedom because you still have to regulate or manage menstruation. Alana commented - "we can't - we can't go away from the fact that we're still female ((laughs))." This could mean several things: that we still have to actively suppress menstruation while on the drug, that 
we have to actively control our reproduction, or that even if the drug makes us feel free, we still might not actually be free in other areas of our lives because of our social status. Regardless of what she intended for this to mean, in each scenario it implies that there are still restrictions that we have to deal with - we cannot have only freedom.

Joyce, who currently uses Depo-Provera said,

yes, but you-you still - I mean you still are (...) consciously taking a birth control. And you still are going in those every 4 months and getting an injection, and filling a prescription (...) and (...) you know hopefully doing all of the other things that you're supposed to do anyways, so like you know, yearly Pap smears and umm, and physicals and stuff to make sure that you're healthy so (...) I don't see how it's much different other than freedom from, you know, maybe the (...) ((short sigh)) pain and annoyance that a monthly period can cause.

She drew attention to all of the bodily management that one still has to engage when using Depo-Provera. Also, she expressed that we ought to be responsible for maintaining our own good health. While menstruation may not occur - it is still something that has to be dealt with - it is something that needs to be actively managed if it is going to be suppressed. Chantal also emphasized that there is still regulation happening with this drug since you have to go to the doctor several times a year. A couple of the women expressed that it is more convenient to get a year-long prescription for the pill than to have to go to the doctor four times a year. It is significant to point out though, that Joyce informed me that her doctor allows her to administer the injections herself, at home.

Many of the women in this group also alluded to the idea of freedom at a cost, in terms of health risks one could experience while pursuing freedom. Jocelyn said that because of these risks "you're not totally free." Also, Kim and Sheila expressed that side effects could impinge on one's sense of freedom. Furthermore, Tamara thought that 'freedom' could “cause some misconceptions." She laughed and remarked that the Depo- 
Provera user that was running, worry-free down the beach, might end up in the hospital with chronic pain. She did not think that the company is necessarily telling the truth but she was uncertain if they really even know what the truth about the product is. This is very interesting - it implies that they are creating a truth rather than telling the truth.

All of the women felt that Depo-Provera was using the word freedom to try to sell a product. Only a few of the women felt that the company should not advertise that they can stop menstruation. Joyce was one of these women. Despite using the product, she said "I - I don't think that they should unless they can prove in a hundred percent of the cases that menstruation will stop." She told me that she could not imagine being the odd case in which one took the drug and then bled excessively. Most of the women thought that Depo-Provera advertising that they can stop menstruation was a good way to sell the product - it is "their edge" (Sheila). Liz earnestly commented, "they're selling a product. They're selling a product. The drug company does not care how, like, you know - what Jean feels about her menstruation." These women did not necessarily condone this advertising - they just thought that it would be effective from a marketing perspective.

While all of the women valued being able to have a certain degree of control over their bodies, not all of them were keen to embrace having the choice to stop menstruating. Those who did value the choice (whether they will exercise it or not) based their answers on the idea that choice is inherently a good thing. For instance, Alana said "I think having choice for anything.is always nice." Tara also attested that "it's good to have the choice." These women also expressed that having increased options is always something positive. Melissa commented,

yeah, options are better, I mean it's good to know all of your different angles with everything. Umm, just because I don't choose that option doesn't mean it's 
necessarily a bad option it's just not the right option for me.

Sheila echoed this sentiment - "it's nice to have options and choices (...) kind of gets you more control over yourself in a sense." She links the idea of control to choice.

Not all of the women felt this comfortable with the choice to stop menstruating. Several of them did not embrace the idea, as they felt that this choice was overstated. Many of these women did not feel that this choice was safe, thus they had a difficult time accepting it. They hoped that other women would make well-informed choices if considering this drug. Chantal rejected the idea of choice as inherently good:

Um. (...) I never want to say choice is bad uhh you know, but I think um, sometimes - especially with feminine sexual health - this is one really good example, the choice is um (...) I don't know, exaggerated without all the knowledge.

She felt that we need to be well-informed, and if we are not then freedom of choice is not such a great thing. Becky also wanted to reject the idea of stopping menstruation with Depo-Provera as a good choice but could not bring herself to do this. She was conflicted because she felt that she had to accept the choice to stop menstruation since she is in favour of women having the right to abortions and control over their bodies. She felt that she had to respect this choice.

On the other hand, a couple of the women were also uncomfortable with embracing 'choice,' as they were uncertain about whether or not this was a choice that we should be able to make. Jocelyn, who believes that menstruation is something natural, wondered,

Jocelyn: having a choice to do something that drastic to a woman's body which is something that's so, I don't know, like I mean it's never (...) like women have been like this for centuries, so should you have to have to do - to have that choice to alter such a - a normal, natural process? 
Emily: $\quad$ mhm

Jocelyn: That's pretty big.

She hoped that if others decided to make this choice, that they would take it very

seriously. Kara approached thinking about choice from a religious perspective. She said,

hmm, (...) I don't know. It's just - again it's natural and I don't know if it's our choice to make? I don't know if you want to go on the whole God bit - that's the way He made us, we obviously have it for a reason and I don't think that we hold the power to make that big of a choice in our lives.

Although both Jocelyn and Kara were uncomfortable with the choice to stop

menstruating, they both remarked that they respect other women's decisions to do this.

Most of the women respected other women's choices regarding the use of Depo-Provera

for menstrual suppression. However, it is significant to note that none of them understood stopping menstruation with this drug as a good, safe choice for adolescents. They

expressed concerns about adolescents' cognitive abilities to make such a decision (for

instance that they will not consider possible future repercussions or that they are

unhappier with their bodies and will be more inclined to want to stop menstruating), as

well as concerns about their health (that their bodies need to develop before altering them

with hormonal drugs and also, concerns about long-term usage if starting young).

I have included a lot of findings in this chapter. The major findings need to be further discussed. In particular, the differences between the women's truths and DepoProvera's truths need to be highlighted. As well, the theoretical discussions from the previous chapters need to be expanded to further reflect on these findings. In the next chapter, I illustrate the significance and implications of what I have found. 


\section{CHAPTER SIX: \\ PLAYING 'TRUTH GAMES': A DISCUSSION}

Despite Depo-Provera's construction of knowledge that monthly menstruation is unnecessary and that its cessation is not that big of a deal, very few women clearly agreed with these promotions. Furthermore, very few women agreed with Depo-Provera's proposed truth that stopping menstruation will lead to freedom. In fact, many of the women outright resisted Depo-Provera's depiction of menstruation and more generally, of menstruating women. Most of the women expressed a lot of mixed feelings about stopping menstruation. Many of them liked the idea that Depo-Provera was proposing but could not fully embrace it because of their own personal concerns about menstruation as something natural that should not be regulated to the point of suppression. In this chapter, I begin by discussing the significance of these major findings. First, I address that while the women generally rejected the idea that monthly menstruation is unnecessary, their truths about menstruation are still quite malleable. I then discuss the idea of resistance in detail. This includes concentrating on how the women in my study exercised resistance, as well as general theoretical concerns about possibilities for resistance with medical consumerism. Next, I tackle conceptual aspects of freedom - challenging the consumerist logic of 'freedom of choice' as leading to freedom, as well as examining the idea of experiencing freedom and regulation simultaneously - this involves considering if selfregulation is 'good' or 'bad.' Furthermore, I raise questions about whether or not it matters if one's sense of freedom is real or an illusion, and whether or not personal freedom and social freedom can be disconnected. These are substantial conceptual concerns and given the nature of this project, regrettably I can only deal with them at a somewhat cursory level. In the latter part of this chapter, I bring up questions about why 
there is such a strong push to stop menstruation now - what is it about our current social condition that is fostering such truths about menstruation to emerge? I pose a prediction that several decades from now, it will be more common to not menstruate (in affluent societies). I use this non-menstruating society to show the potential transformative nature of our truths and how we as a society shift our ideas over time about what is natural and normal. This also allows me to reflect on the question - who benefits from 'freeing' women in this way?

\section{ADJUSTING 'TRUTHS'}

Foucault describes, that in our society, we play 'truth games.' He explains that "In a given game of truth, it is always possible to discover something different and to more or less modify this or that rule, and sometimes even the entire game of truth." (1984:297). There are multiple discourses and truths that exist in our society - they are continuously shifting in power. It is evident from analyzing the responses from the women in my study that we continually draw on and reject discourses - we are continuously shifting our personal truths. Depo-Provera presents a dominant truth that monthly menstruation is not necessary. It builds off of and is consistent with the negative social norms about menstruation, which I describe in Chapter One. Yet this message was generally not wellreceived by the women in my study. Stopping menstruation is a big concern to these women. It is complex and something that few of them have clear, straightforward opinions about. Jennifer Hester, who studied how women understand their use of oral contraception, describes that there is a reliance on multiple types of knowledge. She explains this as bricolage. For the bricoleur, one truth is not satisfactory. Thus, they draw 
on a plurality of truths and might reflect on this with their own experiential and bodily knowledge (2005:82-88).

The pregnancy test, which most of them relied on, is an example of drawing on multiple types of knowledge. Many of the women used the pill or the patch because they were aware of its high efficacy rate - they drew on scientific knowledge. Yet this was not enough for them. The symbolism of menstruation (whether they are aware of this as symbolic or not), is considered a form of bodily and experiential knowledge that is often, in the end, valued over scientific expertise about the efficacy of the pill or patch. ${ }^{30}$ This symbolic pregnancy test is scientifically induced - the withdrawal bleeding is unnatural but it is still valued as something bodily and experiential that happens. Not all women needed this security of the pregnancy test though. Both Carla and Joyce were comfortable with using Depo-Provera and did not need to rely on the bodily experience of the symbolism of menstruation to let them know that they are not pregnant. For them, scientific evidence was sufficient. Interestingly, the drugs that can stop menstruation also offer something symbolic, of a different truth about menstruation. These contraceptives propose a truth that frequent monthly menstruation is unnecessary. ${ }^{31}$

The pregnancy test is something that many of the women hold on to, as it gives them a sense of control. A lot of the women were also hesitant to embrace stopping menstruation with Depo-Provera because of a concern about being vulnerable to potential side effects. As well, many of them expressed that they would feel a lack of control over

\footnotetext{
${ }^{30}$ This pregnancy test is possibly only so reliable because it is medically induced to happen at the exact time every month. If the women were relying on 'natural' menstrual bleeding, it is conceivable that it might not be so predictable.

${ }^{31}$ When women do not menstruate, for example because of breastfeeding, this is a low-estrogen point, whereas stopping menstruation with hormonal contraceptives involves a high amount of hormones (Hitchcock \& Prior 2004a:202).
} 
the administration of the drug. For many of the women, Depo-Provera is a very intrusive method of birth control - it is administered through a needle, most likely by someone else, in a setting outside of one's home (doctor's office), and the drug then stays in the body for three or more months (as was noted previously, the drug could take up to eight to ten months to wear off for some women). Many of the women expressed that they would rather use the pill because it is something that they can administer themselves, and thus they can stop using it if they want to (although the pill can also have an effect on the body several months after discontinuing its use). These women also felt that it is more convenient to fill a prescription for the pill (which for most of them is a year-long supply) than having to make an appointment at a doctor's office.

Why would so many women be willing to use this contraceptive if it is arguably, so intrusive? Perhaps for some, the pay-off of a very effective contraceptive and/or the possibility of stopping menstruation override the invasiveness of the drug. Again, it is important to point out that Joyce administers Depo-Provera herself. She does not feel a lack of control with her contraceptive use of Depo-Provera, nor does she define it as intrusive. Depo-Provera's promotion of their product as convenient and easy to use is appealing to some women and inaccurate for others. It is relevant to point out that another injectable contraceptive exists - Lunelle. This drug is particularly interesting because it is administered once a month (rather than taking contraceptive pills all month). It is aimed at women who want an injectable contraceptive (presumably so they do not have to remember to take pills) yet want to have withdrawal bleeding each month (Garceau 2000:290). If the women had concerns about needles and doctors appointments with Depo-Provera, arguably these concerns would increase with Lunelle. There are more 
appointments required and more injections required. It seems quite intrusive, yet maybe this is appealing because there is more of a sense of control if it is administered on a monthly basis? Perhaps some women would feel that this drug is easier to discontinue, compared to Depo-Provera? Or perhaps they just put up with monthly injections so that they do not have to take a pill yet can still 'menstruate' each month.

Coming to a decision about stopping menstruation is not as straightforward as the Depo-Provera website makes it out to be - if it is a problem or something inconvenient that you do not like, then stop it. It is apparent that most of the women valued two, somewhat conflicting truths - the idea that menstruation is natural and necessary, yet also something that is problematic that needs to be regulated. This is further complicated by questions about control and whether or not the product will increase or decrease their sense of this. Conflict in one's beliefs can be bothersome. Tamara, when asked to think about how she would feel if she was born not menstruating (like males are), commented "if it started off that way, I think that would be awesome because you wouldn't have the conflicts about 'well, is it healthy, is it not [to stop menstruating]' because you don't know any better or any different." For many of the women, they used the symbolism of natural monthly bleeding to somewhat alleviate this dissonance between their thoughts (that menstruation ought to be accepted as something natural and healthy) and their actions (problematizing their bodies to a certain degree by regulating menstruation via hormonal drugs). Perhaps this symbolic bleeding indicates to them that they have not gone too far with their bodily management - they have not abandoned their own personal truths and perceptions too deeply. 
We all bend our truths and often times find justifications for this behaviour, possibly so that we can try to make sense out of, and bring some coherence and consistency to decisions, thoughts, and actions that can quite often be terribly complex. Many of the women were willing to bend or even abandon their truths about monthly menstruation as necessary, natural, and healthy, as long as they felt that they had a reasonable justification for doing so. We can recall that these justifications were to have a sense of control and management over one's bleeding, to have effective contraception, and when considering stopping menstruation, many women were willing to abandon the idea that monthly menstruation is natural and necessary if the practice of menstrual suppression was safe and healthy. Also, the women were more willing to stop menstruation if it was temporary - therefore not permanently violating their own beliefs. There are arguably, a variety of reasons for why women might be willing to stop menstruation - which go beyond what the women in my sample focused on. For instance, some women who are competitive athletes might readily abandon their truths about menstruation as natural and necessary, in order to be menstruation-free while participating in their sport.

Robyn, who had used Depo-Provera and then experienced serious problems with her physical and mental health, now regrets abandoning her truth in the past. She was influenced by her doctor and by others who said that it would not be a big deal to stop menstruating. She said,

Robyn: 'Cause I never really thought it was all that safe to not have your period you know? Like, I-I just felt there was something unhealthy about it. That's why I don't -it happens for a reason you know? Like

Emily: $\quad(($ laugh))

Robyn: if it wasn't supposed to happen, if it was useless, then it wouldn't. 
Emily: $\quad$ mmhmm

Robyn: $\quad$ There's gotta be a reason it happens? Clean us out, you know what I mean?

For Robyn, she strayed from her own beliefs which in the end, made her uncomfortable. The idea of the malleability of our truths is certainly not unique to the context of stopping menstruation. We often seek out justifications in countless spaces in our lives for bending our truths - whether we are knowingly doing this or not. Sometimes these justifications might seem suspect to others, as well as to ourselves.

\section{a) Exercising Resistance}

Foucault contends that the subject is a form which changes in different circumstances and with different types of power, knowledge, and truths (1984:290-291). Resistance is a part of this. Ivison explains that "wherever Foucault discusses the omnipresence of power, resistance is not far behind, because his account presupposes that power always works on the basis of an acting subject" (1997:43). We can recall from Chapter Two, that there is much debate amongst feminists concerning whether or not resistance is possible when power is conceptualized as everywhere. I coincide with McLaren who says that "while subjectivity is constituted through discourses of truth that are imbued with relationships of power, this nonetheless does not automatically preclude the possibility of moral and political agency or resistance" (1997:116). His conceptualization of power recognizes that resistance is often necessary, and can occur in, all aspects of our lives (McLaren 2002:163). Grimshaw notes that his work can encourage feminists to examine power imbalances amongst women as well (1993:56). 
Rose also discusses resistance. Like Foucault, he advocates that we need to stop seeing power and resistance as binaries and instead ought to conceptualize the two as connected and relational. He argues,

Each such binary suggests a principle of division between those political, technical and ethical strategies that have made up our present and those that have opposed them. This way of dividing the matter is illusory. There is not a single discourse or strategy of power confronted by forces of resistance, but a set of conflicting points and issues of opposition, alliance and division of labour. And our present has arisen as much from the logics of contestation as from any imperatives of control. (1999:277)

Although Rose focuses much of his attention on governance throughout his work, he is aware that resistance occurs.

Various instances of resistance were evident throughout the interviews that I conducted. For example, many of the women resisted defining their adolescent experiences with menstruation as negative despite some very traumatic and difficult moments. Lee and Sasser-Coen describe that accepting one's bleeding body, when cultural norms condemn it, is a form of resistance (1996:174). As well, they explain that denial can be a means of resistance - denial "was still a form of resistance, as girls became aware of and began to respond to negative scripts associated with gender" (173). As has already been described, many of the women in my study also resisted the idea that offering them freedom implies that they are not free because they menstruate. They rejected the pathologization of their bodies. In particular, Becky and Liz resisted the overmedicalization of it and rejected the idea that menstruation be depicted as a disease. Another means of resistance is manipulating norms to get what one wants (Lee 2003:9495). Robyn did this:

I like the idea of women being somewhat vulnerable, you know what I mean? Like, just a little bit - having something about us that makes us different from 
men, you know? Not only the fact that you can get pregnant, that's obvious, but something that kind of sets us apart, something that makes our day to day lives different than men, you know, such an obvious physical thing ... women have their periods, men do not, you know? I like having that, that difference. I think it it kind of gives me an excuse too sometimes? Like, if I'm upset or whatever or and I'm just being grumpy or whatever.

She draws on negative norms and stereotypes and manipulates them into something positive. For Foucault, resistance can be an individual or collective task (McLaren 2002: 40). While the women engaged in personal instances of resistance, many of them also advocated that as a whole, our society needs to work toward redefining menstruation in new and positive ways.

Nettleton argues that people might self-regulate in conformity or in resistance (1997). Is using Depo-Provera a means of resistance? For instance, does it provide women with a way to escape negative norms by freeing oneself from menstruation? Does it accommodate resistance in the sense that it enables us to defy traditional ideas about what is 'normal' and 'natural' regarding menstruation? Furthermore, is it possible that for some women, as is the case with Joyce, that using Depo-Provera allows her to resist the idea that menstruating is a necessary part of being a woman? Clearly, 'resistance' can be twisted in countless, often very creative ways and can be influenced by others, as well as one's perceptions about their 'truths' or 'realities' - in this case, about what menstruation is and how our society treats this subject. What I think is an act of resistance might not be recognized as such by others and vice versa. This does not mean though that resistance is always futile. Bauman is correct however when he says that not everyone's acts of resistance will be acknowledged and not everyone can be effective (1988:84). 
Foucault's idea that we practice freedom helps us to understand resistance.

Sawicki explains that a practice of freedom could be resisting or challenging dominant social norms (1998). Grimshaw attests that,

The theme of 'practices of freedom' seems to me to be an extremely important one for feminism. Another way of putting it is to say that questions about 'how one should live' are not answerable wholly by reference to highly general ethical ideals [for example. liberation, freedom, justice, equality and so on]. In addition, it can never be assumed that any particular kinds of 'liberation' will establish freedom, equality or mutuality permanently or without ambiguity, either in women's relationships to men or to other women. (1993:60)

Thus we need to be cautious when resisting and seeking 'freedom.' The idea of practicing freedom can be useful to feminists as long as they do not have a "utopian humanist" vision of complete and total freedom (Sawicki 1998:100). Grimshaw responds to accusations that Foucault is pessimistic about resistance and says, "this 'pessimism' is better seen not as a belief that no change is possible, but as a caution against the potential dangers and deceptions involved in certain kinds of Utopian optimism" (1993:59). Seeking complete freedom is unrealistic.

Lupton uses Foucault's idea of practicing freedom and the care of the self to better understand resistance in the context of medical consumerism. She explains, The doctor-patient relationship is a central site at which subjugated knowledges and the practices of the self play a major role in the interrelation of institutional and localized power. When consulting a doctor, individuals may, on at least some occasions, and if they so choose, attempt to struggle against, challenge or subvert those disciplinary techniques they experience as restricting their autonomy. (1997:105)

Fuqua contends that analyzing the consumption of prescription drugs is difficult since we often need these drugs to maintain our health (2002:668). She questions how much resistance one can exercise in possible 'life or death' situations. While I agree that the idea of choice becomes quite complex in this situation, choice and resistance are still 
possibilities. For instance, Irvine describes that the 'health consumer' emerged to challenge authoritative knowledge. ${ }^{32} \mathrm{He}$ explains that the 'patient' was redefined as the 'consumer' with the anticipation that they might have more power and thus more say and a better understanding with their own health (2002:32-33). The active, resisting, questioning, self-interested health consumer can be understood as a threat to the order and functioning of health institutions (40-41). In other words, it could be a threat to the production of, and power over, knowledge. Irvine explains that since the health consumer was understood as a risk, the term then got taken up by and manipulated by medicine. For instance, medical institutions attempted to set out norms about how the health consumer ought to act. They try to use the term to their advantage but attempt to create an illusion that they are advocating for and empowering consumers. There is evidence of this practice when observing the pharmaceutical industry - Depo-Provera is a good example of something which presents itself as empowering while endorsing normative and regulative behaviour. Irvine argues though that the possibility for resistance still exists with the health consumer, as long as they are aware and critical of whether or not the term consumer is being manipulated by others for purposes of disempowerment rather than empowerment (43).

Nava, who examines consumerism in general, advocates that we can be political through our consumption. She argues that those most often involved in consumer activism are women and younger people - these groups also make up major proportions of consumers in our society. Because of this, there is great potential to exert resistance.

\footnotetext{
${ }^{32} \mathrm{He}$ cites the 1960 s and 70 s as the time when the 'health consumer' emerged (2002:32-33).
} 
Although consumerism is pervasive and powerful, it is also vulnerable. ${ }^{33}$ She encourages others to realize the potential power of the consumer. She says,

It may well be the case that late twentieth-century Western consumerism contains within it far more revolutionary seeds than we have hither to anticipated. It has already generated new grass-roots constituencies of the market-place - and has enfranchised modern citizens in new ways, making possible a new and quite different economic, political, personal, and creative participation in society. The full scale of its power has yet to be imagined. (1999:62)

She examines the idea of freedom and consumption in a different way than the consumerist logic that Bauman explains. He discusses freedom as something that is assumed to be part of consumerism, whereas she frames it in terms of resistance to consumerism. Let us now turn our attention back to Bauman's work to analyze DepoProvera's utilization of this consumerist logic and how the women in this study understood the idea of freedom of choice.

\section{DEPO-PROVERA'S FALLACY}

\section{a) The Falsities of Freedom of Choice}

Bauman explains that with the consumerist logic, people acquire a sense of freedom when purchasing - they are free to be making choices (1988:59). He explains that "In our society, individual freedom is constituted as, first and foremost, freedom of the consumer; it hangs upon the presence of an effective market, and in its turn assures the conditions of such a presence" (7-8). Nettleton describes that health advertisements emphasize choice and present it in a way that aims to empower the consumer and reassure them that they are making the 'correct' choice (1997:208). Depo-Provera's website is illustrative of this consumerist logic. It promotes the idea that not only can the actual product provide women with freedom, but their choice to use it can be

\footnotetext{
${ }^{33}$ For instance, she cites an example that if there is something wrong or dangerous with a product or service, just one public incident could cause the entire company to go under (Nava 1999:61).
} 
empowering as well. As was mentioned in Chapter Three, Rose argues that we are encouraged to believe that we have freedom of choice - "modern individuals are not merely 'free to choose', but obliged to be free, to understand and enact their lives in terms of choice" (1999:87). We are encouraged to recognize exercising our freedom of choice as something positive and normative. Yet, is the consumer really empowered and free simply because they have the 'authority' to choose? Most of the women in my study were not convinced that being able to use Depo-Provera would provide them with freedom. Furthermore, they generally did not talk about choice in terms of freedom of choice; rather they discussed choice as something that was either 'good' or 'bad.'

The women who felt that choice was something good typically came to this conclusion based on the idea that this is the essence of choice - it is inherently something good. Miller explains that we have a tendency to believe that choice makes our lives better. We might like the thought of being able to exercise choice and for some, to show to others what we have chosen (1999:1129-1130). Undoubtedly choice can be a positive part of our lives, but is it inherently good? This is such a common way of understanding choice that it is difficult to conceptualize it otherwise. For instance, Chantal, when describing the choice of menstrual suppression as potentially bad said, “Um. (...) I never want to say choice is bad." There are times when freedom of choice could be understood in this way though. Miller dramatically attests - "To be able to choose - to inherit a culture of autonomy as the greatest good - may be, in certain circumstances, a calamity and a curse, like the mark of Cain" (1999:1130). Thus there are times when some people might not want freedom of choice. 
Carter contends that freedom of choice and freedom are connected, but are also distinct. You could have an increase in the one, but not necessarily in the other (2004:62). Miller further explains that sometimes we make choices but feel little freedom in the matter, for instance because we feel compelled to choose. He uses an example of his health insurance policy to illustrate how freedom of choice does not always lead to freedom. He says, "I wish someone with more time to choose wisely had just gone ahead and made that choice for me. In this case, real freedom to me would have been freedom from - freedom from the need to choose" (1999:1122). He attests that we can often be bombarded with too many choices and for some, this could cause one to "feel paralyzed" (1128). He questions if the idea of freedom is largely an illusion - maybe we are really not so free to choose, and maybe all of our choices are really not so great.

Several of the women in my study were concerned about how safe the choice to suppress menstruation with Depo-Provera is. They were hesitant to define it as a choice since they perceived it as a potentially flawed option. Hendersen and Petersen explain that health consumption is inundated with the idea of freedom of choice, yet they argue that all we are really presented with is "an array of predefined and limited options for action" (2002:2-3). Wacjman also expresses this concern when talking specifically about reproductive technology. She believes that the development of technology is politically and socially infused. She concludes that women's options are actually quite limited because most of the choices are driven by profit rather than women's well-being (1994:172). I agree that the pharmaceutical industry is profit driven, but there are likely researchers who might genuinely work in this industry to help others. Wajcman contends that feminists are divided about the issue of technology and empowerment. Some feel it 
is empowering while others feel it is disempowering. She explains that one feminist perspective to take is that women should be provided with ample information so that they can make informed decisions. The idea of 'informed choice' as empowering is interesting. Does 'informed choice' overcome the problem of 'bad' choices? Does informed choice give women more control and thus freedom? Or, does it burden them, for instance by responsibilizing them too much? Furthermore, how can we be thoroughly informed when the production of knowledge is dominated, in the case of menstrual suppression, by medicine and the pharmaceutical industry (Wajcman 1994:159)?

Alan Petersen (who draws on the work of Giddens), explains how trust and expertise are often a significant part of our decision-making. Freedom of choice implies autonomy, yet it is highly plausible that we depend on others with a large portion of our decisions (1997:197). Rakusen advocates that women be well-informed about DepoProvera but she feels that this is difficult to do when there is a lack of research and biased research exists. She also explains that it can be difficult to be well-informed when medical language can be difficult to understand. She says that women need to be critical of doctors and their expertise. In addition she says that we need to be critical of our own claims and truths and how they affect our decision-making (1981:97-98). JohnstonRobledo further urges that health-care providers endorse and help women to make informed decisions (2003:74). Medical knowledge and expertise can be daunting, yet it is still useful to try to challenge it. Perhaps the entire 'truth' of any given situation cannot be known, it is crucial that we at least be aware of this.

Others might influence how we make our choices. Choices can also be limited in the sense that others might actually constrain our choices - others might make decisions 
for us. This is particularly evident with medical consumption, which most often relies on the decisions of doctors or health-care workers. In her research Lowe found that women often feel that their birth control use is their own decision to make, and they can get very irritated with doctors who deny their requests (2005:369). Fuqua argues that general theories about consumption do not account well enough for the context of medical consumption. She explains,

if consumer culture scholars continue to define the consumer as the one who either directly buys the product, uses it or ingests it at some predetermined 'endpoint' of consumption, then how can this definition of the consumer be expanded to account for the other ways prescription drugs move through the various economic and cultural circuits? Although prescription drug advertising attempts to short-circuit this distribution process by appealing directly to consumers, the physician remains the prescribing agent. (2002:654)

The doctor is a potential barrier to one's decision-making - but how significant is this barrier? Several of the women in my study depicted patients as active medical consumers who can get what they want. They, as well as myself, are not convinced that a doctor is a substantial barrier to getting what one wants. Similar to other types of consumption - you can shop around (Lowe 2005:372). It might not be as simple as walking from store to store, looking for the 'best deal,' but if you really want a prescription, shopping around to different doctors could mean getting one's choice.

Would it be better to focus on consumer preferences rather than consumer choice? Does 'preference' eliminate some of the problems that arise with 'freedom of choice'? Keat advocates using the concept 'consumer preferences.' He says, "What is required of consumers, though is that they should know what their preferences are, and whether they have been satisfied by a particular purchase" (1994:29). Would it be helpful to explain that women choose to use something because they prefer it, not because this choice or use 
of the product frees them? Could 'preferences' overcome some of the problems that arise with the concept 'free choice'? Warde's comments,

Consumer free choice may not be such a profound instance of liberty, partly because more gross, or less image-directed objectives are integral to it. People also use consumption to exercise power, to express indifference to others and to manipulate social situations in accordance with personal ambitions. (1994a:66)

Freedom of choice is not straightforward, nor would 'preferences' be any clearer. Besides, preferences and choice cannot necessarily be detached from one another like this. For instance, some women might prefer to stop menstruation, but might not actually choose to do this in practice because of perceived costs. It is necessary to now focus more on the implications of freedom being limited, or coming at a cost.

\section{b) Consuming Norms: Regulated Empowerment}

Only one woman in my study felt that Depo-Provera could actually offer her freedom.

Depo-Provera's promise of freedom is rejected by the rest of the women. Several of the women felt that choosing Depo-Provera would not empower them because they would be using a product that implies that there is something flawed with their menstruating bodies. Others felt that choosing Depo-Provera could not lead to freedom because of the potential health costs (side effects as risks, unknown safety about the drug or menstrual suppression). A few of the women also expressed that they could not be completely free with Depo-Provera because using it necessitates self-regulating one's body. We can recall Rose's thesis that we are encouraged to self-regulate through the idea of freedom. He argues that regulation and freedom cannot be separated and that they saturate all spaces of our lives. We cannot be entirely free. Gastaldo uses health education as an example to illustrate the idea of instead, simultaneously feeling a sense of freedom and regulation. She says, "no educational process can only liberate because at the same time it disciplines 
bodies. Therefore, health education is seen here as both empowerment and subjugation." (1997:130). Likewise, several of the women in my study understood menstrual suppression as potentially both regulatory and empowering.

While many scholars depict self-regulation as something negative, as Rose explains, socially it is most often purported as positive. We are told from our government, our economy, our bosses, our schools, and so on, that a well managed, selfregulated individual is strong. Rose would argue that governance has been effective if one believes that self-regulation in accordance to social norms is positive. But what if one genuinely understands this type of self-regulation as something positive? Moreover, what if this normative behaviour causes one to feel a sense of freedom? Tova Hartman and Naomi Marmon examine how Orthodox Jewish women deal with menstruation. Jewish law treats menstruation as pollution, thus the women are pushed to regulate their bodies during this time. Some of the women felt severely regulated while others felt a sense of happiness through their self-regulation. For some, they enjoyed complying with the rules (for example, no sex during menstruation) (2004:404-405). Fingerson points out that even when conforming, there is the possibility for agency - conforming might be what one wants to do (2005:98-99). No doubt, there can also be personal benefits from selfregulation, for instance with regulating 'good health.' It is difficult to grasp promoting healthy behaviour as negative if one's self-regulation is causing them to feel better about their health and body. Concerns arise however, about why someone might engage in this behaviour (because they want to or because they feel they ought to) and how much they do as well (is it something that they are generally aware of in their everyday routines, or is it something that they continually focus on and feel inadequate if they let it slide?). 
Rose argues that those who conform are 'praised' and are dubbed a 'good citizen' (1999:87). Freedman, when discussing dieting is concerned about whether or not this type of behaviour is empowering. She says, “The line between strategic practices and internalized oppression is not always clear" (2002:225). Indeed, it is difficult to sort through the idea of self-regulation as either 'good' or 'bad,' or, to assess whether someone's sense of freedom is real or an illusion. It is difficult (and potentially problematic) to tell someone, like Carla, who thinks that Depo-Provera could provide her with freedom, that her feelings might be erroneous, that maybe she is really just being exploited.

Although modern freedom has a focus on the individual, the ultimate goal or purpose is for the whole of society to function properly (Bauman 1988; Rose 1999). Thus while people might feel free or regulated with their individual behaviour - it is difficult to invalidate how people feel, it is not as difficult, I find (and perhaps wrongly), to judge more harshly the broader social outcomes and repercussions of people's actions. Ivison contends that we need to be cautious about normalized behaviour, as normalization is undeniably tied up with power. He says,

For Foucault, building on the work of Georges Conguilhem, the value in the name of which modern normalization has been most concerned has been the welfare of a population. Thus, an alternative account of the ties that bind modern political communities can be told according to this normalization thesis, focusing on the definition, elaboration, and promotion of a population's welfare. Citizens, in other words, are said to be 'formed and normed' in relation to a particular conception of welfare, along with related conceptions of sociability and political order. (1997:35: emphasis added).

Both Foucault and Rose are not overly concerned with whether or not people's sense of freedom is real or an illusion. Instead they are more concerned with asking about why we think and act in ways which take freedom into account. Furthermore, it is important to 
ask how power is a part of our understanding of freedom and its role in our lives (Rose 1999; Ivison 1997).

Is it useful to differentiate freedom from empowerment? Does the concept of empowerment allow us to focus on how individuals feel, while leaving 'freedom' to describe something broader? Riordan would warn against doing this. When examining the 'girl power' movement in the $90 \mathrm{~s}$ in the US, she says,

Over the past decade, the rhetoric of empowerment in the United States has been commodified in popular discourse and in self-help literature (much of which is aimed at women), thereby confining agency to an individual level and not contributing to structural transformations that will indeed change the lives of women living within patriarchal and capitalist structures. Collective transformations cannot occur if individuals only work to make themselves feel better. (2001:284:emphasis added)

Riordan argues that women could feel more empowered if they acted in non-normative ways. She says, women must be able to recognize "what is a feminist project originating from feminist roots and what is feminist rhetoric being packaged and sold by media industries and bought by a large number of young women" (2001:295).

If women who use Depo-Provera feel a sense of freedom, does it matter if this personal freedom is recognized or not on a broader social level? Must one also achieve social freedom in order to be free? Or, must one engage in collective pursuits of freedom? Foucault's care of the self is intended to be an individual project of freedom not one that necessitates social acceptance and freedom. Yet he does explain that if people take care of themselves, society will function more smoothly (1984:287). McLaren thinks that one's self project ought to be conscious of and geared toward social and political change (2002:161). This is not what Foucault's care of the self is intended to do though. Perhaps Foucault advocates practicing freedom at the level of the individual because he is so critical of the possibility of social freedom. Again, it is also relevant to 
consider that his project on freedom regarding the care of the self is a contextually specific analysis. He did not aim to (or would ever want to) develop a theory of freedom. It is difficult to answer questions about if freedom ought to be something that is a personal or collective project, or both. Tackling this is beyond the scope of this thesis. I think that for this contextually specific project on stopping menstruation, it is relevant to examine freedom as something that is both an individual and a social act. Perhaps Foucault's care of the self needs to be abandoned at this point for this project, as my understanding of women's self-regulation is strongly connected to and influenced by culturally normative codes of conduct. I think that examining our self projects requires more of a consideration of social influences and implications than Foucault's care of the self affords.

\section{III. 'FREEING' WOMEN}

\section{a) Why Stop Menstruation Now?}

The women replicated normative sentiments when they described menstruation as a nuisance and something that is inconvenient. They also echoed normative sentiments when they described monthly menstruation as natural and necessary. Again, many of them want to stop it but feel conflicted, as they are afraid to do this since we are taught that it is something natural. Although medicine and culture are strongly connected - is there a slight disconnect going on here between the cultural idea that it is problematic and the medical idea that it is necessary? The common usage of the pill to regulate menstruation does validate the cultural norm that it is inconvenient. The pill offers the potential for predictability, less bleeding, and less pain. It offers the possibility of a wellmanaged body. No doubt negative cultural norms do influence how medicine constructs 
menstruation as problematic and that it is beneficial to regulate it. But why not ally cultural and medical norms even further? Is it possible that, in part, because of technological advancements, that our norms about the value of menstruation and our norms about its necessity are starting to align more clearly? In other words, if menstruation is culturally depicted as such a hassle, then why not shift the medical truths to define menstruation predominantly as unnecessary?

Andrist et al. describe how the pill has always had the capabilities to stop menstruation, yet the producers of the drugs and doctors, felt that society and women were not ready for something like this (2004a:31). Why are truths about monthly menstruation as not necessary starting to emerge so strongly now? This is not just a cultural, medical, or technological shift. All of these are connected. Thomas and Ellertson argue that perhaps the idea of menstruation as natural is a myth and something that we have been socialized into believing. They question if this belief stemmed from a time in which it was believed in medicine in general, that bleeding was good and healthy (bloodletting). Furthermore, they question if everyone just settled for this truth about menstruation because there were not many options in the past for regulating or stopping it (2000:922).

Is menstrual suppression simply more popular now because the drugs that can do this recently got approved and therefore more people think that these drugs are relatively safe, as well that more people use them and the increased usage is shifting and challenging our norms? Were the cultural norms there all along but the technology was not? Wajcman argues that rather than just trying to understand how technology influences politics and the political, we need to understand how "technology itself is the product of 
political forces" (1994:154). We need to reflect on a broader context when attempting to comprehend why certain technologies develop while others do not.

Wajcman asks - does technology change society - or does society change technology (1994:154-155)? I question, if several decades from now, medical truths about the necessity of menstruation will shift because of social and technological influences. I suggest that 'normal' menstruation will predominantly mean something that is suppressed and unnecessary. In her Maclean's article, George describes the option of menstrual suppression as a "cultural upheaval" (2005:41). What might facilitate this kind of change? Our current negative cultural norms about menstruation are a safe place to start. Also, perhaps the idea of the 'modern woman' having a very active, busy life might lead some to believe that life will just get increasingly busier and we need not deal with menstruation. Possibly there is an increased acceptance of using prescription drugs in our society, particularly for lifestyle reasons. Maybe as these drugs are around longer (assuming no major health hazards occur), women will come to accept them. It is possible that, just as some women appreciate using the pill because they became dissatisfied with managing their menstruation only with pads and tampons, that maybe women will become dissatisfied with symbolic monthly bleeding with the pill as well. Furthermore, perhaps stopping menstruation will increasingly come to be recognized as a right that women feel they ought to have.

There are of course many things that could derail this shift to a non-menstruating society. For instance, maybe women, like in my study, will not conceive of the idea of stopping menstruation as something positive and freeing. Also, the practice of menstrual suppression would not likely become very popular if major studies came out to prove that 
stopping menstruation or using the drugs that can do this is very unsafe (although, DepoProvera is currently quite popular amidst debates about its safety). Another possibility that could alter this potential future shift is if cultural norms about menstruation became more positive and accepting. Many of the women in my study thought that society is becoming increasingly more open toward menstruation, as well as increasingly more positive. Why then, has the idea of stopping menstruation gained such popularity? I concur with Martin who says - "It is difficult to see how our current scientific ideas are infused by cultural assumptions; it is easier to see how scientific ideas from the past, ideas that now seem wrong or too simple, might have been affected by cultural ideas of an earlier time" (1987:27).

\section{b) Striving for a Society without Menstruation}

I asked the women in my study, how they thought that the topic of menstruation would be treated in a society in which it was abnormal to menstruate. Many of them were surprised and bothered by this question, possibly because it caused them to have to challenge their current understandings of normality. For some, it was an extreme shift to conceptualize. I asked them this question because I wondered if Depo-Provera became incredibly popular, would this push the topic of menstruation into non-existence, or would it normalize the topic because it was more controlled and thus perhaps people would be more comfortable with it? Interestingly, the women's responses included these two possibilities.

The majority of the women felt that the topic of menstruation would become increasingly silent, negative, and less accepted. For instance Robyn described how menstruation would become increasingly taboo. She said,

I think that it would become even more negative, even more taboo to talk about it. It's like - ((mimicking) ) 'why are you even talking about it? Why do you do that, 
you know, you have a choice, you don't have to do this, it's yucky, it's gross, why can't you be like so-and-so who doesn't have it anymore?'

It is interesting how Robyn highlights 'choice' in her response. Melissa also expressed concerns about the subject of menstruation going into non-existence and mentions how menarche could be the start of this practice:

it wouldn't become a topic at all. It would - if it's not around for the majority of women then I don't think it would be (...) even a thought for most people. I mean, you'd get your period that first time and they'd be like ((mimicking voice)) 'oh! Time for your shot! You won't get it ever again!' So (...) it would become society - to not have it.

Many of the women felt that our social situation regarding menstruation would worsen.

For example, Liz described how the physical absence of menstruation could lead to its social absence -

I don't think it would get better - if less people were menstruating, why would they talk about it more? They might talk about how to stop it - NO! I think it would be - I think you're saying like it's a bad thing. I think you'd be taking drugs that can stop it - you're sending out a message that's saying like it's a bad thing but ((mimicking)) 'hey! Here's a pill that can stop it!' (...) 'Don't worry, like blood comes out of you every month but oh! Here's a pill, we can stop it! we can stop it - let's take a pill take a pill TAKE A PILL!'

She drew particular attention to how menstruation would be over-medicalized in this society. As well, she articulated that stopping menstruation does convey and validate the normative cultural messages that there is something problematic with our bleeding bodies.

A couple of the women considered the possibility that increased regulation and control over menstruation could lead to positive social changes regarding our cultural perceptions. For instance, Kim wondered,

Kim: I think you could almost argue that it would go back to the way that is was - that it was sort of hush-hush and something to be ashamed of, (...) umm (...) although, if - because the lines of communication or - or the topic of Depo were to be as talked 
about as say menstruation is now, then I guess, there wouldn't be much fear of that, but (...) I guess it would depend on - on sort of if you just forgot all about menstruation or never talked about it again.

Emily: $\quad \mathbf{m m}$

Kim: I mean I definitely think it would be a danger of it becoming 'a secret.'

She was hesitant to predict that the outcome could be positive. Joyce stated more confidently that the topic could be more accepted if menstruation was more controlled. Again, this was something that I had considered before. In our society, we tend to regulate and push for self-regulation of that which is perceived as out of control. Women's bleeding bodies are typically depicted as something that needs to be managed as something uncontrollable. Both Oinas and Martin discuss how the body came to be seen by some as a machine. Oinas says - "The machine metaphor has one crucial consequence: the machine has to be under control. A machine out of control is a disaster in the cultural imagery of industrialised societies" (1998:64). Martin explains that this machine metaphor stemmed from the industrial era. It emphasizes that if our bodies are working properly - than our social order will generally follow in such a manner (1987:19-20). Like Joyce, I speculate, that if there is increased control over menstruation, then this could remove the idea that it is uncontrollable - this could allow us to be more comfortable with the topic. One problematic aspect of this proposal is that it relies on the premise that we only stigmatize menstruation on the basis of uncontrollability. Furthermore, it assumes that menstrual suppression redefines the bleeding body as controlled, when it is plausible that the practice of menstrual suppression could further emphasize the bleeding body as something uncontrollable. 
In Chapter Two, I asked - if the idea of menstrual suppression were to eventually become widely accepted, does this mean that women who fail to stop menstruation will become pathologized and perceived as lacking control over their bodies? I questioned if the 'menstruators' would be seen as irresponsible menstrual managers in comparison to the 'non-menstruators.' I asked the women in my study how they thought that the 'minority menstruators' would be treated in a predominantly non-menstruating society. All but one of them felt that these women would not be treated well. Tamara did not think that women who decide to continue to menstruate would be treated as "black sheep." She thought they would only be treated differently if the pad and tampon industry went under.

The rest of the women felt that those who do not stop menstruating in the nonmenstruating society would be questioned and looked down upon. They felt that the 'minority menstruators' would have to continuously defend themselves to others. Laura thought that perhaps these women would be labeled as "outdated" or "hippy-ish." Liz considered this scenario in the context in which a mother might not want her daughters to stop menstruating, but all of the daughter's friends were. She said, "she [one of the daughters] would feel out of the ordinary right? Because her body's like, doing something natural - she would feel unnatural. That's a concern! Ooh!" The shifted definition of what is normal and natural in this hypothetical society bothered her. Sheila also thought that young girls would be pressured to stop menstruating if this was the norm. She wondered if the decision would really be a choice then. Typically Sheila had connected choice and control together when talking about stopping menstruation, but with this scenario, she linked choice to a lack of control because of the consequences of not conforming. She said, 
Sheila: I think that - that it would be talked about even less and that umm, even like companies, such as like Tampax and stuff, umm, it - it'd probably be harder to like, or maybe more - maybe more

expensive to, if you were the one of few menstruating

Sheila: $\quad$ it'd be like - it would almost seem as if it was forced on you to adapt towards society and to not menstruate

Emily: $\quad$ hmm

Sheila: because, now you're like a minority instead of the majority and they don't usually care about minorities in society.

She illustrated that part of the exclusion of these minorities could come from

consumerism - the traditional 'feminine hygiene' market as we know it, would dwindle it would not be the market for controlling menstrual bleeding.

Chantal predicted that in this non-menstruating society, only poor people would continue to menstruate as they would not be able to afford Depo-Provera. She said that these women would have to hide their menstruation, but for a different reason from what we are used to. Furthermore, she suspected that those who could afford Depo-Provera would see menstruation as "dirty" and would equate poor women with dirt. Laws describes how beliefs about pollution and dirt "define according to the dominant ideology, what is 'matter out of place' ... the idea that people with certain characteristics are dirty is very often found as part of the attitudes of a dominant group towards a less powerful one" (1990:36). Chantal's prediction is interesting - yet what about DepoProvera's history of targeting poor women around the world? This was done for 'family planning' reasons rather than to suppress menstruation. It is difficult to imagine that Depo-Provera will stop targeting these women - thus it is possible that many less affluent women will also stop menstruating.

What are the implications of the 'minority menstruators' not engaging in this proposed menstrual suppression market? Women might not consume these drugs because 
of a lack of resources, because they would encounter serious health risks if they used the drug, or they might act in this way as a means of resistance. Bauman explains that with the consumerist logic - you are either 'in' or 'out' when it comes to consumption. He describes that this ideology advocates that we see ourselves and others through the lens of consumption -

The insiders of the consumer society think of the outsiders sometimes with fear, sometimes with deprecation; with pity, at best. In a society organized around consumer freedom everybody is defined by his or her consumption. Insiders are wholesome persons because they exercise their market freedom. Outsiders are nothing else but flawed consumers. (1988:92-93)

How do we know though, which women have used these products and have stopped menstruating? How would we know which women have 'freed' themselves and which have not if the consumption of this drug and its effects are private? Would we as a society still hold on to normative conceptions of women's bodies as cyclical and potentially problematic? If menstrual suppression became popular enough, would societal norms regarding menstruation shift and we would just assume women were stopping it?

\section{c) Who Benefits from 'Freeing' Women?}

If women feel freed, is this only a personal achievement rather than a social transformation? Or, will their behaviour contribute to eradicating these negative norms because of the 'disappearance' of menstruation? Several of the women in my study are worried that Depo-Provera is sending out a message of regulation and problematization, not one of freedom. Can menstrual suppression really bring about meaningful social changes for women or will their behaviour simply be reinforcing and strengthening negative social and cultural norms?

Laws contends that males gain from menstrual management. She argues that men benefit because women are more 'free' to have sex with them more often if they are not 
bleeding. She says, "Men's concern is that women should be 'free' to have sex with them - not that women should be free at all times to determine their own behaviour" (1990:128). This is a very bold statement to make about men's perceptions. Furthermore, women do not manage menstruation only for males, they manage it around other women as well. Wajcman, when talking about reproductive technologies, argues that "If technological innovation is a product of the society which gives rise to it, it follows that technological outcomes of a society structured by gender inequality will reflect this bias" (1994:154). She suggests that if women were largely involved in the development of technology, then "we might have a radically different set of choices" (172). Perhaps we would. One must acknowledge though that women have oppressed each other before and unfortunately will continue to do so. Furthermore, just because women develop the technology, this does not necessarily mean that women know and can accommodate what all women want. These concerns aside, I do appreciate Wajcman's outlook of having more women involved in the production of knowledge about their bodies.

It is interesting to ask who benefits from stopping menstruation. Certainly some males will and some females will. It is more problematic to ask and answer - who do we blame if this practice of stopping menstruation is actually a regulatory effort to control women's bodies? Bauman argues that there are so many points of power and authority in our society (either structured or unstructured) that often those who are not free do not know precisely who or what to blame. Often "social oppression" is blamed (1988:50). Ivison is also concerned that 'power' is not a straightforward enough concept to easily deduce, on a social scale anyway, who is to blame. He attests that "Power exists when it is put into play, and the exercise of power is a way in which certain actions modify 
others. Power does not necessarily act immediately or directly on others; it acts in their actions, whether currently existing ones or those that may arise in the future" (1997: 3031). Again, Foucault suggests that understanding power goes beyond trying to figure out who possesses it. He says, 'I don't believe that this question of 'who exercises power?' can be resolved unless that other question 'how does it happen?' is resolved at the same time" (1978:103). Like Foucault, I think that if we are going to attempt to lay blame, trying to sort this out cannot be done hastily. Trying to ascertain why menstruation is depicted so negatively and why women's bleeding bodies are problematized so thoroughly is horrendously complex. There are numerous, historically contingent possibilities as to why women's bodies are socially constructed in the way that they are. We ought to recognize that our answers about blame should potentially be recognized as tentative. 


\section{CHAPTER SEVEN: \\ CONCLUSION}

Multiple facets of society engage the promotion of regulating menstruation - physically, socially, psychologically, and even spiritually. Menstruation has for a variety of reasons, and for a variety of women, become a project of self-regulation. The approval and widespread promotion of hormonal contraceptives that can lessen or stop menstruation provide women with more choices concerning how they could manage menstruation. While this is advertised as a self-project of freedom, it is also one of regulation, which has implications beyond the individual woman. Depo-Provera encourages women to seek freedom by engaging in bodily management in accordance with negative social norms. Although one woman felt that the product could provide freedom, it is apparent that Depo-Provera does not free women from having their bleeding bodies problematized, at least certainly not at the social level. Women who use or support the drug may not believe that there is something inherently wrong with their bodies, yet this is the message being sent out. As has been discussed, rather than freeing women from social stigmas by eliminating menstruation, it is conceivable that these drugs further reinforce cultural conceptions - they offer a more extreme way to self-regulate which insinuates even more so that menstruation is an impending hazard in our everyday lives. Rather than trying to manage bleeding with pads or tampons, drugs like Depo-Provera (if working as promised) eliminate the risk of leaks, smells, and discarded wrappers (the evidence of bleeding). These drugs offer superior menstrual management. Undoubtedly this will be seen as a positive, empowering thing for countless women. I do not mean to devalue the sense of choice and control that women could feel. I just want it to be recognized that there is more going on here than a liberatory project. This behaviour is also regulatory. 
The women's views on menstrual suppression were quite conflicting. The topic becomes even more convoluted in the context of doing this with Depo-Provera. Working through such a complex subject does not generally produce 'either/or' answers - meaning it is not simply 'good' or 'bad' to stop menstruating for most of the women. It is complicated. Concerns about advertising, health, what is natural, what is normal, what is desired, what women might be conveying about their bodies, and what freedom is, all arise. These are not straightforward matters to deal with. Most of the women had mixed feelings and rightfully so. They were conflicted by truths that monthly menstruation is something natural that they ought to accept (because they believe it is healthy and that it is important to respect their bodies) and that it is also problematic and something that needs to be controlled and regulated via hormonal drugs. A fascinating way of coping with this dissonance, for many, was by embracing the symbolism of monthly menstruation. Furthermore, many of them developed what they felt to be good justifications for why they have, or might, bend their truths about stopping menstruation. Only some of the women were acutely aware of how malleable their truths are.

For most of the women, Depo-Provera's truth about monthly menstruation as unnecessary clashed with their own personal understandings. Undoubtedly connected to this, most of the women were also not able to fully embrace Depo-Provera's promotion of freedom. To answer my research questions posed in Chapter One, Depo-Provera does have the potential to provide women with a sense of personal freedom but this must be recognized as necessarily coming along with regulation, and must be recognized as a potentially exploitative effort. I, and many of the women in this study, argue that this self-regulation does not simply limit women in the sense that they are engaging in this 
behaviour (which takes up time, there could be health risks, etc.), but it also limits them in terms of the implications of this behaviour - in terms of engaging in something that validates the normative idea that there is something wrong with their bodies. Thus while one might personally feel freedom from using Depo-Provera, on a broader social scale, I argue that this drug cannot free women. Indeed it does have the potential to be socially transformative - definitions about normality, naturalness, and health could shift - but as I have suggested, a transformation such as this will likely build off of negative cultural values, rather than eradicate them.

Part of my goal with this project was not only to examine how women feel about stopping menstruation but to also explore and raise some theoretical ideas about the concepts freedom and regulation. Bauman's work enabled me to examine the relationship between consumerism and freedom and to challenge the prevalence of the consumerist logic in our everyday lives. This consumerist logic did not completely play out as it ought to (as Bauman suggests it often does not), when I examined the Depo-Provera website and the women's responses to the idea of choice. In addition, Rose's work is useful to articulate the idea of governing through freedom - encouraging people, under the guise of freedom, to self-regulate in a way that contributes to social order. When trying to sort through this normative behaviour that is being promoted, it is useful to turn to Foucault's work on power and resistance. Although there are pervasive cultural and social norms about menstruation, and although these influence the construction of knowledge and truth that medicine and Depo-Provera presents, the women in my study do not necessarily buy into this - resistance is also part of our everyday lives. He encourages us to be critical of utopian promises of freedom and instead suggests practicing freedom, for instance 
through the care of the self. The ideas from these theorists cannot simply be extracted from their work and be nicely applied to this project. Inconsistencies did arise, but these need to be appreciated, as they help to further work through these abstract ideas of regulation and freedom. I agree with Rose who contends that "concepts are more important for what they do than for what they mean. Their value lies in the way in which they are able to provide a purchase for critical thought upon particular problems in the present" (1999:9).

\section{LIMITS OF THIS STUDY}

Depo-Provera is generally recognized as a debated drug, primarily in terms of safety. Again, the academic literature on the debate about menstrual suppression and DepoProvera is limited though. Since it is such a contentious drug, does this mean that my findings are skewed? For instance, if a lot of the women in my study were aware of this debate and were aware of safety concerns, does this lead them to be less open to the idea of menstrual suppression? It is possible that if I were asking women about stopping menstruation in general, or if I were asking them about a different drug that can suppress menstruation that I could have had different findings. Other drugs that can stop menstruation would have similar safety concerns as well though. Rakusen, who is quite critical of Depo-Provera cautions that

to single out DP as dangerous can lead to confusion. It tends to result in DP being labelled the arch-villain, eclipsing the known and as yet unknown dangers of other methods, including female sterilisation, while at the same time the problems of who controls research, promotion, and information, etc. remain. (1981:99)

While I intended to study the concepts of freedom and regulation, and women's attitudes toward menstruation, I did specifically want to study the drug Depo-Provera. Its history is 
fairly well-researched, it has been around for several decades, and it has been approved for more than just a couple of years. As well, the idea of freedom is explicitly worked into the marketing campaign for this product. Furthermore, I wanted to examine this drug because one of its developers - Coutinho - poses an interesting challenge to how we typically define the necessity of monthly menstrual bleeding.

It is important to reiterate that my research sample was not intended to be something that I could generalize from. The sample was very homogenous - university educated, white, young women, living in (and for many growing up in) a specific geographical region. My findings could have turned out differently if the sample was constructed more randomly. In addition, the women who volunteered for my study were very comfortable speaking openly about contraception and menstruation. It would be interesting to know how women who are less comfortable with these topics would feel about menstrual suppression. This of course would require a different methodology to garner voluntary participation. Perhaps a survey would be useful in this case, as it would afford more anonymity (yet could come at the cost of detailed responses). It is also possible that different findings could have emerged if more of the women in my sample were using Depo-Provera. It would be interesting to conduct another study in which only Depo-Provera users were asked about menstrual suppression. Perhaps more of these women would understand the product as actually providing them with freedom.

There are other directions that future research on this topic could take. For instance, it would be valuable to further explore the historical connectedness of DepoProvera and race, and to examine how racialized scripts transpire even today with the administration of the drug. Our current understanding of menstrual suppression might be 
furthered as well by carrying out an analysis of media debates over the past several decades. This could highlight if concerns about stopping menstruation have changed, as well as if concerns about particular drugs have changed dramatically or not. Furthermore, our knowledge about Depo-Provera and attitudes toward stopping menstruation could expand greatly if a diverse assortment of women were asked how they feel about it. For example, I only spoke with women between the ages of 18 and 25 . I am curious to know what adolescents, women in their thirties and forties, and menopausal women think about menstrual suppression. It would also be beneficial to examine the attitudes of health-care providers. Moreover, it would be interesting to explore how males feel about menstrual suppression. There is clearly a lot more that could be explored than what I was capable of doing for my project. My findings need to be understood as tentative.

\section{DEPO-PROVERA - A UNIQUE REGULATOR?}

As has been illustrated by drawing on the work of Rose, Foucault, and Bauman, regulating through the idea of freedom is not unique. Bauman reinforces that "freedom in our society is simultaneously a condition indispensable for social integration and systemic reproduction, and a condition continuously recreated by the way society is integrated and the system 'works'" (1988:7). 'Freedom' is so often promoted in a way that aims to maintain social order. Embracing that kind of 'freedom' is unlike what someone might feel or experience if exercising resistance of that which is culturally normative. The first conception of 'freedom' is tied up with power while the second is a challenge of it.

Depo-Provera's marketing presents itself as inscribing women's bodies in a new way - as free, liberated bodies. I have shown, however, that this is illusory. Depo-Provera 
is just another way of encouraging women to manage their bodies in socially desirable ways. It is an extension of medicalization - it takes up and relies on medical knowledge that constructs women's bodies in a particular fashion. Thus it is also an extension of cultural norms. Furthermore, in terms of consumerism, Depo-Provera is an extension of the feminine hygiene industry. Rather than understanding it (and other drugs that suppress menstruation) as something that has the potential to diminish or abolish this currently flourishing industry, it needs to be recognized as an extension of it. The feminine hygiene industry is about managing bleeding in a socially appropriate manner, and drugs like Depo-Provera, are increasingly commodified and are simply the 'next best thing.' The increasing popularity of Depo-Provera merely provides a new space in our society to reinforce what medicine, technology, and consumerism already say - that women's bleeding bodies are flawed and disruptive to all if not managed 'properly.' I have shown that what is 'proper,' shifts. For instance, if we understand monthly bleeding as necessary then the proper way to manage this is through pads or tampons, and for many through hormonal contraceptives like the pill or the patch. If we come to eventually understand monthly menstruation as unnecessary, than the proper means for management would become drugs that eliminate bleeding. 'The social' defines and promotes ideas about how we ought to live our lives - from how to be a productive, hard-working citizen, all the way down to how one ought to handle the menstrual blood that comes out of their body.

Menstruation, while a terribly private experience, is clearly not exempt from standards of social civility. How do we break free from having our bodies problematized in the way that it is though? How can we shift standards of social civility to respect 
women's bodies rather than respect the control of women's bodies? Moreover, how can we overcome defining the normative civilized body as only that of the healthy, white, male? I wonder, what do we do with this topic of menstruation? This bodily function? This cultural symbol? Thankfully we do have agency and the potential for resistance exists in every space in which there is power - thus according to Foucault, we can dare to resist everywhere. Yet doing this in an effective, meaningful way is quite mind-boggling. If medicine, consumerism, and technology are all implicated by cultural norms, then perhaps addressing cultural values is a reasonable place to start (although one could not only challenge cultural values). If we could shift the cultural conception of menstruation to something more positive, would this then allow for changes in other institutions, as well as in our everyday lives? If that is a possibility, the next challenge becomes what should this new notion of menstruation look like? Lander cautions that embracing menstruation completely could cause more problems than good. She says, "the menstrual glorifiers ... are so detached from the political - and the historical - that they have blindly constructed a political trap and have backed into the arms of the resurrected Victorians of the New Right" (1988:126). She is concerned that accepting menstruation as a part of being a woman insinuates too heavily the idea that women's biology determines who they are. I do think that cultural norms about menstruation need to become more positive, yet I do not know how this should actually happen in practice, or how much we should embrace it as part of who we are. Menstruation does mean different things to different women and thus their acts of resistance might play out in diverse ways and for various reasons. Furthermore, not everyone disagrees with the normative depiction of menstruation and not everyone wants to be political. It is also quite possible 
that women do not care about, or pay attention to, Depo-Provera's marketing and whether or not they feel a sense of freedom if they use the product.

I offer no solution here for how to positively shift cultural values about women and their bodies, which have been developing for centuries. This is without a doubt, beyond me. Certainly there can be unfavourable aspects of menstruation, it can be painful, it can be messy, and it can get in the way, but we need to be aware that these ideas are normative and that quite often they are exploited and used against us. We need to be aware that gender inequality can be a large part of the structures which create knowledge about us and our bodies - inequalities are part of those institutions which aim to help us. We need to be critical of those who promise us freedom and to question what is actually being requested and why. It would be valuable to teach girls while they are young, and in a way that they can understand, that what we are told about our bodies needs to be questioned and talked about. Our culture is malleable and positive change is possible. I am aware that much of this sounds idealistic - but in the predicament that we are in - facing immense cultural norms about menstruation and more broadly gender, facing medicine, and a multi-billion dollar a year pharmaceutical industry - what else do we have if not an idealism and hope that we will increasingly continue to find these spaces of resistance that so many theorists advocate exist? 


\section{APPENDIX 1 \\ DEPO-PROVERA WEBSITE EXCERPTS \\ Depo-Provera. Freedom from the everyday}

\section{Dapo-Prowerar \\ Contraceptive Injection

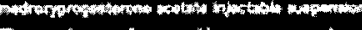 \\ Freedom from the everyday}

The Depou.Provera advantage

How Depo-Provera works

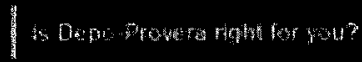

What to expect

Important patiant intormation

\section{Ask Dr Arias}

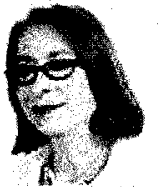

We Decoprovera etlecimy ontods?

Are there zav side oftack?

Can luse Depo-prowere enter bavinatabar

Click below tor more FAOs:

Thinking sboul Depo-Prowere? DAreedy using Depo Prowere?

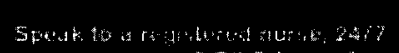
$1-866-554-D E P O(3376)$

\section{Is Depo-Provera right for you?}

If turth controt that fits inte yom the
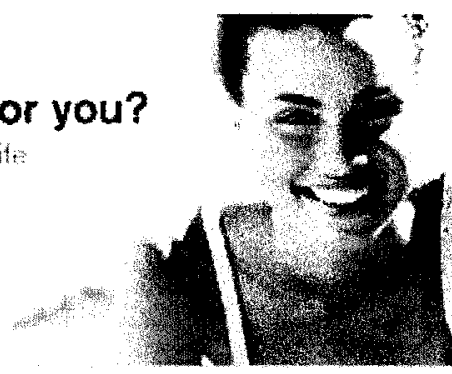

Is it a butden to take your pill every day?

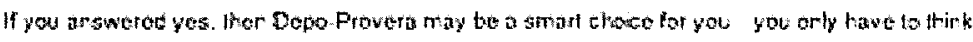
about 4 tines a year

- You just get a cose every 3 marths, are youre protectet

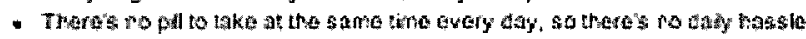

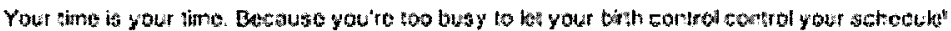

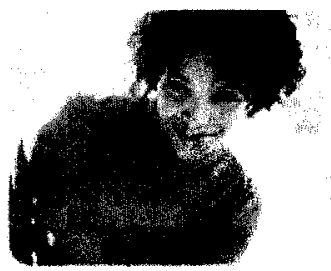

Wh Depo-Provera, you have the freedom to:

- Think about birth controu just 4 times a vear. not 365 times

- Have lighter periods or no periods at all

- Feel confident your birth control is working

Have you aver forgotten your birth control and worried?

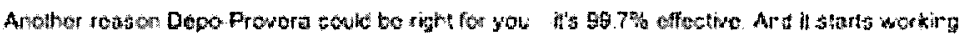
immodialoly."

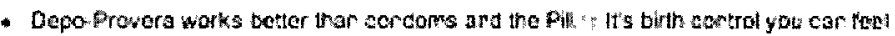

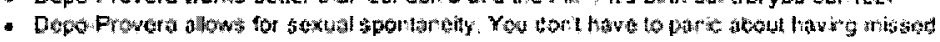
3 pil or far yout cateh has come boso

As kry as you get each doso on time, you car foel conficont that Depo Provera s workiry. Wh Depo Prowa there's ro dahy haste pst waty contederce.

Does a lighter period, or no period at all, appeal to you?

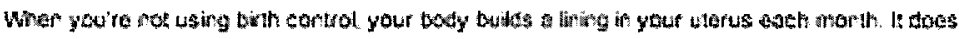
this to precare for preprancy. If you tont pot pregrant. your body feleases this lwirg. That what we krow as a period. Wht Dopo Provera. your body coesnit buld this frirg or butes orly a wery thin are. So theres simply littice or ro lining to be reased. some womer may loel fraed up by having a lighter now of no proriot. 
We'll remind you!

Tell us the date of your next dose. and wo til send you a reminder mail.

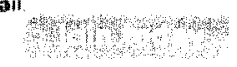

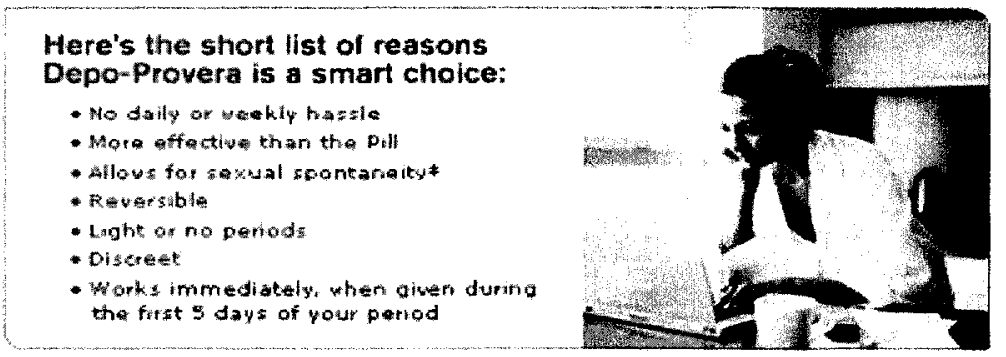

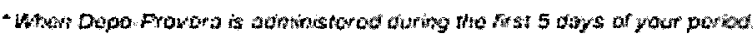

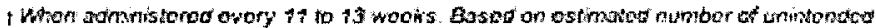

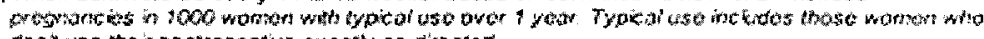
tont use ho contracopho axach as diroctod.

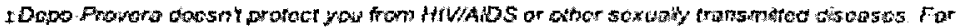

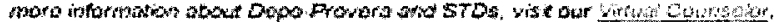

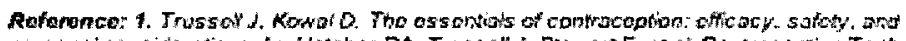

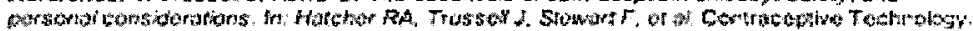
Thth od. Now Work. NY Arcent Hodia $1906.217 \cdot 247$.

Uso of Dopo.Prowora Controcoptlyo injection may cjuso you to lose calcium stoned in your bonos. Tho longar you usp Dapo-Provora

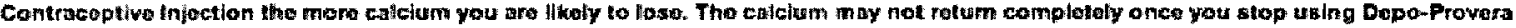
Contraceptive injection.

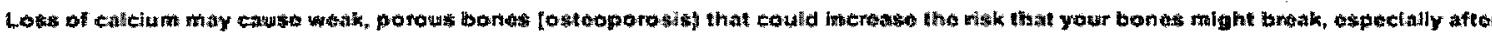

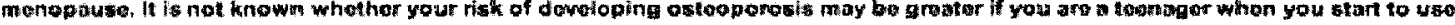
Dejo-Provera Contraceptivo injoction.

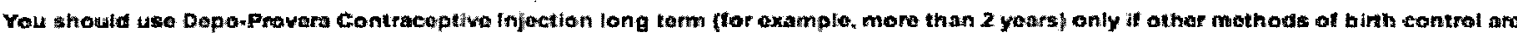

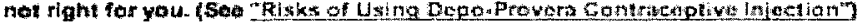

\section{Dopo-Provera Contraceptive Injoction doesn't protect you trom HiVialos or other Boxually tranametted diseasos.}

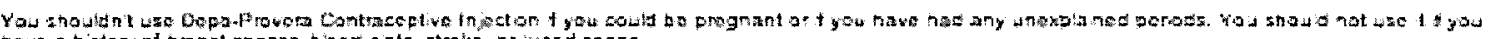

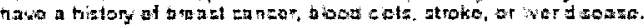

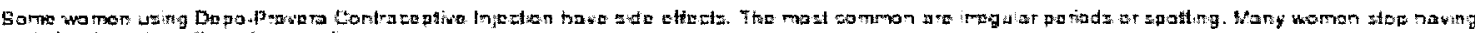

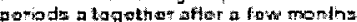

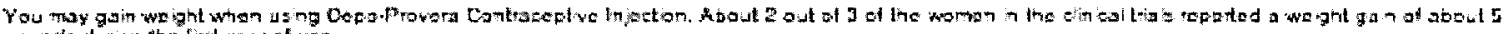
poumed d jor the frit year of use.

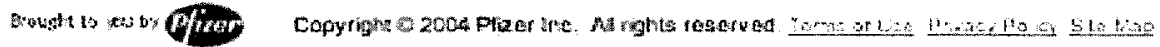

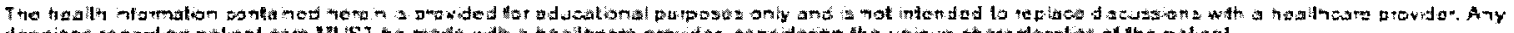

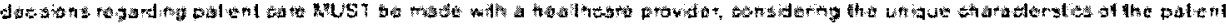

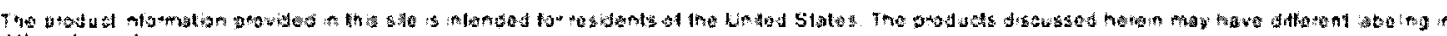
ditorost cosingres 


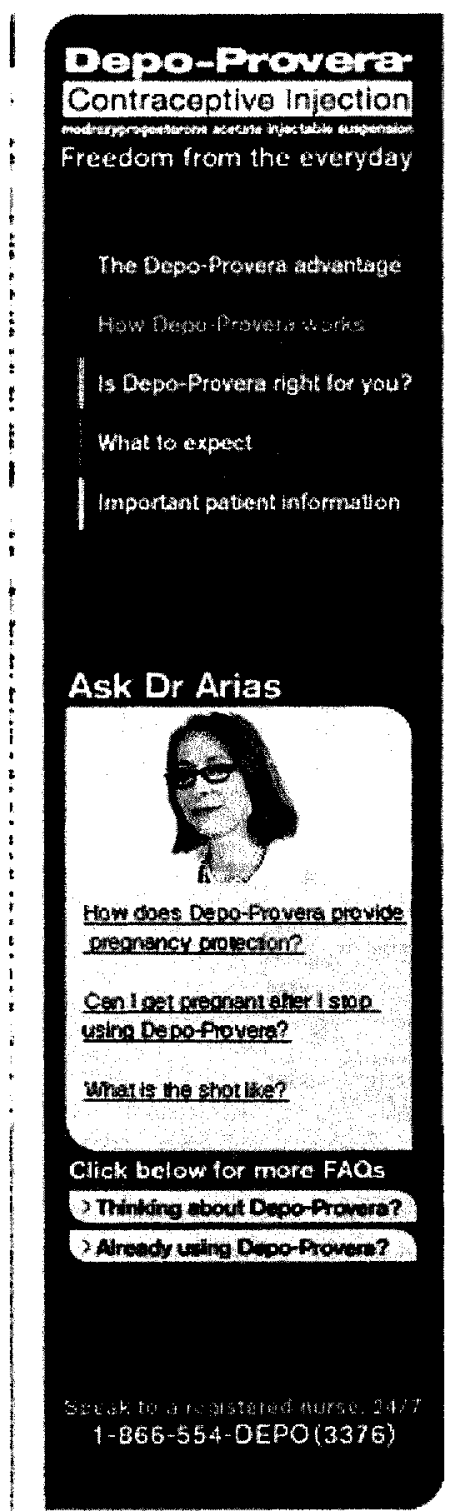

We'll remind you!

To: us the date of your next dose, and we'll tend you a reminder mail.
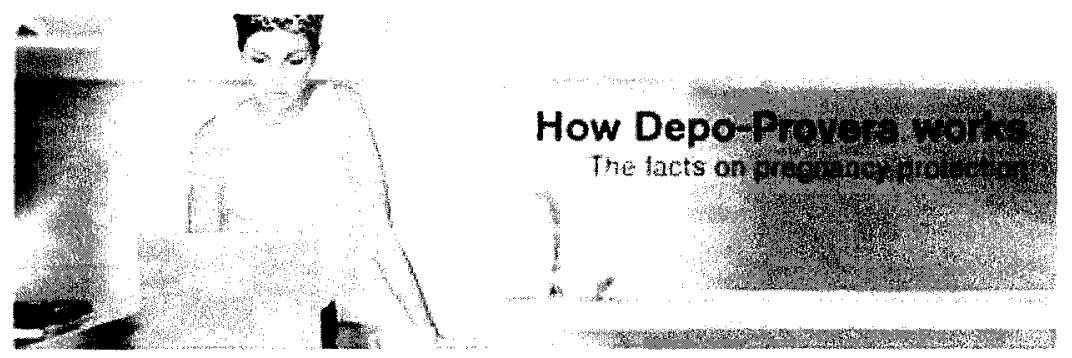

Here's how Depo-Provera works, and why you know it's working

Heres now therk

- Wher you las Depo Frowery, you dor' towlate it tops the rolasede of egs thom your cwarics. That usay, thefe's ro ego presert lor sperm to forthize

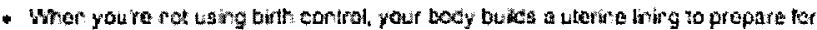
pregnaticy

- Hou cont get pregrart your body relenges tha hring "tha's what we krow as a ceriot

- With Depo prowera, your body coese'y build a bring Or buks orly a wery thin bre, se

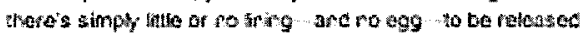

What this mears that art the your perrod may got very hat or could aver stro Your bady

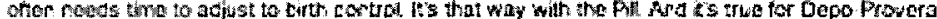

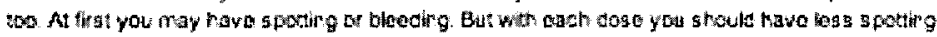
ane blectirg. And trom the start." your owaries ate ir a resting state.
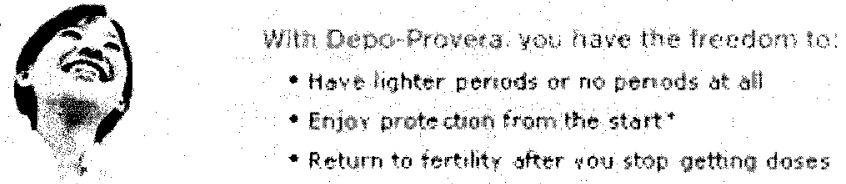

Protection from tha start

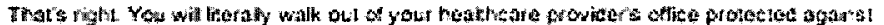

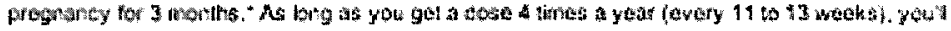
cortinue to be protected it jut works

\section{Doso timing}

Its mportant to zet your irioctiars on time Get your roxt dose cuery 11 to 13 weoks to make sure you stay protested. You and

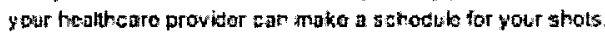

If you to miss a stoi or more thar 13 waks go by youll raec to crotest yoursol wh an allernatwe bith control motho. Use concoms, spormicides, cisphrans, or owon abstinence wath ather you got your rext shot. As soon as you get a shot, yould be protactec agar. Your heatheame prowber should deternice of

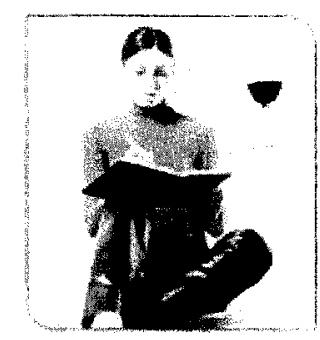


Roturning to fertility

Depo-Provera is revarsible barth coprot

- Hyou choose to get pregrart tor ste first the or dacide to ravo ar the chic that's entireli possite ater usirg Dopo. Provera?

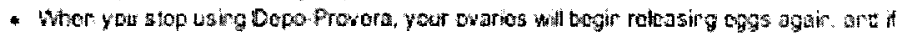
you poriods tave stopet. merstruatior will overtually retur

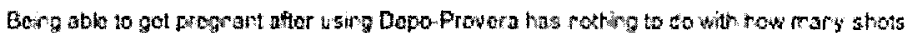

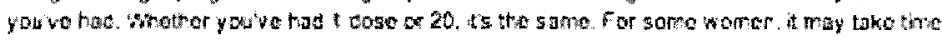
Fet othor womer. aregrers may hacoon faster.

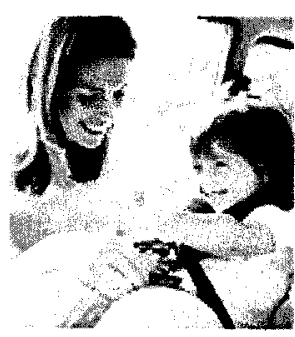

Women who have used Depo Provera are as Itkely to become pregnant within a year as those who do not use birth control:

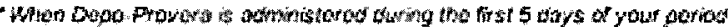

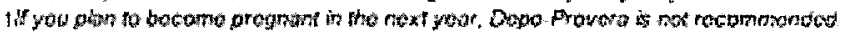

Use of Depo-Provora Comtraceptive inicction may caluse you to lose calcium etored in yowr bonds. The longer you use Depo-Provera Contracoptive injoction the mono calcium yous she likely to loso. The calcium may not retum complotoly onco you stop using bopo-provera Contracoptivo inipation.

Loss of calcium may causo wonk, porous bonos fosteporosis) that could increase the risk that your bones might broak, ospocially after menopausa. It is not known whether your his of deweloping osteoporosis may be grator if you aro a teenagor whon you alart to uso Dopo-Provara Comtracoptivo Injection.

You showld wso Depo-Provara Contracoptive injoction long term (for oxample, more than 2 years) only il othor mathods of birth controf aro

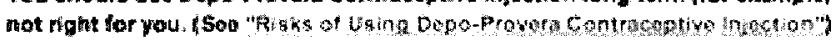

Dopo-Provera centracoptive Injoction doesnt protect you from HWADS or othor gexwally transmittod disensos.

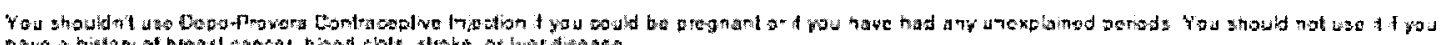

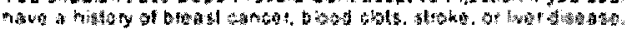

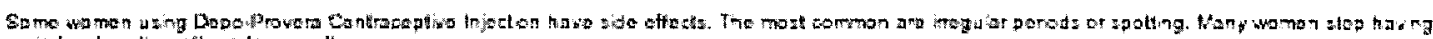
gerods a togeher affer a tow montho.

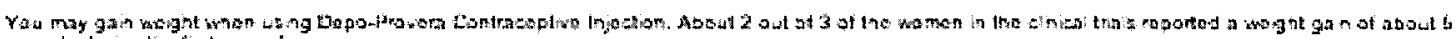

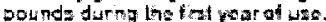

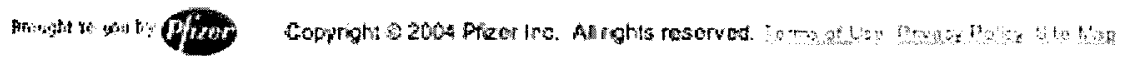

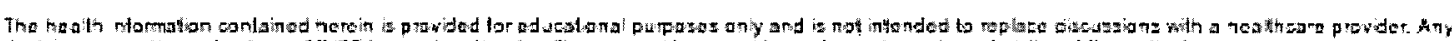

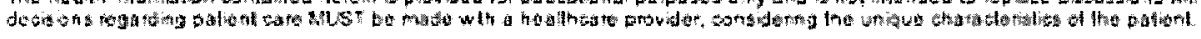

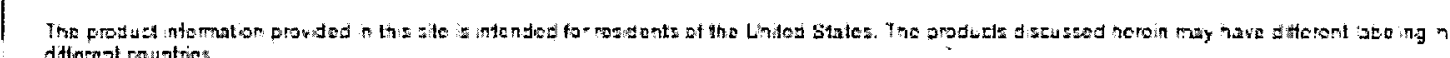
ditionet esuatrias 


\section{APPENDIX 2 \\ DEPO-PROVERA WEBSITE ANALYSIS ${ }^{34}$}

\section{DESCRIBE THE MAIN LAYOUT OF THE WEBSITE:}

Content?

Design? What colours are used? Style of text?.

Photos? What do the women in the pictures look like? What are they doing?

Who does the website appear to be aimed at? Do these women have a particular lifestyle?

What assumptions are made about gender? About women? About reproduction? About the 'modern woman'?

\section{DEPO-PROVERA:}

How it works:

Are the side effects prominent? Or are the benefits? Or both?

Are the side effects treated as minor or serious? Are certain side effects prioritized?

How?

\section{MENSTRUATION:}

How prominent is the idea of menstruation on the website? Is the website primarily about contraception? Is menstrual suppression prominent enough to claim that it is promoted on the website? Explain how it is promoted and how it is linked to the idea of freedom.

Do they use the word menstruation? Or do they use euphemisms?

What assumptions are made about women's attitudes toward menstruation? Are any made?

Is menstruation treated as something that acts on women, or something that is a part of them?

\section{KNOWLEDGE:}

How is expertise appealed to on the website? How is medical knowledge presented - as something that is the ultimate authority? Are women told to trust their doctors? Trust the company/drug manufacturer?

Is there an option to consult with an 'expert'?

\footnotetext{
${ }^{34}$ An almost exact copy of this was used to also analyze the depo-subQ provera 104 website.
} 
How does the website try to alleviate anxieties women have about their bodies? About the product?

Are there any other links to other sources of knowledge, or is this website promoted as the authority on Depo-Provera?

\section{FREEDOM:}

What 'truth' of freedom are they promoting? How does the website promote freedom? What does freedom mean when they use it in their slogan? What is it freedom from one's body? One's self? Society? Men? Pain? Inconvenience?

Is freedom conceptualized as absolute freedom? Or, is it presented as coming at a cost to women?

Is freedom offered to every woman? If not, who is it offered to? Why might some women be absent in the marketing campaign?

How is the idea of offering women 'choice' treated? Is it apparent whether or not women are being treated as consumers or patients? Both? Is the audience perceived as active, passive, or both?

\section{REGULATORY ASPECTS:}

How does the website promote self-regulation? Self-management? Are women encouraged to be responsible for their own health?

Are the ideas about regulation and self-regulation overt or covert? How are these ideas manifested (e.g., in the idea of 'good health' or 'good hygiene' or 'freedom' or fitting in with what the 'modern woman' is, etc.)?

Is the product presented in a way that states or implies that a woman's body management is inadequate without this product? Or, will the product simply make a woman's life better? 


\section{APPENDIX 3 \\ INTERVIEW QUESTIONS}

\section{Background information:}

1) What year are you in at UPEI?

2) What degree are you working on?

3) Do you have a declared major yet?

4) How old are you?

5) Have you lived in P.E.I. for most of your life?

\section{Learning about Menstruation:}

6) I thought I would start off by looking back a bit to when you were a kid, before you started getting your period. Do you remember how you first learned about menstruation? [PROBES - $\rightarrow$ Was it from your mother? From a sex-ed class? From peers? From TV?]

7) Did different people tell you different things about it? How did this make you feel?

8) Do you remember approximately how old you were when you first learned about menstruation?

9) Do you remember where you were when you learned about it?

10) Can you remember how you felt about it then?

11) During that time, do you remember what others said about it, or how others felt about it?

- For example, your mom?

- Sex-ed teachers?

- Your friends?

- Do you have any memories about how any males in your life felt about it? Or, how they reacted to the topic?

\section{First Period:}

12) I would like to move on to the topic of when you actually got your first period. Do you remember what age it happened at?

- Do you remember where you were?

- Did you know what was happening or not?

- Do you remember what your mother said when you told her? Your friends?

- How did any of the males in your family react?

13) Do you remember how you felt for the first couple of years that you had your period

- Do you know if your friends felt the same way? 
- Do you know if your mother felt the same way?

14) Overall, would you describe your first experience with your period as positive? Negative? Or neither?

\section{Perceptions of Menstruation now:}

I would like to discuss how you feel about menstruation now.

15) Do you feel differently about it from when you first got your period?

- If yes, do you know what caused you to think differently about it?

- How exactly do you feel about it now?

16) How do you think that the topic of menstruating women is treated in our society?

- Do you believe that this portrayal is accurate of how women feel about their bodies?

- Do you have any thoughts on why the topic is treated this way?

\section{Discussion of Birth Control:}

I would like to change over to talking about birth control. I want reinforce, that I am not a health-care provider and that any medical questions should be directed to a health-care professional.

17) I have a list of several different forms of birth control - would you like to go through the list and tell me what you think the pros and cons are of them? If you do not know what some of them are, or have nothing to say about them, you can just say 'no comment.' I can also explain some of them if you would like.

withdrawal

female condoms

diaphragm and cervical cap

the pill

Depo-Provera spermicides

male condoms

IUD (Intrauterine Device)

Norplant

18) If you were to use birth control, what type (or types) would you want to use?

- Would you rather use barrier methods? Or drugs?

- Why? What concerns would you have?

- Does the type of relationship that you are in matter?

- Does age matter?

19) Would you ever take contraceptive drugs for reasons other than preventing pregnancy? For example, if you were to develop problems with your period and you wanted to regulate it, would you use contraceptive drugs? Or, if you were at a point in 
which you felt like you had serious problems with acne and wanted to control it, would you ever use contraceptive drugs to do so?

\section{Stopping Menstruation:}

I would like to move on to the idea of stopping your period.

20)Do you believe that most women like menstruating? Or, do you think that most women want to stop it? Or, do you think that women have mixed feelings about this?

- Do you think that some women might be more inclined than others (for example because of age, pain etc) to either stop it or leave it?

21)What, if there are any, do you think might be some of the reasons that would cause some women to want to stop menstruating?

- Do you agree or disagree with some of those reasons?

22) Have you ever used a prescription drug that stopped your period? Or one that controlled it?

- Was this a positive or negative experience for you?

- Was there any particular benefit or drawback that made you feel this way?

- Did you ever use a prescription drug that effected your period, and then stopped using it? What were your reasons for stopping? How did you feel after stopping it?

23) Hypothetically speaking, do you think that your life would be changed if your period stopped for good - if you had no more periods? In this situation, we will pretend that you will still have the opportunity to have children when you want, so this is a 'fantasy' situation, because often when stopping menstruation with Depo-Provera, you cannot become pregnant immediately after using it. So returning to the hypothetical question how would that make you feel - if you could still have children if you wanted to, yet the rest of the time was spent menstruation-free? Do you think that your life would be any different if this happened?

\section{Depo-Provera:}

Before beginning this section, I want to remind you that I spoke about the advantages and disadvantages at the beginning of the interview. Would you like any of this information repeated? Again, if you have any questions about Depo-Provera, other forms of birth control, or any other means of menstrual suppression, they should be directed to a healthcare professional.

24) Have you ever heard of Depo-Provera before this interview?

- If yes, had you ever considered using it?

- What motivated you to use it? Or not use it?

- Lf the participant did use it, or is using it ... Do you feel that your doctor sufficiently conveyed all of the side effects to you? 
- If not, how does that make you feel now? What did your doctor not tell you? Do you have any idea why they may not have told you about all of the side effects?

[if participants answered 'no' that they have never heard of the drug before now, then skip to \#25]

25) Coming back to the idea of stopping menstruation, what do you think about the idea of stopping it with Depo-Provera?

- Are there any concerns that you would have about stopping menstruation with this drug?

- Would you have any concerns about your health? Long-term health?

- Would the length of time that the product is used influence whether you would want to use it or not?

- Would you have any concerns related to pregnancy?

- Would these concerns stop you from taking the drug?

- If answered 'no' to stopping menstruation with a contraceptive drug does it bother you that other women might take Depo-Provera, particularly when they are motivated by trying to stop their period?

26) What do you think of doctors prescribing Depo-Provera to women because they want to stop their period?

- Does the age of the patient matter?

- What do you think about Depo-Provera advertising that they can stop menstruation with their contraceptive drug?

27) If there was a drug that had absolutely no side effects and was created solely to stop menstruation, would you take it or not? Keep in mind that this is just a 'fantasy-drug' no such product exists.

- Why or why not?

28) In its marketing campaign, Depo-Provera offers women freedom from their bodies. What do you think they mean by this? Do you agree or disagree with the idea? In what way?

- If you think that they are not offering freedom - what might they be encouraging women to do instead? Do you think they are encouraging women to do something that is positive? Negative? Both? Neither?

29) Many decades ago, stopping menstruation was not really an option for women. How do you feel about having the choice to stop menstruating or not? In other words, how do you feel about having the option to continue to menstruate or stop it?

I have a couple of general questions left to ask ...

30) Do you think that how women think about menstruation has changed? For example how are your ideas on it different from your grandmothers, even your mothers? 
- If you have seen a change - do you think that it is a positive one? Why?

- If you do not see a change - do you think things will ever change?

31) If a large number of women took Depo-Provera and stopped their periods, do you think that how society treats menstruation might change?

32) Do you have any questions or final comments? 


\section{APPENDIX 4 \\ LETTER OF INFORMATION}

I am doing a research study on women's thoughts on stopping menstruation. The purpose of this research is to explore women's ideas about using the injectable birth control drug Depo-Provera which can be used to lessen or stop menstruation. I hope to better understand women's motivations for wanting to stop or continue menstruating.

You can participate in this study if: you are a female between the ages of 18 to 25, and you DO NOT have any major problems with your period. To participate, it DOES NOT matter whether or not you are using any form of birth control. If you participate in this study, you would be involved in an interview that will be one to two hours long. During this interview, you will be asked questions about your experiences and thoughts on menstruation and birth control. At any time during the interview, you may decline to answer questions, or can stop the interview altogether without any consequences. You also have the right to ask that data not be used after an interview has been conducted. The interview will be held on the UPEI campus in a private, quiet room that will be booked by me, or at a location that is convenient for you. I (Emily Snyder) will be the only person present at the interview. Also, I will be the only person that has access to your interview transcript. Notes will be taken and an audio tape-recorder will be used during the interview. You have the option to not be tape-recorded. At the end of the interview, you will be offered fifteen dollars for your time. You will only be interviewed once, however, there will be an opportunity for email follow-up afterwards. This is intended to allow you to express any further questions, concerns, or thoughts. Also, with your permission, I would be able to email you if clarification is necessary with any of your responses.

Your participation in this study is voluntary. It is possible that you might not benefit from this study. One of the anticipated benefits is that you will have the chance to speak openly about a subject that is often silenced. You will be able to express your thoughts in a secure, non-judgmental environment. Some possible risks involved in this study include emotional, psychological, and/or social discomfort with the topic. Personal questions will be asked, which for some, might cause uneasiness. It is up to you to decide if you will benefit or not from participating in an interview.

If you choose to participate, I will do my best to make your identity anonymous. Under no circumstances would I tell anyone that I was going to meet with you, or who you are. For the final report, you will be given a pseudonym (alternate name). However, despite all of my efforts, because the sample size for my project is small, there is the possibility that someone could recognize a description of you or your experiences in the research. Also, if you learned about this study from someone that you know, they might be aware that you are participating, or could recognize your responses, and this could reduce your anonymity further. If you have any further questions about any of this, please ask me.

The audio tape, transcripts, and back-up files will be confidential and will be stored in a locked drawer in my office. There will be electronic files on my computer that others do not have access to. Lastly, a separate email account will be set-up for this project. I am the only person with access to this account. The data will be destroyed 5 years after the project is completed. It is being kept for this period of time because it is possible that it could be used for an expanded project in the future (my $\mathrm{PhD}$ thesis). If 
you have concerns about your interview being used in the future, please tell me. I will not use it in the future if you are uncomfortable with this.

The research findings will be presented in the form of my Master's thesis. It is possible that the findings could also be used as a paper at a conference, or published in a scholarly journal. Once the project is completed (June 2006), you will have the opportunity to read a copy of it.

This project has been reviewed and approved by the Carleton University Research Ethics Committee and the University of Prince Edward Island Research Ethics Board. If you have any concerns about your involvement in this research project, please contact them. Their phone numbers and email addresses are attached to this letter. If you have any other questions, please email me at emily_snyder@hotmail.com, or, you may also contact my supervisors.

Thank you for your time,

Emily Snyder

Researcher

Researcher:

Emily Snyder

Carleton University

Graduate Student, Sociology Department

Phone: (902) 367-5259

Email: emily_snyder@hotmail.com

\section{Supervisors:}

Dr. Alan Hunt

Carleton University

Professor, Sociology Department

Phone: (613) 520-2600 ext. 2591

Email: ahunt@ccs.carleton.ca

Dr. Jennifer Pylypa

Carleton University

Professor, Anthropology Department

Phone: (613) 520-2600 ext. 6329

Email: jen_pylypa@carleton.ca

\section{Ethics Committee contacts:}

Carleton University Research Ethics Committee

Contact: Leslie MacDonald-Hicks, Committee Coordinator

Phone: (613) 520-2517

Email: ethics@carleton.ca

University of Prince Edward Island Research Ethics Board

Contact: Lynn MacPhee

Phone: (902) 566-0637

Email: Imacphee@upei.ca
Jennifer Pylypa

Committee Member 


\section{APPENDIX 5 \\ INFORMED CONSENT FORM}

By signing this form, I agree to participate in the research study being conducted by Emily Snyder (the researcher). This study will take place between September 2005 and June 2006, however I will only be needed for a one to two hour interview during this time. I will be offered fifteen dollars in exchange for my time. I have read and understood the information in the Letter of Information. Also, I understand that I can keep a copy of this Informed Consent Form - signed and dated.

I understand that the project is about women's thoughts on stopping menstruation, as well as on the use of birth control. I recognize that I will be asked personal questions about my experiences and thoughts on these topics. I am aware that the study is being done by the researcher for her Master's thesis at Carleton University.

I understand that the interview will be audio tape-recorded, however, I may decline this and notes will just be taken instead. I acknowledge that there are potential social, emotional, and psychological risks involved with the interview because the topic has the potential to make me uncomfortable. By participating, I have thought about these risks and have concluded that either I will experience minimal or no risks, or that the benefits of being involved outweigh these risks.

I am aware that my responses will be confidential and will be treated within the limits of the law. If any revelations of violence or abuse arise, I understand that the researcher will have contacts available for all participants if they would like access to them. I will be given a pseudonym for the project. Only Emily Snyder will have access to the data. I know that it will be stored in a locked drawer that others do not have access to. I also recognize that the electronic files will be secure. I am aware that, with my permission, the data could be used again in the future. Lastly, I know that the data is to be published in the form of a Master's thesis, but that it could also be used at a conference or published as an article in a scholarly journal. I understand that I can have an electronic copy of the final thesis if I want one.

I recognize that my participation in this study is voluntary. I can withdraw from the study at any point - including asking to have the data withdrawn part way through the interview or after the interview has been conducted. If this occurs that data can be destroyed (tape erased, notes shredded). I have the right to refuse to answer the questions that are asked. Lastly, I may contact anyone on the following sheet if I have concerns.

Please complete the following statements:

If I decide to withdraw from the interview after it has begun, I DO / DO NOT (please circle one) give the researcher permission to use the data that she has collected.

I AGREE / DECLINE to be tape-recorded during my interview.

I DO / DO NOT want to have email communication after this interview.

I DO / DO NOT give the researcher permission to use the data from my interview for future projects.

I WOULD / WOULD NOT like an electronic copy of the final research project emailed to me (to be completed in June 2006). 


\section{Researcher:}

Emily Snyder

Carleton University

Graduate Student, Sociology Department

Phone: (902) 367-5259

Email: emily_snyder@hotmail.com

\section{Supervisors:}

Dr. Alan Hunt

Carleton University

Professor, Sociology Department

Phone: (613) 520-2600 ext. 2591

Email: ahunt@ccs.carleton.ca

Dr. Jennifer Pylypa

Carleton University

Professor, Anthropology Department

Phone: (613) 520-2600 ext. 6329

Email: jen_pylypa@carleton.ca

\section{Ethics Committee contacts:}

\section{Carleton University Research Ethics Committee}

Contact: Leslie MacDonald-Hicks, Committee Coordinator

Phone: (613) 520-2517

Email: ethics@carleton.ca

\section{University of Prince Edward Island Research Ethics Board}

Contact: Lynn MacPhee

Phone: (902) 566-0637

Email: Imacphee@upei.ca 


\section{APPENDIX 6 \\ RECRUITMENT ADVERTISEMENT}

\section{HOW WOULD YOU FEEL IF YOU COULD STOP YOUR}

\section{PERIOD?}

How do you think other women might feel? I am doing research on the injectable bith control drug Depo-Provera, which can be used to lessen or stop menstruation. I am conducting several interviews to try to understand young women's thoughts on stopping menstruation, as well as their thoughts about the advantages and disadvantages of using Depo-Provera to do this. You DO NOT need to be taking this drug to participate. If you have never even heard of it before, you can still contribute.

\section{HOW CAN I BE A PART OF THIS?}

By participating in a confidential, non-judgmental, private, 1 to 2 hour interview.

You will be compensated $\$ 15$ for your time.

\section{WHO CAN PARTICIPATE?}

Women ages 18 to 25 .

Women who DO NOT have any major problems with their periods.

Women who ARE or ARE NOT using birth control.

Women who are willing to openly express their thoughts on menstruation and birth control.

The interview can be held on the UPEl campus in a private setting, OR at a place of your choice (eg. your home). The interview will be at a time that is convenient for you.

If you are interested, or have any questions, please contact me by email:

\section{Emily Snyder}

research.project@hotmail.com

* Approval for project by: Carleton University Research Ethics Committee \& University of

Prince Edward Island Research Ethics Board 


\section{Bibliography}

Abercrombie, Nicholas (1994). "Authority and Consumer Society." In Russell Keat, Nigel Whiteley, and Nicholas Abercrombie (Eds.) The Authority of the Consumer, London: Routledge, 44-57.

Akin, David (2003). “Concealment, Confession, and Innovation in Kwaio Women's Taboo." American Ethnologist, 30(3), 381-400.

Alvesson, Mats \& Sköldberg, Kaj (1999). Reflexive Methodology: New Vistas for Qualitative Research: Chapter I - Introduction - The Intellectualization Model. London: Sage Publications.

Anderson, F.P. et al. (2003). "A Multicenter, Randomized Study of An Extended Cycle Oral Contraceptive.” Contraception, 68(2), 89-96.

Andrist, L.C. et al. (2004a). "The Need to Bleed: Women's Attitudes and Beliefs about Menstrual Suppression." Journal of the American Academy of Nurse Practitioners. 16(1), 31-7.

Andrist, L.C. et al. (2004b). "Women's and Providers' Attitudes Toward Menstrual Suppression with Extended Use of Oral Contraceptives." Contraception, 70(5), 359-363.

Armstrong, David (1997). "Foucault and the Sociology of Health and Illness: A Prismatic Reading." In Alan Petersen and Robin Bunton (Eds.). Foucault: Health and Medicine, London: Routledge, 15-30.

Basara, Lisa Ruby (1992). “Direct-to-Consumer Advertising: Today's Issues and Tomorrow's Outlook." Journal of Drug Issues, 22(2), 317-330.

Bauman, Zygmunt (1988). Freedom. Milton Keynes, England: Open University Press.

Bernard, H. Russell (1988). Research Methods in Cultural Anthropology. London: Sage Publications.

Bonaccorso, Silvia N. \& Sturchio, Jeffrey L. (2002). "Direct to Consumer Advertising is Medicalizing Normal Human Experience.” British Medical Journal, 324, 910911.

Bordo, Susan (1993). "Feminism, Foucault and the politics of the body." In Caroline Ramazanoglu (Ed.) Up Against Foucault: Explorations of Some Tensions between Foucault and Feminism, London: Routledge, 179-202.

Bramwell, Ros. (2001). "Blood and Milk: Constructions of Female Bodily Fluids in Western Society" Women and Health, 34(4), 85-96. 
Bransen, Els (1992). "Has Menstruation been medicalised? Or will it ever happen ..." Sociology of Health and Illness, 14(1), 98-110.

Briggs, Charles L. (2002). "Interviewing, Power/Knowledge, and Social Inequality." In Jaber F. Gubrium \& James A. Holstein (Eds.). Handbook of Interview Research: Context and Method, Thousand Oaks, CA: Sage, 911-922.

Bunkle, Phillida (1993). "Calling the Shots? The International Politics of Depo-Provera." In Sandra Harding (Ed.) The 'Racial' Economy of Science: Toward a Democratic Future, Bloomington: Indiana University Press, 287-302.

Carter, Ian (2004). "Choice, Freedom, and Freedom of Choice." Social Choice and Welfare, 22(1), 61-81.

Caudill, T. Shawn\& Lorie, Nicole (1992). "The Influence of Pharmaceutical Industry Advertising on Physician Prescribing." Journal of Drug Issues, 22(2), 331-338.

CBC website. "Doctor offers to stop menstruation for the right price." Posted October 9, 2002. www.cbc.ca/story/news/national/2002/10/09/Consumers/menstruation 021009.html. Retrieved on February 13, 2006.

Coutinho, Elsimar M. (1999). Is Menstruation Obsolete? (Translator:S.J. Segal) New York: Oxford University Press.

Corea, Gena (1991). "Depo-Provera and the Politics of Knowledge.” In H. Patricia Hynes (Ed.) Reconstructing Babylon: Essays on Women and Technology. Bloomington: Indiana University Press, 161-184.

Coupland, Justine \& Williams, Angie (2002). "Conflicting Discourses, Shifting Ideologies: Pharmaceutical, 'Alternative' and Feminist Emancipatory Texts on the Menopause." Discourse and Society, 13(4), pp.419-445.

Coutts, L. Block and Berg, D.H. (1993). “The Portrayal of the Menstruating Woman in Menstrual Product Advertisements" Health Care for Women International, 14(2), 179-191.

Curtis, Sarah et al. (2000). “Approaches to Sampling and Case Selection in Qualitative Research: Examples in the Geography of Health." Social Science and Medicine, 50, pp.1001-1014.

Denzin, Norman K. \& Lincoln, Yvonaa S. (1998). "Introduction: Entering the Field of Qualitative Research.” In Norman K. Denzin and Yvonna S. Lincoln (Eds.). Strategies of Qualitative Inquiry. London: Sage Publications, 1-34.

Depo-Provera website. www.depoprovera.com. 
depo-subQ provera 104 website. www.depo-subqprovera104.com.

Doucet, Andrea. \& Mauthner, Natasha (2003). "Reflexive Accounts and Accounts of Reflexivity in Qualitative Research."Sociology, 37(3), 413-431.

Douglas, Mary (1966). Purity and Danger: An Analysis of Concepts of Pollution and Taboo. London: Routledge and Kegan Paul.

Fingerson, Laura (2005). "Agency and the Body in Adolescent Menstrual Talk." Childhood, 12(1), 91-110.

Foucault, Michel (1978). “On Power” In Lawrence D. Kritzman (Ed.) Michel Foucault: Politics, Philosophy, Culture, (1984), New York: Routledge, 96-109.

Foucault, Michel (1982). "Space, Knowledge, and Power." In James D. Faubion (Ed.) Michel Foucault: Power. Volume 3: The Essential Works of Michel Foucault, (1994), New York: The New Press, 349-364.

Foucault, Michel (1984). "The Ethics of the Concern for Self as a Practice of Freedom." In Paul Rabinow (Ed.) Michel Foucault: Ethics: Subjectivity and Truth. Volume 1: The Essential Works of Michel Foucault, (1997), 281-301.

Foucault, Michel (1986). The Care of the Self: The History of Sexuality: Volume 3. New York: Vintage Books.

Frank, Arthur (2002). "What's Wrong with Medical Consumerism." In Saras Henderson.and Alan Petersen (Eds.). Consuming Health: The Commodification of Health Care. London: Routledge, 13-30.

Freedman, Estelle B. (2002). No Turning Back: A History of Feminism and the Future of Women. New York: Ballantine Books.

Fuqua, Joy V. (2002). “ ‘Ask Your Doctor About ...': Direct-to-Consumer Prescription Drug Advertising and the HIV/AIDS Medical Marketplace." Cultural Studies, 16(5), pp.650-672.

Garceau, Roger J. et al. (2000). “Bleeding Patterns of women using Lunelle monthly contraceptive injections (medroxyprogesterone acetate and estradiol cypionate injectable suspension) compared with those of women using Ortho-Novum 7/7/7 (norethindrone/ethinyl estradiol triphasic) or other oral contraceptives." Contraception, 62(6), 289-295.

Gastaldo, Denise (1997). "Is Health Education Good for You? Re-Thinking Health Education Through the Concept of Bio-Power." In Petersen, A. and Bunton, R. (Eds.). Foucault: Health and Medicine, London, New York: Routledge, 113-133. 
George, Lianne (2005). “The End of Menstruation” Maclean's, 118(50), 40-46.

Goldman, Robert (1992). Reading Ads Socially. New York: Routledge

Grimshaw, Jean (1993). “Practices of Freedom.” In Caroline Ramazanoğlu (Ed.) Up Against Foucault: Explorations of Some Tensions Between Foucault and Feminism, New York: Routledge, 51-72.

Guba, Egon G. \& Lincoln, Yvonna S. (1998). "Competing Paradigms in Qualitative Research." In Norman K. Denzin and Yvonna S. Lincoln (Eds.). Strategies of Qualitative Inquiry. London: Sage Publications, 195-220.

Gubrium, Jaber F. \& Holstein, James A. (2002). "From Individual Interview to Interview Society." In Jaber F. Gubrium \& James A. Holstein (Eds.). Handbook of Interview Research: Context and Method, Thousand Oaks, CA: Sage, 3-32.

Hardey, Michael (2001). "E-Health': The Internet and the Transformation of Patients into Consumers and Producers of Health Knowledge." Information, Communication and Society, 4(3), 388-405.

Harding, Jennifer (1997). "Bodies at Risk: Sex, Suveillance and Hormone Replacement Therapy." In Petersen, A. and Bunton, R. (Eds.). Foucault: Health and Medicine, London: Routledge, 134-150.

Hartman, Tova \& Marmon, Naomi (2004). "Lived Regulations, Systematic Attributions: Menstrual Separation and Ritual Immersion in the Experience of Orthodox Jewish Women." Gender and Society, 18(3), 389-408.

Hendersen, Saras \& Petersen, Alan (2002). "Introduction: Consumerism in Health Care." In Saras Henderson and Alan Petersen (Eds.). Consuming Health: The Commodification of Health Care. London: Routledge, 1-10.

Hester, Jennifer Sarah (2005). "Bricolage and Bodies of Knowledge: Exploring Consumer Responses to Controversy about the Third Generation Oral Contraceptive Pill." Body and Society, 11(3), 77-95.

Hitchcock, Christine \& Prior, Jerilynn C. (2004a). "Evidence about extending the duration of oral contraceptive use to suppress menstruation." Women's Health Issues, 14(6), 201-211.

Hitchcock, Christine \& Prior, Jerilynn C. (2004b). "Is Menstruation Obsolete? (1999)." Women and Therapy, 27(314), 195-203.

Houpper, Karen (1999). The Curse: Confronting the Last Unmentionable Taboo: Menstruation. New York: Farrar, Straus and Giroux. 
Hyde, Janet Shibley et al. (2001). Understanding Human Sexuality: Canadian Edition. Toronto: McGraw-Hill Ryerson.

Irvine, Rob (2002). "Fabricating 'health consumers' in Health Care Politics." In Saras Henderson and Alan Petersen (Eds.). Consuming Health: The Commodification of Health Care. London: Routledge, 31-47.

Ivison, Duncan (1997). "The Freedom to Be Formed and Normed: Foucault on Power/Government" (Chapter 2) in The Self at Liberty: Political Argument and the Arts of Government London: Cornell University Press, 24-52.

Johnston-Robledo, Ingrid et al. (2003). “To Bleed or Not to Bleed: young women's attitudes toward menstrual suppression." Women and Health, 38(3), 59-75.

Kane, Kate (1990). "The Ideology of Freshness in Feminine Hygiene Commercials" Journal of Communication Inquiry, 14, 83-92.

Kaunitz, A. M. (2000). "Menstruation: Choosing Whether ... and When." Contraception, 62(6), 277-284.

Kaunitz, A.M. (2001). "Injectable Long-Acting Contraceptives." Clinical Obstetrics and Gynecology, 44(1), 73-91.

Keat, Russell (1994). "Scepticism, Authority, and the Market." In Keat, R. Whiteley, N. and Abercrombie, N. (Eds.) The Authority of the Consumer, London: Routledge, 23-42.

Kendall, Gavin \& Wickham, Gary (2004). "The Foucaultian Framework." In Clive Seale et al. (Ed.) Qualitative Research Practice. Thousand Oaks: Ca: Sage Publications, $141-150$.

Knoiny, F.E. (1996). "Use of Depo-Provera in Teens." Journal of Pediatric Health Care, Sept/Oct. 195-201.

Kholer Riessman, Catherine (2003). "Women and Medicalization: A New Perspective." In Rose Weitz (Ed.). The Politics of Women's Bodies: Sexuality, Appearance, and Behavior, Second Edition, New York: University of Oxford University Press. 4663.

Kincheloe, Joe L. \& McLaren, Peter L. (1998). "Rethinking Critical Theory and Qualitative Research." In Norman K. Denzin and Yvonna S. Lincoln (Eds.). Strategies of Qualitative Inquiry. London: Sage Publications, 260-299.

Kitzinger, Celia (2004). "Feminist Approaches." In Clive Seale (Ed.) Qualitative Research Practice. Thousand Oaks: CA: Sage Publications, 125-140. 
Lander, Louise (1988). Images of Bleeding: Menstruation as Ideology. New York: Orlanda Press.

Laws. Sophie (1990). Issues of Blood: The Politics of Menstruation. London: MacMillan.

Lee, Janet (2003). "Menarche and the (Hetero)sexualization of the Female Body." In Rose Weitz (Ed.) The Politics of Women's Bodies: Sexuality, Appearance, and Behavior, Second Edition. New York: University of Oxford Press, pp.82-99.

Lee, Janet \& Sasser-Coen, Janet (1996). Blood Stories: Menarche and the Politics of the Female Body in Contemporary U.S. Society. London: Routledge.

Lodziak, Conrad (2000). “On Explaining Consumption.” Capital and Class, 72, 111-133.

Lowe, Pam (2005). "Embodied Expertise: Women's Perceptions of the Contraceptive Consultation." Health, 9(3), 361-378.

Lupton, Deborah (1997). "Foucault and the Medicalisation Critique." In Alan Petersen, and Robin Bunton (Eds.). Foucault: Health and Medicine, London: Routledge, 94-110.

Martin, Emily (1987). The Woman in the Body: A Cultural Analysis of Reproduction. Boston: Beacon Press.

Martin, Emily (1997). “Medical Metaphors of Women's Bodies: Menstruation and Menopause." In Katie Conboy, Nadia Medina, and Sarah Stanbury (Eds.) Writing on the Body: Female Embodiment and Feminist Theory, New York: Columbia University Press.

Mason, Jennifer (2002a). Qualitative Researching. London: Sage.

Mason, Jennifer (2002b). “Qualitative Interviewing: Asking, Listening, and Interpreting." In Tim May (Ed.) Qualitative Research in Action. London: Sage, 225-241.

McLaren, Margaret A. (2002). Feminism, Foucault, and Embodied Subjectivity. New York: State of University of New York Press.

Merskin, Debra (1999). "Adolescence, Advertising, and the Ideology of Menstruation" Sex Roles, 40(11-12), 941-957.

Miller, James (1999). “Of Choice.” Social Research, 66(4), 1121-1135.

Miller, Kate (1999) "Forward." In Elsimar M. CoutinhoElsimar Is Menstruation Obsolete? (Translator:S.J. Segal) New York: Oxford University Press, ix-xi. 
Mintzes, Barbara (2002). "For and Against: Direct to Consumer Advertising is Medicalising Normal Human Experience." British Medical Journal, 324, 908909.

Morrow, Raymond A. (1994). Critical Theory and Methodology: Contemporary Social Theory: Volume 3. London: Sage Publications.

n.a. (2003). "Controlling Menstruation: Period Piece." The Economist, Aug. 16, US Edition, 368(8337), 71.

Nava, Mica (1999). "Consumerism Reconsidered: Buying and Power." In Morag Shiach (Ed.) Feminism and Cultural Studies. New York: Oxford University Press, 45-65.

Nettleton, Sarah (1997). "Governing the Risky Self: How to Become Healthy, Wealthy and Wise." In Alan Petersen and Robin Bunton (Eds.). Foucault: Health and Medicine, London: Routledge, 207-222.

Oinas, Elina (1998). "Medicalisation by whom? Accounts of Menstruation Conveyed by Young Women and Medical Experts in Medical Advisory Columns." Sociology of Health and Illness, 20, 52-70.

Petersen, Alan (1997). "Risk, Governance and the New Public Health." In Petersen, A. and Robin Bunton (Eds.). Foucault: Health and Medicine, London: Routledge, 189-206.

Potter, Jonathan (1997). "Discourse Analysis as a way of Analysing Naturally Occuring Talk." In David Silverman (Ed.) Qualitative Research: Theory, Method and Practice. London: Sage, 200-221.

Potter, Jonathan (2004). "Discourse Analysis." In Melissa A. Hardy \& Alan Bryman (Eds.) Handbook of Data Analysis. London: Sage, 607-624.

Public Health Agency of Canada. "Frequently Asked Questions on Contraception." Posted May 2002. www.phac-aspc.gc.ca/publicat/epiu-aepi/std-mts/contracept ives_e.html. Retrieved on February 13, 2006.

Rako, Susan (2003) No More Periods?: The Risks of Menstrual Suppression and Other Cutting-Edge Issues About Hormones and Women's Health. New York: Harmony Books.

Rakusen, Jill (1981). "Depo-Provera: the Extent of the Problem: A Case Study in the Politics of Birth Control." In Helen Roberts (Ed.) Women, Health and Reproduction. Routledge \& Kegan Paul: London, 75-108.

Rapley, Tim (2004). “Interviews.” In Clive Seale et al. (Eds.). Qualitative Research Practice. London: Sage, 15-33. 
Riordan, Ellen (2001). “Commodified Agents and Empowered Girls: Consuming and Producing Feminism.” Journal of Communication Inquiry, 25(3), 279-297.

Roberts, Tomi-Ann \& Waters, Patricia L. (2004). "Self-Objectification and that 'Not So Fresh Feeling': Feminist Therapeutic Interventions for Healthy Female Embodiment." Women and Therapy, 27(3-4). 5-21.

Rose, Nikolas (1999). Powers of Freedom: Reframing Political Thought. Cambridge: Cambridge University Press.

Rosenberg, J. (2003). "Substantial Proportions of Contraceptive Clinic Clients Would Try Methods that Can Cause Amenorrhea." International Family Planning Perspectives, 29(2), 95-96.

Rosengarten, Marsha. (2000). "Thinking Menstrual Blood." Australian Feminist Studies, 15(31), 91-101.

Sawicki, Jana (1998). "Feminism, Foucault and 'Subjects' of Power and Freedom." In Jeremy Moss (Ed.) The Later Foucault: Politics and Philosophy, Thousand Oaks: Sage Publications, 93-107.

Seale, Clive (2004). “Quality in Qualitative Research.” In Clive Seale et al. (Ed.) Qualitative Research Practice. Thousand Oaks: Ca: Sage Publications, 409-419.

Seasonale website. www.seasonale.com.

Sorofman, Bernard (1992). "Drug Promotion in Self-Care and Self-Medication." Journal of Drug Issues, 22(2), 377-388.

Still, Judith (1994). “"What Foucault Fails to Acknowledge ...': Feminists and the History of Sexuality." History of the Human Sciences, 7(2), 150-157.

Strauss, Anselm \& Corbin, Juliet (1998). Basics of Qualitative Research: Techniques and Procedures for Developing Grounded Theory ( $2^{\text {nd }}$ Edition). London: Sage Publications.

'The Way Back Machine.' www.archive.org.

Thomas, Sarah L. \& Ellertson, Charlotte (2000). "Nuisance or Natural and Healthy: Should Monthly Menstruation be optional for women?" Lancet, 355(9207), 922924.

Tone, Andrea (1996). "Contraceptive Consumers: Gender and the Political Economy of Birth Control in the 1930s." Journal of Social History, 29(3), 483-506. 
Turner, Bryan (1995). Medical Power and Social Knowledge (Second Edition). Thousand Oaks, CA: Sage.

Wajcman, Judy (1994). “Delivered into Men's Hands? The Social Construction of Reproductive Technology" In Gita Sen and Rachel C. Snow (Eds.). Power and Decision: The Social Control of Reproduction. Harvard University Press, 153175.

Walker, Anne (1997). The Menstrual Cycle. New York: Routledge.

Warde, Alan (1994a). "Consumers, Identity and Belonging: Reflections on Some Theses of Zygmunt Bauman." In Keat, R. Whiteley, N. and Abercrombie, N. (Eds.) The Authority of the Consumer, New York: Routledge, 58-74.

Warde, Alan (1994b). "Consumption, Identity-Formation and Uncertainty." 28(4), Sociology, 877-898.

White, Clarissa et al. (2003). "Reporting and Presenting Qualitative Data." In Jane Ritchie \& Jane Lewis (Eds.) Qualitative Research Practice: A Guide for Social Science Students and Researchers, Thousand Oaks, CA: Sage, 287-320.

Williams, Simon J. (1998). Health as Moral Performance: Ritual, Transgression, and Taboo. Health, 2(4), 435-458.

Wilska, Terhi-Anna (2002). Me- A Consumer? Consumption, Identities and Lifestyles in Today's Finland. Acta Sociologica, 45(3), 195-210.

Women's Health Clinic. “Depo-Provera approved: lessons for the future.” Posted on the Canadian Women's Health Network in 1997. www.cwhn.ca/resources/ birth_control/depoApproved.html. Retrieved on February 13, 2006. 